The Role of Afferent Feedback from the Human Knee Extensors in Their Control during Human Movement 



\section{The Role of Afferent Feedback from the Human Knee Extensors in Their Control during Human Movement}

PhD Thesis by

Natalie Mrachacz-Kersting

Center for Sensory-Motor Interaction, Department of Health Science and Technology, Aalborg University, Denmark

River Publishers

Aalborg 
ISBN 978-87-93102-65-1 (e-book)

Published, sold and distributed by:

River Publishers

Niels Jernes Vej 10

9220 Aalborg Ø

Denmark

Tel.: +45369953197

www.riverpublishers.com

Copyright for this work belongs to the author, River Publishers have the sole right to distribute this work commercially.

All rights reserved (C) 2013 Natalie Mrachacz-Kersting.

No part of this work may be reproduced, stored in a retrieval system, or transmitted in any form or by any means, electronic, mechanical, photocopying, microfilming, recording or otherwise, without prior written permission from the Publisher. 


\section{ENGLISH SUMMARY}

Sir Charles S. Sherrington (1906) was one of the first to recognize the complexity of spinal reflex circuits. Autogenic reflex pathways influence the muscles from which they arise whereas heterogenic pathways influence the activation of muscles apart from the muscles of origin. Both types of pathways are also influenced by supra-spinal structures. To effectively comment on the significance of these pathways, data on their neural interconnectivity has to be combined with the functional consequences using biomechanical data such as the resulting changes in joint stiffness.

Joint stiffness is made up of the algebraic sum of the stiffness of all muscles and ligaments crossing it. The muscle stiffness constitutes passive, intrinsic and reflex stiffness. However, in the execution of a movement, several joints are typically displaced and it was initially proposed by Winter (1981) that dynamic balance is maintained during standing, walking and running as the total leg stiffness never varies. The contribution made by the reflex stiffness to the total joint stiffness has been quantified only for the ankle joint of the lower limb where it attains values of up to $50 \%$. Similar data is not available for the knee joint.

This $\mathrm{PhD}$ project was designed to investigate the functional significance and the neural pathways underlying the human quadriceps stretch reflex; in particular the following aspects were studied: i) the reflex and non-reflex stiffness of the quadriceps muscles quantified by the methods developed for the ankle joint (Sinkjær et al., 1988), ii) the integration of the afferent information arising from the stretch reflex at the spinal and cortical level, iii) how the central nervous system makes functional use of this afferent information. The stretch reflex was elicited by a whole joint rotation using either a stationary or a portable stretch 
device. Subjects without a prior history of neurological diseases participated in the various studies presented in this thesis. Such data will also be important in the artificial control of the quadriceps during FES assisted standing in paraplegic patients.

The results demonstrate that the human quadriceps stretch reflex can contribute importantly to the total knee joint stiffness. Electromyographic (EMG) recordings revealed that the response is comprised of at least three burst similar to the soleus stretch reflex. These burst were labeled short (SLR), medium (MLR) and late (LLR) latency reflex. While the mechanical response is similar for ankle and knee extensors, this was not always the case for the neural responses observed. For example, while the SLR of the soleus is strongly enhanced during co-contraction compared to isolated plantar flexor activity, the SLR of the quadriceps is decreased during co-contraction. Such discrepancies may be reflective of the monosynaptic and polysynaptic heteronymous projections to quadriceps motoneurons. The quadriceps motoneurons thus receive substantial excitatory and inhibitory inputs from both their antagonists as well as the muscles spanning the ankle joint (Marque et al., 2001; Marque, et al. 2005). Such connections have been postulated to reflect a functional coupling between muscles acting as synergists. The studies presented in this thesis provide important information on the role of afferent feedback during an imposed stretch to a single joint and muscle group. However the results also emphasize the need to further investigate the role of heteronymous reflex pathways as these provide the ability to link muscles that span different joints. 


\section{DANSK SAMMENFATNING}

Sir Charles S. Sherrington (1906) var en av de første til å forstå hvor viktig spinale reflekser er. Autogene refleksbaner påvirker musklene de stammer fra, mens heterogene refleksbaner påvirker andre muskler enn den de stammer fra. Begge type refleksbaner blir også påvirket fra højere nerve center. For å kunne kommentere om signifikasjonen til disse refleksbanene, må man kombinere data som omhandler komunikasjonen dem imellom med data som måler funksjonelle konsekvenser som bruker biomechanisk data som for eksempel forandringene i stivhet omkring ledd.

Ledd stivhet er den algebraiske summen av stivheten til alle musklene og ligmentene som krysser et ledd. Muskel stivheten inholder/konstituerer passiv, intrikativ og refleks stivhet. Men under bevægelse fåføres flere ledd vinkelændring og det var først fåreslott av Winter (1981) at den dynamiske balansen er vedlikeholdt mens man står oppreist, under gange og mens man løper siden bein stivheten aldri forandres. Reflex stivhet bidrar til den totale ledd stivheten, og har blitt kvantifisert kunn for ankelleddet hvor den bidrar med opp mod 50\%. Lingende data finnes ikke for knæleddet.

Dette ph.d.-projektet omhander den funksjonelle signifikasjonen og nervebanene som underligger quadriceps strækrefleks hos mennesket. De følgene aspekter ble det spesielt fokusert på: i) refleks og ikke-refleks af quadriceps muskelen kvantificering metoder som er utviklet for ankelen (Sinkjœr et al., 1988), ii) integrasjonen av afferente informasjon som stammer fra strœkk refleksen på ryggmargs nivået og på højere nerve center nivået, iii) hvordan det sentrale nervesystemet bruker denne afferente informasjonen. Stræk refleksene ble frembragt ved å rotere et ledd enten med en mobil strœkk-machine eller en fastlåst 
strœkk-machine. Forsøgspersoner uten nevrologisk sjukdom deltok i de forskjellige studiene.

Resultanen demonstrerte at quadriceps strœkkrefleksen kan bidra signifikant med op mod 50\% af den samlede stivhed omkring knæleddet. Elektromyografiske (EMG) resultatene viste at responsen er en kombinasjon af minst tre observerbare komponenter i likhet med det man ser i soleus strækkrefleksen. De tre komponentene ble kaldt kort (SLR), medium (MLR), og lang (LLR) latent refleks. Den mekaniske responsen observert i ankelen og knæet var veldig like, men den nervrologiske responsen obervert i knæet og ankelen var ikke like. For eksempel, SLR målt i soleus ble forøget under co-kontraksjon samenlignet med isolert plantarfleksion, mens SLR målt i quadriceps ble mindre under co-kontraksjon. Denne forskellen kan refleketere de monosynaptiske og polisynaptiske heteronomiske banene til quadriceps motorneuronerne. Quadricepsmusklene må derfor motta kraftig exitatorisk og hæmningen indgång fra både sine antagonister og musklene som krysser ankelleddet (Marque et al., 2001; Marque, et al. 2005). Det har blitt foreslått at slike forbindelser reflekterer en funksjonell kobeling mellom synergistike muskler. Studiene som er fremlagt her i denne afhandling gir viktig informasjon om rollen til afferent feedback under et strekk av et ledd og en muskelgruppe. Data som dette vil bli viktig i den artifizielle kontrollen av quadriceps under FES assistered stående for paraplegiker pasienter. Men resultatene fremhever også at det trengs videre utforsking av rollen til heteronomiske refleksbaner siden de tilvejebringe de evnen for sammen muskler som krysser andre ledd. 


\section{DEUTSCHE ZUSAMMENFASSUNG}

Schon frühzeitig wurde von Sir Charles S. Sherrington (1924) auf die Komplexität spinaler Reflexverschaltungen hingewiesen. Autogene und heterogene Reflexbögen regulieren Muskelaktivierungen bei kurzfristig eingeleiteten Längenänderungen. Beide Reflex $\neg$ mecha $\neg$ nismen werden wiederum von höheren Zentren moduliert. Zur Vervollständigung unseres Verständnisses über das Zusammenwirken dieser Steurungsprozesse müssen ihre neuro $\neg$ nalen Verschaltungen sowie ihre funktionellen Effekte anhand der Erfassung biomecha $\neg$ nischer Daten wie beispielsweise Gelenksteifigkeit einbezogen werden.

Die Steifigkeit eines Gelenks kann als die algebraische Summer der Steifigkeiten der es überspannenden Musklen und Bänder aufgefaßt werden. Muskelsteifigkeit setzt sich zusammen aus passiver, intrinsischer und reflexvermittelter Steifigkeit. Zielgerichtete sowie zyklische Bewegungen erfolgen üblicherweise als Kombination von Bewegungen um mehrere Gelenke. So hat Winter (1981) vorgeschlagen dynamisches Gleichgewicht beim Stehen, Gehen oder Laufen unter dem mechanischen Konzept der Gesamtbeinsteifigkeit zusammen zu fassen, welche sich als relativ konstante Größe darstellt. Die Steifigkeiten einzelner Gelenke in der kinematischen Kette können sich durchaus beträchtlich ändern. Der Beitrag der reflexbedingten Steifigkeit zur Gesamtgelenksteifigkeit wurde bisher nur für das Sprunggelenk quantifiziert. Der Anteil kann bis zu 50\% betragen. Bisher wurden keine Vergleichsdaten für das Kniegelenk dokumentiert.

Diese Doktorarbeit befaßt sich mit der funktionellen Bedeutung und den zugrundeliegenden neuronalen Verknüpfungen des Dehnungsreflexes der menschlichen Kniestreckermuskulatur. Die folgenden Themenschwerpunkte wurden bearbeitet: i) Quantifizierung der reflexunabhängigen und reflexbedingten Steifigkeit des 
Kniegelenks anhand der Übertragung von Methoden, welche am Sprunggelenk angewendet wurden (Sinkjaer et al., 1988), ii) Ermittlung des Zusammenhangs zwischen afferenten Informationen des Dehnungsreflexes und supraspinalen sowie kortikalen Einflüssen, iii) Erfassung der Rolle der afferenten Information im funktionalen Kontext. Mit diesem Ziel wurden Dehnungsreflexe durch Gelenkrotationen mittels eines stationären und eines portablen mechanicschen Aktuators realisiert. Experimente wurden an neurologisch gesunden Probanden durchgeführt.

Die Ergebnisse machen deutlich, daß der Dehnungsreflex zu mehr als 50\% zur Kniesteifigkeit beitragen kann. Elektromyographische (EMG) Messungen belegen, daß die Reflexantwort in drei Phasen zerlegt werden kann, ähnlich wie es für den Dehnungsreflex des $M$. soleus gezeigt wurde. Die Phasen wurden als kurze Latenz-(SLR), mittlere Latenz-(MLR) und lange Latenzkomponente (LLR) des Reflexes bezeichnet. Während die mechanischen Effekte für Knie- und Sprunggelenksextensoren vergleichbar ausfallen, kann dies nicht allgemeingültig für die neuronalen Mechanismen bestätigt werden. Beispielsweise wurde gezeigt, daß der SLR des M. soleus bei Kokontratktion deutlich verstärkt ist im Vergleich zu selektiver Aktivierung des M. soleus allein. Für den M. quadriceps femoris hingegen reduziert sich die Reflexantwort bei Kokontraktion der Flexoren. Diese Unterschiede könnten durch die mono- und polysynaptischen heteronymen Projektionen der morischen Neurone des M. quadriceps verursacht sein. Dies bedeutet, daß die motorischen Neurone des quadriceps von einer Vielzahl von verstärkenden sowie inhibierenden Einflüssen ihrer Antagonisten als auch der sprunggelenksüberspannenenden Muskulatur ausgesetzt sind (Marque et al., 2001; Marque et al., 2005). Es wurde postuliert, daß solche Verschaltungen einer funktionelle Kopplung von synergistischen Muskelgruppen entsprechen. Die 
Studien dieser Doktorarbeit dokumentieren bedeutsame Relationen über die Integration afferenter Information als Antwort auf unerwartete Muskelzustandsänderungen. Diese Zusammenhänge haben wichtige Implikationen beispielsweise für die Anwendung von funktioneller elktrischer Stimulation bei Paraplegikern. Es konnte aufgezeigt werden, daß weitere Experimente notwendig sind, um die heteronymen Verschaltungen zwischen verschiedenen Muskelgruppen vollständig zu erfassen. 


\section{ACKNOWLEDGEMENTS}

I wish to express my sincerest gratitude to my supervisor Professor Thomas Sinkjær for his inspiration and encouragement throughout this work. I also wish to thank my dear co-supervisors Dr. Jacob Buus Andersen and Dr. Brigitte Lavoie. Jacob, I will always remember with fondness the great fun we had when making the casts, and Brigitte, your enthusiasm and support of my work have been invaluable - as have the many happy times spend running and climbing the hills (yes hills) in Aalborg Park, making profiterolls and generally enjoying the Danish lifestyle.

The one person without whom I would have been lost when conducting the experiments using the MTS is Knud Larsen. Knud, thank you for all the hours spend and for being there when I experienced the first “fainting” during TMS.

Many subjects participated throughout the studies presented in this $\mathrm{PhD}$ and $\mathrm{I}$ am forever grateful for their time, patients and adventure.

Finally, but most of all I wish to thank my incredible family. My dad Achim and my mum Karin as well as my dear brother Michael; thank you for always believing in me and for telling me that I can do anything if only I want to. My beloved husband Uwe you are the most incredible husband and I could not wish for more. Thank you for always being there and for making me remember the most important things in life.

The work has been supported by the Danish National Research Foundation. 


\section{ORIGINAL PAPERS AND OTHER CONTRIBUTIONS}

This PhD thesis is based on four original papers, referred to in the text by their Roman numerals. The original papers may be found in the appendix. Further dissemination of the data collected throughout this thesis occurred at numerous conferences through poster and oral presentations.

\section{Original papers}

I. Mrachacz-Kersting N, Sinkjaer T (2003). Reflex and non-reflex torque responses to stretch of the human knee extensors. Exp Brain Res 151: 72-81.

II. Mrachacz-Kersting N, Sinkjaer T . The Human Quadriceps Stretch Reflex during a Sitting Task. To be submitted to Exp Brain Res

III. Mrachacz-Kersting N, Grey MJ, Sinkjaer T (2005). Evidence for a supraspinal contribution to the human quadriceps long latency stretch reflex. Provisionally accepted to Exp Brain Res

IV. Mrachacz-Kersting N, Lavoie, BA, Andersen JB, Sinkjaer T (2004). Characterisation of the quadriceps stretch reflex during the transition from swing to stance phase of human walking. Exp Brain Res 159: 108-122. 


\section{Other publications related to this thesis}

Mrachacz-Kersting N, Andersen JB, Sinkjaer T (1999). A Technique for applying a Mechanical Stretch to the Human Quadriceps Muscle Group during Walking. ECSS Conference: Limiting Factors of Human Neuromuscular Performance. Jyväskilä ,Finland.

Mrachacz-Kersting N, Lavoie, BA, Andersen JB, Sinkjaer T (2000) The characterisation of the human quadriceps stretch reflex during human locomotion. P57.4 Proceedings of the $26^{\text {th }}$ Annual meeting for the Society for Neuroscience. New Orleans, U.S.A.

Larsen. B.; Mrachacz-Kersting, N.; Lavoie, B.A. and Voigt, M. (2001) Quadriceps H-reflex modulation during walking. Proceedings o the ISPG Symposium. Maastrich, Netherlands.

Mrachacz-Kersting N, Sinkjaer T (2001). Reflex and non-reflex torque responses to stretch of the human knee extensors. Program Number: 126.66 Proceedings of the Movement and Sensation International Symposium, Cairns, Australia.

Voigt M, Mrachacz-Kersting N (2001) Input-output characteristics of the cotricospinal pathways to knee extensor and flexor muscles during pedalling. Program Number: 105.45 Proceedings of the Movement and Sensation International Symposium, Cairns, Australia. 
Mrachacz-Kersting N, Sinkjaer T (2001) Reflex and non-reflex torque responses to stretch of the human knee extensors. Proceedings of the 23rd Annual International Conference of the IEEE Engineering in Medicine and Biology Society, EMBC, Istanbul, Turkey. Full paper available on CD-ROM. Abstract book no. 3.4.2-3 (ISBN 0-7803-7211-5).

Mrachacz-Kersting N, Grey MJ, Graven-Nielsen T, Sinkjaer T (2002) Does a transcortical pathway contribute to the human quadriceps stretch reflex during sitting? Program Number: 15.13 Abstract Viewer/Itinerary Planner. Washington, DC: Society for Neuroscience, 2002. Online.

Lin JY, Dubey R, Mrachacz-Kersting N, FunkGD, Lipski J (2002) Receptor subtype - specific modulation of postsynaptic glutamate responses in striatal spiny neurons by dopamine. Program Number: 344.13 Abstract Viewer/Itinerary Planner. Washington, DC: Society for Neuroscience, 2002. Online. 


\section{ABBREVIATIONS}

\begin{tabular}{|c|c|}
\hline ANOVA & Analysis of Variance \\
\hline $\mathrm{BF}$ & Biceps Femoris \\
\hline EMG & Electromyography \\
\hline ES & Electrical Stimulation \\
\hline FDI & First Dorsal Interosseous \\
\hline FPL & Flexor Pollicis Longus \\
\hline GM & Gastrocnemius \\
\hline GRR & Global Reflex Response \\
\hline GTOs & Golgi Tendon Organs \\
\hline H-Reflex & Hoffmann Reflex \\
\hline LLR & Long Latency Reflex \\
\hline MEP & Motor Evoked Potential \\
\hline $\mathrm{MH}$ & Medial Hamstrings \\
\hline MLR & Medium Latency Reflex \\
\hline M-max & Maximum M-wave \\
\hline MVC & Maximum Voluntary Contraction \\
\hline RMS & Root Mean Square \\
\hline RF & Rectus Femoris \\
\hline SEP & Somatosensory Evoked Potential \\
\hline SLR & Short Latency Reflex \\
\hline TA & Tibialis Anterior \\
\hline TES & Transcranial Electrical Stimulation \\
\hline TMS & Transcranial Magnetic Stimulation \\
\hline VL & Vastus Lateralis \\
\hline VM & Vastus Medialis \\
\hline
\end{tabular}




\section{TABLE OF CONTENTS}

English summary ....................................................................................

Danish summary I Dansk sammenfatning............................................iii

German summary / Deutsche Zusammenfassung.................................v

Acknowledgements ............................................................................viii

Original articles and other contributions ........................................ix

Abbreviations...................................................................................

$1 \quad$ INTRODUCTION ..................................................................... 1

1.1 MECHANICAL IMPORTANCE OF THE STRETCH REFLEX ……........................................ 3

1.2 NEURAL RESPONSE TO SUDDEN MUSCLE LENGTH CHANGES ………………................... 5

1.3 TASK SPECIFICITY OF THE NEURAL RESPONSE ……..................................................... 8

$2 \quad$ AIMS OF THIS PHD PROJECT …......................................... 12

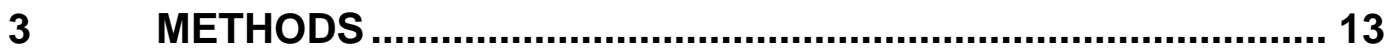

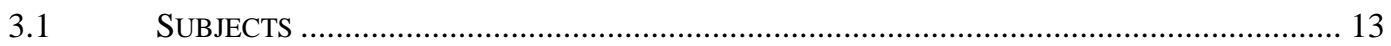

3.2 STATIONARY HYDRAULIC JOINT ACTUATOR SYSTEM.................................................... 14

3.2.1 Experimental set-up .............................................................................. 14

3.2.2 Experimental session ........................................................................... 15

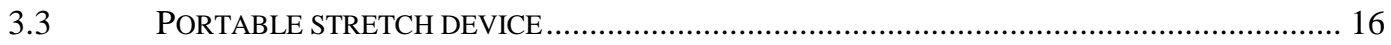

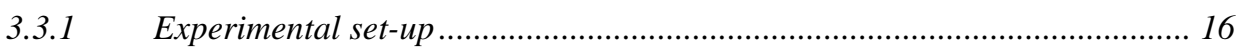

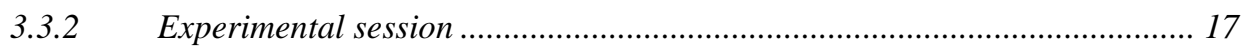

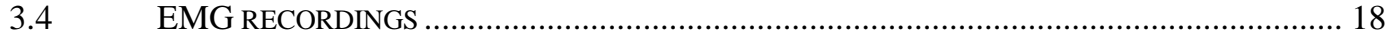

3.5 EMG ANALYSIS - QUANTIFICATION OF THE REFLEX RESPONSE ........................................ 19

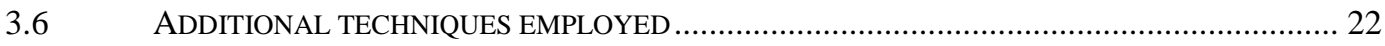

3.6.1 Electrical stimulation of the femoral nerve.................................................. 22

3.6.2 Transcranial magnetic stimulation (TMS)................................................ 24

3.6.3 Somatosensory evoked potentials (SEPs) ………………………………... 25

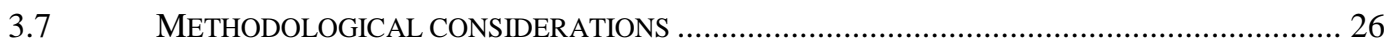

3.7.1 Portable stretch device ......................................................................... 26

3.7.2 Stationary stretch device .......................................................................... 27

3.7.3 Electrical stimulation of muscle ................................................................. 27

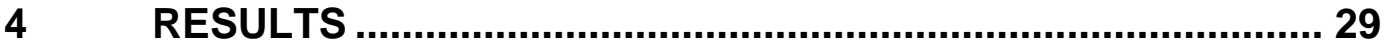

4.1 KNEE EXTENSOR REFLEX CONTRIBUTION TO TOTAL TORQUE AROUND THE KNEE JOINT . 29

4.1.1 Electromyographic Results ................................................................ 29

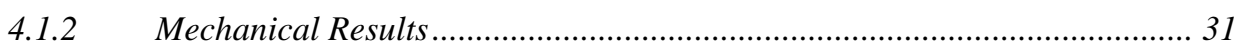

4.2 KNEE EXTENSOR STRETCH REFLEX RESPONSE TO PERTURBATIONS OF LOW AMPLITUDE 33

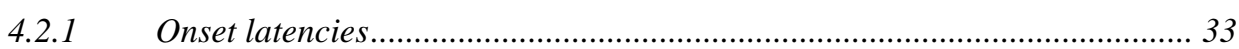


4.3 PERIPHERAL PATHWAYS GENERATING THE DIFFERENT QUADRICEPS STRETCH REFLEX COMPONENTS

4.3.1 Characteristics of the response to perturbation modifications....................... 34

4.3.1.1 Velocity sensitivity ..................................................................................................... 34

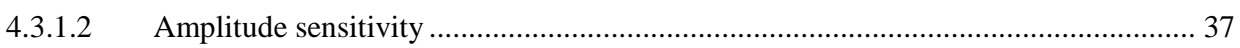

4.3.2 Characteristics of the response to background contraction modifications... 39

4.3.2.1 Response size at increasing levels of isolated knee extensor contraction..................... 39

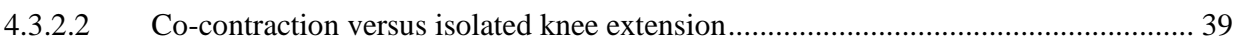

4.4 CORTICAL CONTRIBUTION TO THE QUADRICEPS STRETCH REFLEX................................42

4.4.1 Motor and Somatosensory Evoked Potentials............................................ 43

4.4.2 MEP facilitation as a response to stretch ................................................. 45

4.5 KNEE EXTENSOR STRETCH REFLEX RESPONSE MODULATION DURING A DYNAMIC TASK. 47

4.5.1 Non-reflex torque modulation during walking......................................... 51

4.6 KNEE EXTENSOR REFLEX MODULATION BETWEEN TASKS ............................................. 52

4.7 KNEE FLEXOR RESPONSES WHEN KNEE EXTENSORS ARE STRETCHED ........................... 54

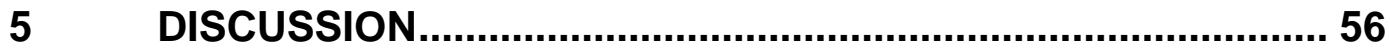

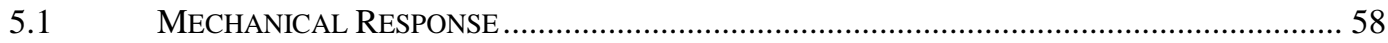

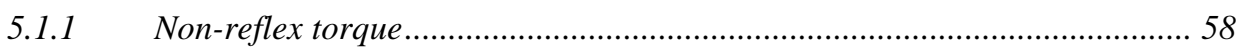

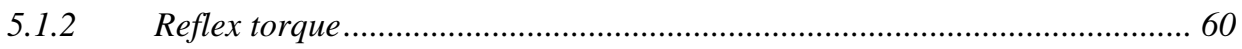

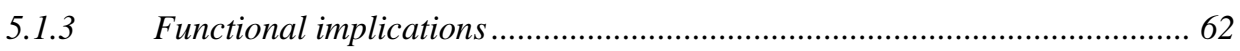

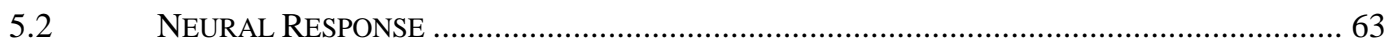

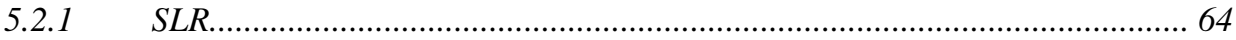

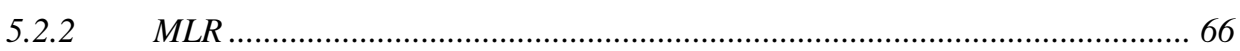

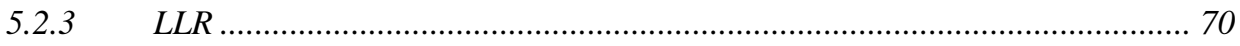

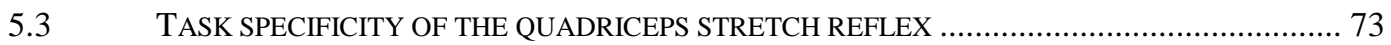

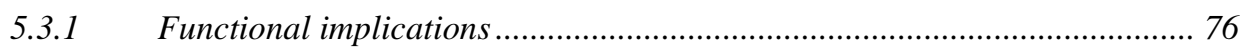

5.4 KNEE FLEXOR RESPONSES WHEN KNEE EXTENSORS ARE STRETCHED .......................... 77

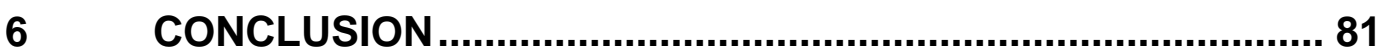

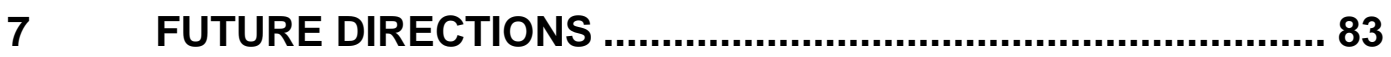

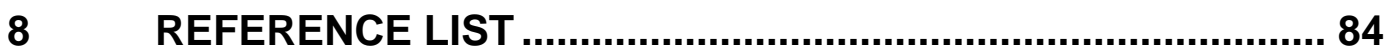

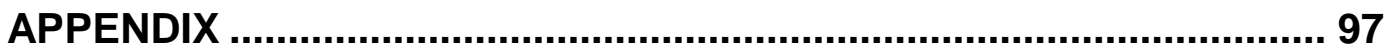




\section{Introduction}

The regulation of joint stiffness is of paramount importance in the accurate and precise execution of human movement. Depending on the individual skill level, an increased stiffness results in a more successful control of position - hence the overly stiff posture frequently observed in novices - while low stiffness allows for a better adaptability to a changing environment. The total stiffness about a joint is comprised of the algebraic sum of the stiffness of all muscles crossing the joint as well as the stiffness attributed to the ligaments. However, the latter contribute mainly if the joint is moved to its extremes. The individual muscle contributions from both the agonists and antagonists to the total joint stiffness can be further subdivided into the passive, intrinsic and reflex components. The former two are often referred to collectively as the non-reflex component.

Recently, it has become accepted that proprioceptive feedback generates part of the ongoing muscular activity and hence contributes significantly to the overall joint stiffness (Sinkjaer et al., 2000; Nielsen \& Sinkjaer, 2002). This feedback provides our nervous system with the ability to sense the position as well as the orientation of our body and its various parts in relation to the environment and arises from various sources. These include the muscle spindles and Golgi Tendon Organs (GTOs) located within the musculo-tendinous unit as well as joint and cutaneous receptors. An important consideration to the idea that afferent feedback from these receptors assists in maintaining joint stiffness is that reflex pathways form a rich network and the afferent feedback provided is subject to homonymous, heteronymous and supraspinal influences. These pathways were originally investigated in the cat (for a review see Baldissera, 1981) where it became apparent that afferent feedback arising from receptors located within one 
muscle may affect the action of another muscle crossing the same joint (synergist or antagonist) as well as a muscle crossing a different joint (Wilmink \& Nichols, 2003). In recent years such information has also become available for humans through a number of excellent studies conducted in the laboratory of PierrotDeseilligny (e.g. Pierrot-Deseilligny et al., 1981; Forget et al., 1989; Meunier et al., 1994). It is beyond the scope of this thesis to investigate the heteronymous interconnectivity that exists between muscles of the human lower limb. However, these connections imply that the total joint stiffness is not as simple as an individual muscle contribution to the stiffness of the joint it spans.

During the execution of a movement several joints are typically displaced. In a task such as walking, biomechanists refer to total leg stiffness rather than ankle, knee and hip joint stiffness independently. The concept of total leg stiffness was introduced by Winter (1980) and later refined by Hof (2000). In their argument, dynamic balance is maintained during standing, walking or running since the total leg stiffness never varies while that of the individual joints of the lower limb (ankle, knee and hip) varies greatly. Interestingly, at least during running, the knee joint stiffness contributes more than $50 \%$ to the total leg stiffness (McMahon et al., 1987). This greater contribution from the knee joint as compared to either the ankle or the hip joint may be attributed to a number of factors. Firstly, the greater bulk of the muscles surrounding the knee joint may provide a greater intrinsic stiffness. Secondly, the knee extensors and flexors co-contract during tasks such as walking compared for example to the ankle flexors and extensors. Cocontraction has been shown to increase the joint stiffness (Feldman, 1980; Akazawa et al., 1983; Llewellyn et al., 1990) beyond what would arise if muscles were activated separately. A third possible explanation is that the knee extensors 
may be able to generate a greater relative reflex contribution to the total stiffness of the knee joint compared to that of the flexors and extensors at the ankle joint.

The first study of this thesis was designed to address this latter possibility. Subsequent to the quantification of the contribution that knee extensor reflexes can make to the total knee joint stiffness the next step was to investigate which afferent pathways give rise to this reflex. Lastly, it was of interest to determine if the quadriceps stretch reflex is modulated during a functional task such as walking. That is, does the nervous system regulate the size of the stretch reflex in a task dependent manner as has been found for the soleus stretch reflex and hence make use of its potential mechanical contribution?

While it is important to understand the role of afferent feedback during ongoing tasks, of equal importance is an understanding of the modulation of this feedback during the generation of corrective responses to unexpected perturbations. This approach involves introducing an excess of afferent input to the system, on top of what is already present. An example would be to apply a sudden lengthening perturbation to the target muscle and quantifying both the mechanical and physiological consequence of this perturbation. It is acknowledged that perturbations occurring in non-artificial situations (outside the laboratory) may affect not only one but several joints. However, to gain an understanding of an individual muscle or muscle group contribution to the displacement of the joint it crosses, it is important to investigate its behaviour in a functionally isolated state.

\subsection{Mechanical importance of the stretch reflex}

In both human and animal reflex responses of individual muscles to sudden changes in muscle length are well documented in the literature (Nichols \& Houk, 
1976; Hoffer and Andreassen, 1981; Allum et al., 1982a; Allum \& Mauritz, 1984; Sinkjaer et al., 1988; Toft et al., 1991; Yang et al., 1991; Stein \& Capaday, 1988; Capaday, 2002; Grey et al., 2002).

It has been suggested that the stretch reflex not only increases muscle and thus joint stiffness but also allows for a more uniform stiffness over a diverse range of the muscles physiological operating lengths and tension (Nichols \& Houk, 1976; Hoffer \& Andreassen, 1981; Allum et al., 1982a). In the cat the reflex-mediated stiffness has been shown to be independent of changes in muscle length (Nichols \& Houk, 1976; Hoffer \& Andreassen, 1981), indicating that the short latency reflex is controlled by muscle and / or joint stiffness rather than by pure muscle length changes. Human studies revealed that the stretch reflex at low and medium level contractions contributes significantly (approximately 50\%) to the overall joint stiffness (Crago et al., 1976; Thomson \& Chapman, 1988; Sinkjaer et al., 1988; Stein \& Kearney, 1995). This has led to the suggestion that the short latency stretch reflex is part of a central control strategy where the central nervous system (CNS), as the first line of defence to an unexpected joint perturbation, stiffens the joint (Sinkjaer, 1997).

To determine the reflex contribution to the total torque produced around a joint several researchers have taken the approach of investigating the mechanical state before and after deafferentation. The latter state was accomplished by various techniques such as cutting the nerve supply (Nichols \& Houk, 1976; Hoffer \& Andreassen, 1981), imposing ischemia (Allum \& Mauritz, 1984; Sinkjaer \& Hayashi, 1989), electrical stimulation (Sinkjaer et al., 1988; Carter et al., 1990), administering drugs, and more recently through mathematical modelling (Stein \& Kearney, 1995; Kearney et al., 1997; Mirbagheri et al., 2000; Mirbagheri et al., 
2001). During low ankle extensor contraction levels up to two thirds of the total stiffness arose from the reflex mediated stiffness when measured 200 ms after stretch onset (Toft et al., 1991). At higher contraction levels the reflex contribution became less. In contrast, dissimilar results have been reported for muscles acting across the wrist and elbow joints of the upper limb. Here it appears that the reflex contribution to joint stiffness increases across all levels of background torque (Crago et al., 1976; Carter et al., 1990).

The importance of the knee extensor stretch reflex from a mechanical point of view has been investigated in the cat (Wilmink \& Nichols, 2003), while information on the mechanical properties of the human knee joint is scarce. A joint driving device was implemented by Zhang et al. (1998) to examine the changes in total knee joint stiffness as a function of both joint position and muscle contraction. Stiffness was highest at a knee joint angle of $30^{\circ}$ flexion increasing progressively as joint torque was increased. Unfortunately, their set-up did not allow the authors to determine reflex and non-reflex contributions to total joint stiffness. In light of the fact that the knee joint stiffness is the major contributor to the total leg stiffness at least during a running task it is important to differentiate between the intrinsic and reflex contributions.

\subsection{Neural response to sudden muscle length changes}

The mechanical contribution made by the actions of the stretch reflex arises due to proprioceptive feedback from several sources. These include muscle receptors (muscle spindles and GTOs), joint receptors, cutaneous receptors, which act on the alpha motoneurons through monosynaptic, disynaptic, oligosynaptic or supraspinal pathways. The question arises as to which afferents are responsible for the observed mechanical response. Due to the greater complexity introduced when 
dynamic tasks are investigated it is beneficial to initially functionally isolate the joint which is spanned by the target muscle. One technique that has been used in the past is to apply a tap to the tendon of the target muscle which causes a subsequent lengthening of the muscle attached to it. One major disadvantage is that a tendon tap elicits one single synchronized volley as observed in the electromyogram (EMG) (Dietz et al., 1990b). This is not synonymous with the response observed when the whole joint is rotated to cause a length change in both the target muscle and its antagonist(s). Using the latter technique, Bergui et al. (1992) described at least two main bursts of activity in the tonically pre-activated quadriceps of sitting subjects, while Lamontage et al. (2000) reported at least three distinct bursts. Throughout this thesis the first, second and third bursts will be referred to as the short (SLR), medium (MLR) and late latency reflex (LLR).

While the quadriceps SLR has received much attention in the past, data on later occurring reflex bursts is scarce. Bergui et al. (1992) reported the presence of a later burst of activity that followed the initial SLR when the pre-activated quadriceps femoris was unexpectedly stretched. Lamontagne et al. (2000) reported at least two additional burst of activity termed MLR and LLR. Matthews (1986) showed that these later events were not present during tendon vibration which preferentially excites the velocity sensitive group Ia afferents. He postulated that they must arise from different pathways and suggested the possibility of the Group II spindle afferents to be the primary candidate for generating all of the later responses through oligosynaptic pathways. Group II afferents contribute markedly to the MLR of the soleus muscle (Dietz, 1998; Schieppati \& Nardone, 1997; Schieppati \& Nardone, 1999; Nardone \& Schieppati, 1998; Dietz \& Duysens, 2000; Grey et al., 2001) 
The long latency response (LLR) of upper limb muscles such as the flexor pollicis longus (FPL), and lower limb muscles such as tibialis anterior (TA) has been suggested to be partially mediated by a long-loop pathway that traverses the motor cortex (Marsden et al., 1973; Marsden et al., 1977; Capaday et al., 1991; Palmer \& Ashby, 1992; Petersen et al., 1998; Hansen et al., 2001; van Doornik et al., 2004). However, data from Zuur et al. (2004) does not support a contribution from transcortical pathways to the soleus SLR.

A distinction should be made between the stretch reflex response observed in muscles of the upper limb and muscles of the lower limb (Marsden et al., 1983; Thilmann et al., 1991). The absence of a SLR in certain hand muscles such as the flexor pollicis longus (FPL) (Marsden et al., 1983), the absence of the LLR in FPL in patients with lesions of the corticomotoneuron pathway (e.g. Marsden et al., 1977; Thilmann et al., 1991) and the strong cortical projections repeatedly demonstrated to the muscles of the upper limb (e.g. Capaday et al., 1991; Palmer \& Ashby, 1992) have been used as arguments that muscles of the upper limb are preferentially controlled by cortical structures. Thilmann et al. (1991) however presented evidence that while the LLR of the muscles of both the hand and fingers is partially mediated by a transcortical pathway, this may not be the case for the more proximal muscles such as the biceps brachii. Instead, the more proximal muscles may be mediated by slower conducting group II afferents and / or a polysynaptic pathway restricted to sub cortical structures (Matthews, 1984).

In the lower limb a transcortical pathway contributes to the LLR of the ankle dorsiflexor TA during a static sitting task (Petersen et al., 1998; van Doornik et al., 2004), and during human walking (Hansen et al., 2001). For the soleus muscle, conflicting results exist (Sinkjaer et al., 1999; Zuur et al., 2004). The 
stretch reflex of more proximal leg muscles such as the knee extensors has been described in the past for both static and dynamic tasks, although the origin of the various reflex components is not yet known (Bayoumi \& Ashby, 1989; Dietz et al., 1990a; Bergui et al., 1992; Bergui et al., 1993;Lamontagne et al., 2000).

It is evident from the brief review above, that data is still lacking on the possible pathways which mediate the different reflex bursts observed in the tonically preactivated knee extensors.

While data on the response of the isolated knee extensors presents the first logical step in increasing the understanding of the stretch reflex during a dynamic task, investigating the modulation of these reflexes for example during walking provides deeper insight into their possible functional role.

\subsection{Task specificity of the neural response}

In the human it is difficult and cumbersome to impose reliable stretches to a muscle during a dynamic task. Yang et al. (1991) reported that at least SLR of the soleus stretch reflex contributes $30-60 \%$ to the ongoing activity recorded during walking. Sinkjaer et al. (1996) used a semi-portable stretching apparatus to show that the stretch reflex of the soleus muscle is significantly modulated during the gait cycle. During the transition from the swing to the stance phase of walking, at a time when the ankle dorsiflexors are active the reflex is completely suppressed. In contrast to the ankle joint, the extensors of the knee are activated concomitantly with the knee flexors during walking. The knee flexors have their maximal activity just after the foot touches the ground, initially contracting while being actively lengthened, followed by a shortening contraction (Wells \& Evans, 1987). Using a patellar tendon tap, Dietz et al. (1990a) showed that the amplitude of the 
SLR of the rectus femoris (RF) varies independently of the ongoing background activity decreasing progressively throughout the stance phase. The authors observed a similar modulation for the quadriceps H-reflex (Dietz et al. 1990b). The decrease in quadriceps reflex amplitude occurred prior to the time of maximal activity of the quadriceps muscles, while the maximum reflex amplitude was recorded when the knee flexors had their maximal activity. These results indicate that during a dynamic task such as walking, the potent inhibitory effect of the knee flexors onto the knee extensors, which was first demonstrated by (Sherrington, 1905), is diminished. Whether this is due to an actual decrease in reciprocal inhibition during co-contraction or due to some other mechanism is as yet unclear. In addition it is questionable to what extent data obtained by applying a tendon tap or an H-reflex can be extrapolated to situations when the entire joint is rotated to stretch the target muscle. Tendon taps and H-reflexes are not natural perturbations that the system has to deal with during dynamic tasks. During human walking for example, the soleus H-reflex and SLR are not modulated in the same manner (Andersen \& Sinkjaer, 1999). The modulation of the H-reflex during human walking has been attributed to changes in pre-synaptic inhibition (Dietz et al., 1990b). As the H-reflex and the SLR have different sensitivities to pre-synaptic inhibition (Morita et al., 1998), this may adequately explain the discrepancies in their modulation during human walking. It is not known if the synchronous reflex burst induced by a tendon tap can be compared to the H-reflex or if it, like the SLR (evoked by a joint rotation) differs from the H-reflex. If they are different, the question arises as to why Dietz et al. (1990a, b) failed to show discrepancies between the tendon tap reflex and the H-reflex modulation during human walking. 
While the ankle flexors and extensors are also reciprocally activated during walking this is not the case for the knee flexors and extensors. During a cocontraction task, the size of the soleus H-reflex does not change with increasing levels of co-contraction while the soleus SLR increases (Nielsen et al., 1994). Evidence from cat experiments suggests that this may be attributed to an increased fusimotor discharge during co-contraction while human experiments have demonstrated an increase in pre-synaptic inhibition during the sensorimotor challenging task of beam walking (Llewellyn et al., 1990). During high levels of co-contraction, the soleus SLR was significantly greater than during isolated plantar flexion. Thus it seems surprising that the quadriceps H-reflex should be modulated in the same manner as the SLR (Dietz et al., 1990b; Dietz et al., 1990a). Nielsen et al. (1994) reported that during low levels of co-contraction the soleus SLR and H-reflex were of the same magnitude as during isolated agonist activation and therefore not modulated. However, during high levels of cocontraction, the SLR was significantly increased during co-contraction unlike the H-reflex which remained similar in size as during the isolated contraction. Thus it seems that at least during low levels of co-contraction both the SLR and the Hreflex behave in a similar manner. The activity of the quadriceps during human walking is well below their maximum voluntary contraction and hence the level of co-contraction would be comparable to the low levels of co-contraction reported by Nielsen et al. (1994). This could explain why there was no difference in the modulation between the two types of reflexes.

The review of past studies suggests that similar to the ankle extensors, a sudden lengthening of the knee extensors produces several distinct bursts of activity as observed in the EMG recording. The possible afferent pathways contributing to 
these bursts have been extensively studied for the human ankle extensors but not for the knee extensors. In addition, the mechanical significance of this reflex and whether the nervous system controls its size in a functionally meaningful way remains unknown. The studies presented in this thesis were conducted to extend previous studies on the human knee extensors stretch reflex and thereby attempt to provide answers to the questions outlined above. 


\section{Aims of this PhD project}

There are three major aims of this $\mathrm{PhD}$ project.

1. To investigate if muscle afferent feedback information from the quadriceps muscle complex contributes significantly to the total torque produced around the knee joint.

2. To investigate if the central nervous system makes functional use of this afferent information.

3. To investigate if the afferent information from the quadriceps muscle complex is integrated at the spinal and / or cortical level.

To fulfil these aims, four separate studies were performed:

Study I: "Reflex and non-reflex torque responses to stretch of the human knee extensors” (Exp Brain Res. 2003)

Study II: “The Human Quadriceps Stretch Reflex during a Sitting Task”

Study III: "Evidence for a supraspinal contribution to the human quadriceps long latency stretch reflex" (Provisionally accepted to Exp Brain Res. 2005)

Study IV: "Characterization of the quadriceps stretch reflex during the transition from swing to stance phase of human walking” (Exp Brain Res. 2004)

All the experimental procedures applied in this $\mathrm{PhD}$ project were approved by the Local Ethics Committee and performed in accordance with the Declaration of Helsinki. 


\section{Methods}

\subsection{Subjects}

All subjects that participated in the various studies presented within this $\mathrm{PhD}$ thesis gave their informed consent. None had any history of neurological or muscular disorders. All studies were conducted in accordance with the Declaration of Helsinki and approved by the local ethics committee. Subject numbers and mean ages are presented in Table 1.

Table 1: Subject details.

\begin{tabular}{|l|c|c|c|}
\hline & $\begin{array}{c}\text { Number of } \\
\text { Subjects }\end{array}$ & $\begin{array}{c}\text { Minimum Age } \\
\text { [Years] }\end{array}$ & $\begin{array}{c}\text { Maximum Age } \\
\text { [Years] }\end{array}$ \\
\hline Study I & 10 & 22 & 31 \\
\hline Study II & 11 & 24 & 30 \\
\hline Study III & 13 & 23 & 31 \\
\hline Study IV & 11 & 21 & 31 \\
\hline
\end{tabular}

For all experiments included in this thesis, a response was evoked in the target muscle either by an externally applied unexpected knee flexion perturbation, electrical stimulation, transcranial magnetic stimulation (TMS) or by a combination of these. The unexpected knee flexion perturbations were applied either with a stationary hydraulic joint actuator system or a portable stretch device. Both these systems have been described in detail elsewhere (Voigt et al., 1999; Andersen \& Sinkjaer, 1995; Andersen \& Sinkjaer, 2003), the setup for the respective experiments will therefore only be presented in brief here. 


\subsection{Stationary hydraulic joint actuator system}

\subsubsection{Experimental set-up}

In Studies I, III and IV, a stationary device was implemented to rotate the knee joint (Fig. 1). For all experiments, the subjects were seated in a chair that was fixed to the floor. Their hip and knee joints were flexed at $90^{\circ}$ and $30^{\circ}$, respectively. The right leg was affixed to a servo-controlled hydraulic actuator (MTS-systems Corporation, 215.35; Voigt et al., 1999), such that the anatomical knee axis of rotation was closely aligned with the fulcrum of the actuator. The
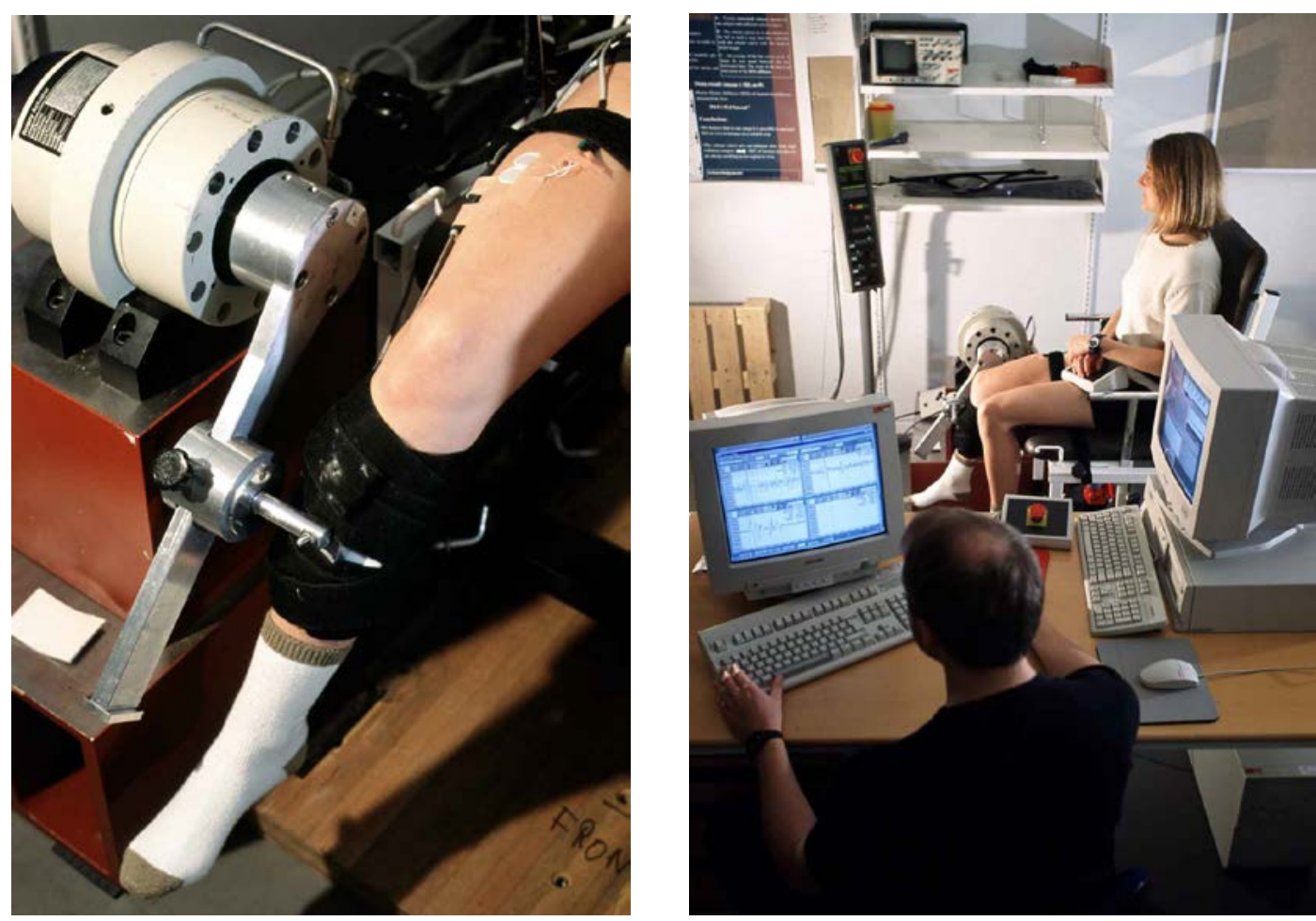

Figure 1: Experimental set-up of stationary hydraulic actuator system.

foot and leg segments of the right leg of the subject were firmly strapped to a custom made plate that extended from the actuator, thus producing a tight interface between the arm of the motor and the leg of the subject. In addition, the knee was fixed with a custom made adjustable bar attached to the chair and placed over the upper thigh slightly proximal to the knee joint. This position minimized 
both hip and ankle movement, ensuring that the movement of the actuator was transmitted solely to the leg. The angular position of the actuator was monitored by an angular displacement transducer (Transtek, DC ADT series 600). In addition a load cell (Kistler Slimline) was mounted on the custom made plate which provided continuous feedback of the force which the subject exerted against the plate

\subsubsection{Experimental session}

In all experiments, the subjects were initially asked to perform a maximum voluntary contraction (MVC) of the quadriceps to determine the maximum force which the subject was able to voluntarily exert at the plate. Subjects were instructed to extend their knee joint as powerfully as possible on the word 'go', and to maintain it there until instructed to relax. They were then allowed to relax for one to three minutes prior to the next trial. The best of a total of three collected trials was deemed the subject's MVC.

For studies I and III, the force (expressed as a percent MVC) applied at the plate by the subject was displayed on an oscilloscope that was positioned in front of the subject. For Study II, the EMG level (expressed as a percent MVC) was displayed. The subjects were asked to match either the force or EMG level that had been pre-set on the oscilloscope. The instructions to the subjects at all times were to maintain the force or EMG level without interfering with the imposed knee flexion perturbation.

The knee extensors were subsequently stretched by the actuator. Due to the various questions addressed within studies I, II and III, the type of perturbations applied varied in terms of the amplitude, velocity and hold time (Table 2). 
Table 2: Characteristics of the applied knee flexion perturbation.

\begin{tabular}{|c|c|c|c|}
\cline { 2 - 4 } \multicolumn{1}{c|}{} & \multicolumn{3}{c|}{ Perturbation Parameters } \\
\hline Study & Amplitude $\left.{ }^{\circ}{ }^{\circ}\right]$ & Velocity $\left[{ }^{\circ} / \mathrm{s}\right]$ & Hold time [ms] \\
\hline I & 20 & 67 & 500 \\
\hline II & $4,6,8$ & $50,130,150,180,220$ & 500 \\
\hline III & 4 & 150 & 500 \\
\hline
\end{tabular}

The stretches were randomly applied at intervals ranging from three to five seconds. Generally a set of five to 10 perturbations was interspersed by rest periods of one to three minutes.

\subsection{Portable stretch device}

\subsubsection{Experimental set-up}

The portable stretch device used in Study II consisted of a functional joint that could reliably induce unexpected knee joint rotations (Fig. 2) (Andersen \&
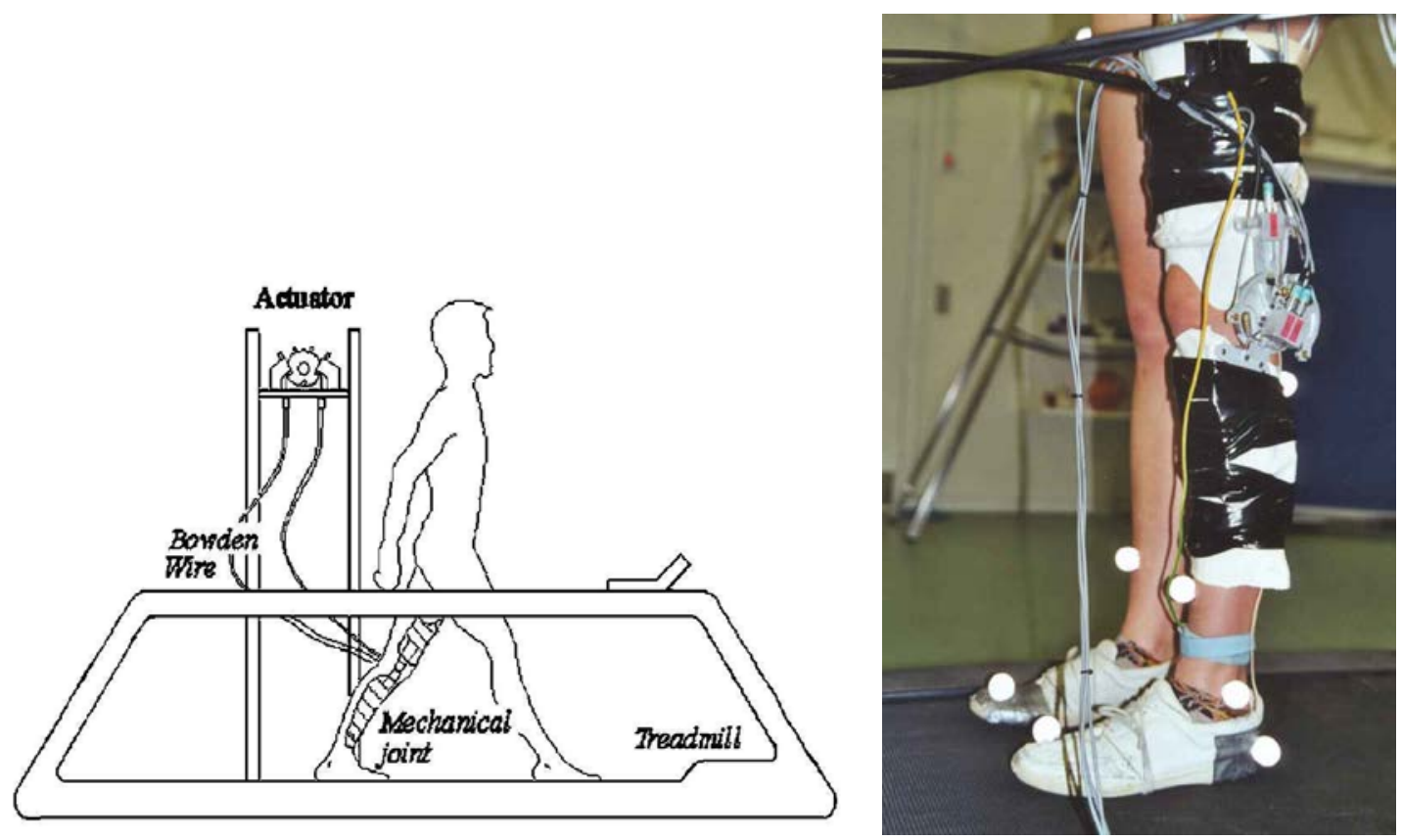

Figure 2: Experimental set-up of portable stretch device. 
Sinkjaer, 2003). To align the axis of rotation of the functional joint with the anatomical knee axis of rotation, an individual brace was constructed for each subject. This consisted of a thermoplast, which had previously been made by moulding it onto a positive plaster cast of the left leg of each subject. The functional joint and a supporting joint were mounted on the brace level and aligned with the knee joint axis of rotation. A thin layer of foam rubber was applied to the inside of the brace to make it comfortable to wear. During testing, the brace was attached to the leg of the subject by velcro straps and duct tape. The functional joint consisted of a two-link joint connected to a powerful actuator by bowden wires. The actuator was positioned next to the treadmill on which the subject was walking. The motor was regulated by a position feedback from the joint in such a way that it followed the movement of the knee joint without influencing the gait pattern. During most parts of the gait cycle it is possible to impose a knee rotation in either the flexor or extensor direction (Andersen \& Sinkjaer, 2003).

\subsubsection{Experimental session}

The subjects were asked to walk at their preferred speed with the portable knee perturbator attached to their left leg until they felt comfortable. A footswitch attached to the heel of the left foot marked foot strike. Following this familiarization period, data collection began for a total of 30 strides during which no perturbations were applied. From the averaged data, total stride time was calculated and the gait cycle divided into nine to ten phases representing $-10,-5$ (late swing phase), 0, 4, 8, 12, 16, 20, 24 and 33\% (stance phase).

Subjects were then instructed to commence walking on the treadmill at their preferred speed. The portable perturbator was programmed to apply knee flexions 
with a ramp and hold (200 ms) input of constant velocity $\left(230-350^{\circ}\right)$ and amplitude $\left(6-12^{\circ}\right)$. These were interspersed randomly, every three to five steps. A total of 30 stretches were applied in each phase of the gait cycle and for each subject. Seven of the 11 subjects were subsequently asked to pre-contract their quadriceps to a pre-set level while standing on the treadmill with arms loosely by their side. Data were collected for 30 stretches, after which the subject was asked to relax. This was repeated for four more trials, each time the pre-contraction level was altered. A total of five different pre-contraction levels, matched to the quadriceps contraction levels of various parts of the walking cycle, were investigated.

\subsection{EMG recordings}

Bipolar surface EMG was used to quantify muscle activity throughout the studies contained in this thesis. EMG activities of the rectus femoris (RF), vastus lateralis (VL), vastus medials (VM), biceps femoris (BF), medial hamstrings ( $\mathrm{MH}$, comprised of semitendinosus and semimembranosus) and of the medial gastrocnemius (GM) were recorded from the left (Study IV) or the right (Study I, II and III) leg by bipolar surface electrodes (Medicotest, 720-01-K). Electrodes were placed on the skin overlying the muscle belly according to recommendations of (Garland et al., 1994). The EMG signals were amplified and band pass filtered at $20 \mathrm{~Hz}$ to $1 \mathrm{kHz}$, rectified and first order low pass filtered at $20 \mathrm{~Hz}$ or at $40 \mathrm{~Hz}$ (Butterworth 1st order digital filter). A custom-made PC-system controlled the acquisition of the signals from the position-feedback channels and the surface EMGs. All data were collected at a sampling frequency of either 2 or $4 \mathrm{kHz}$. 


\subsection{EMG analysis - quantification of the reflex response}

To quantify the amplitude of the response to the imposed knee flexion for each muscle, the mean EMG activity was calculated for different time windows. Previous studies have not attempted to divide the extensor stretch reflex response into different components but rather have concentrated on the first observable peak which is assumed to be monosynaptic. In the studies conducted within this thesis, it was found that similar to the muscles spanning the ankle joint, the knee extensors respond with a multi-peak burst of activity. In Study I, it was difficult to determine if this multi-burst consisted of true separate responses as the applied knee flexion perturbation was large in amplitude $\left(20^{\circ}\right)$ and slow in velocity $\left(67^{\circ} / \mathrm{s}\right)$. For that study the EMG responses were therefore divided into phasic and tonic response windows as has been done in the past for the soleus muscle (Toft et al., 1991). However, for all subsequent studies, the applied perturbation was either smaller in amplitude (range: $\left.4-8^{\circ}\right)$ and greater in velocity $(50-350 \%$ s) or greater in both. The resulting response consisted of three distinct bursts. An example of these recordings is shown in Figure 3. Hence for studies II to IV the reflex burst was divided into at least three time windows based on the occurrence of these distinct peaks in the surface EMG recordings. Each time window represents a different aspect of the stretch response, which are not necessarily shaped by distinct neural pathways. These were labelled the short latency reflex (SLR), the medium latency reflex (MLR) and the late latency reflex responses (LLR), respectively, according to the terminology of Schieppati et al. (1995). 


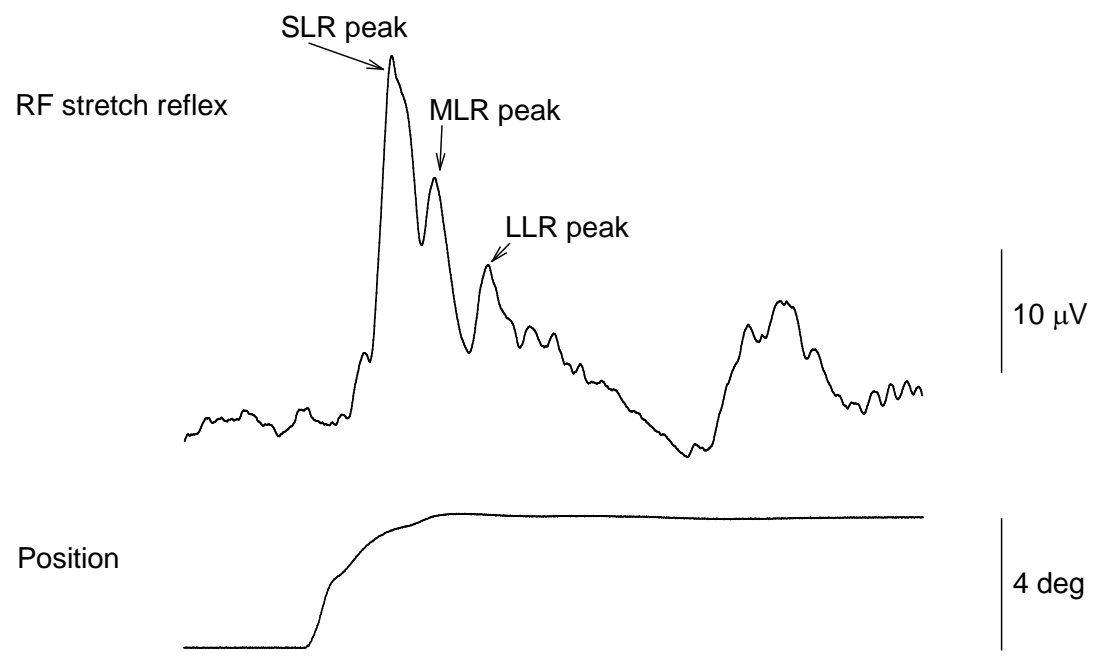

Figure 3: Typical stretch reflex response

The SLR corresponding to the first peak was defined from the onset of the first visible response plus $20 \mathrm{~ms}$, the MLR which included the second peak from plus 20 to plus $40 \mathrm{~ms}$ and the LLR which corresponds to the third peak from plus 40 to plus $75 \mathrm{~ms}$.

In Study II an additional response was quantified consisting of a time window that extended from the onset of the first observable response for a total of $110 \mathrm{~ms}$, referred to as the global reflex response (GRR). An increase in EMG activity was also observed following the GRR. However, this was not investigated further as the aim of this thesis was to characterize the reflex responses of the knee extensors to an imposed perturbation. Any activity commencing at $120 \mathrm{~ms}$ following the perturbation is likely to contain volitional responses (Lee \& Tatton, 1975). An example of the different response windows investigated in Study II is exemplified in Figure 4. 


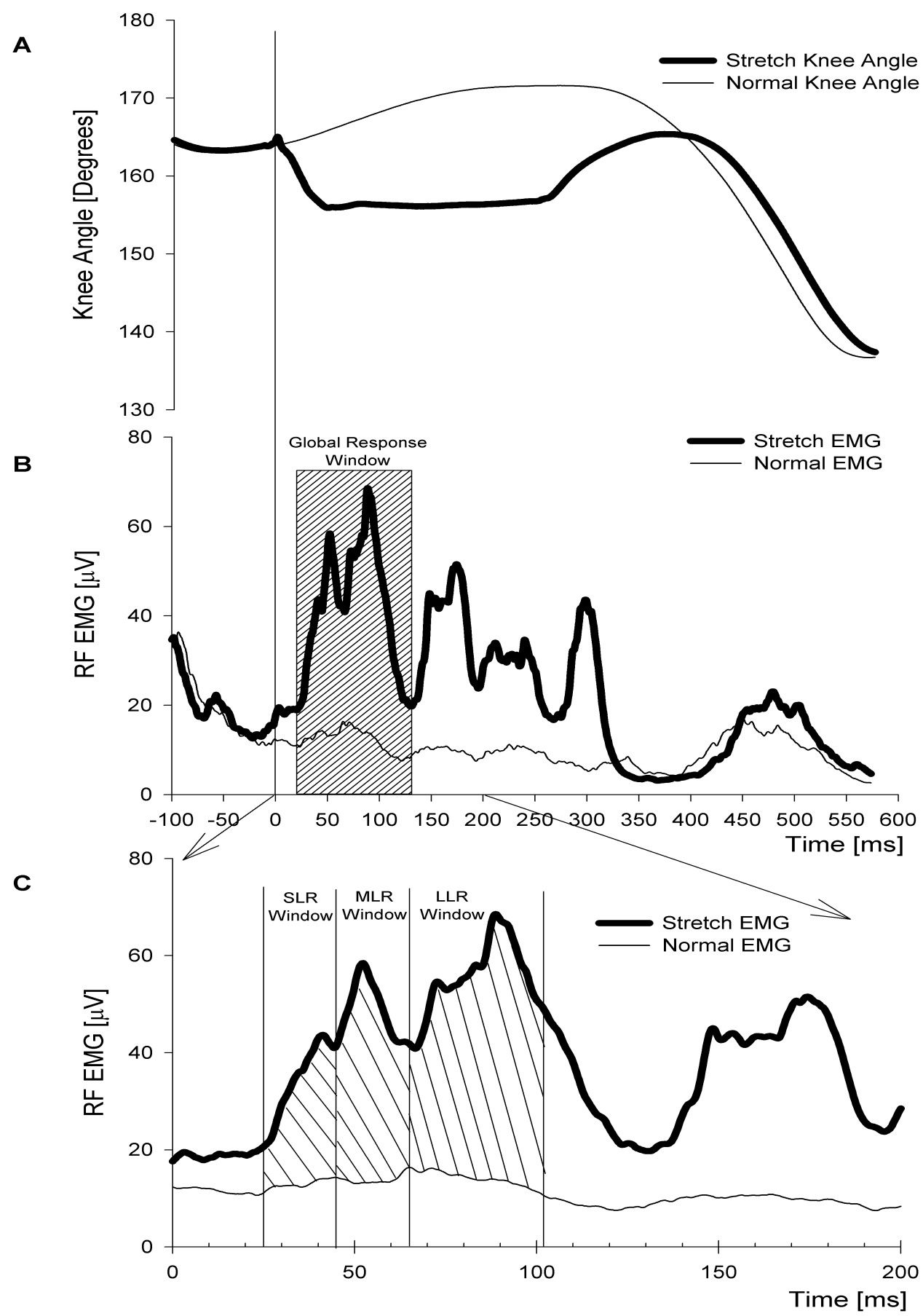

Figure 4: Example recording from Study IV. A) Knee angular displacement during a perturbed and unperturbed step. Onset of the stretch was defined by the diversion of the two curves. B) The start and end of the reflex response window was determined by observation. This area was defined as the reflex response and termed the global response window. C) Based on the occurrence of distinct peaks in the rectified EMG signal, the response was further subdivided into three time windows labeled the short, medium and the long latency responses (SLR, MLR and LLR). For all time windows, the magnitude of the reflex responses were defined by the area between the perturbed trace (thick) and control trace (thin). 
To obtain the absolute mean amplitude of the reflex responses, the ongoing background activity, that is, the muscle activity when no stretch was applied during the equivalent time window was subtracted from those values when a stretch was applied. To enable inter-subject comparisons of these responses, the resulting reflex amplitude data were normalized to the respective maximum reflex response - this was either the respective muscle MVC (Studies I, III and IV) or the muscle maximal activity during walking (Study II). The scaled values were subsequently averaged across all subjects to obtain the mean response across the group. To enable inter-muscular comparisons, the mean reflex amplitude in each time window and for each subject was also scaled to the ongoing background activity and averaged across subjects.

\subsection{Additional techniques employed}

\subsubsection{Electrical stimulation of the femoral nerve}

In Study I it was of interest to investigate the contribution made by the extensor stretch reflex to the total torque around the knee joint. It is known that all reflex activity is abolished during electrical stimulation high enough to produce a tetanic contraction (Hoffer \& Andreassen, 1981). The resulting measure of torque can thus be attributed to the intrinsic properties of the contracting muscle. In Study I, the femoral nerve innervating the quadriceps muscle complex was therefore stimulated electrically during the imposed knee flexion rotation for some trials. A suitable position for stimulation, defined as the site where a maximal M-wave was produced in the RF with minimal activity from the synergists VL and VM and no activity from the antagonists $\mathrm{BF}$ and the $\mathrm{MH}$, was located. Palpation of RF, VL, $\mathrm{VM}, \mathrm{BF}$, and $\mathrm{MH}$ muscles was performed during stimulation trials to ensure that 
this was occurring. The femoral nerve was stimulated in the femoral triangle. A constant current isolated stimulator (Axon Isolator-11) provided 1 ms squared pulses at a frequency of $1 \mathrm{~Hz}$ and various manually adjusted amplitudes. No stretches were applied during these initial trials. In this way the input-output relationship between stimulation amplitude and peak to peak M-wave amplitude was obtained. It also served as an indication for the maximum M-wave for the RF (M-max). To be able to measure the non-reflex torque increment, the pulse frequency was increased to $20 \mathrm{~Hz}$. This ensured that a fused contraction of the RF was produced which exerted a constant force on the plate. Five consecutive stretches were now applied at the knee joint while EMG, force, and position data were collected. The peak to peak M-wave was monitored online to ensure a constant stimulus to the RF muscle as well as to monitor possible unwanted reflex responses and activation of synergistic muscles. To attain various background torque levels, the stimulus intensity was varied manually for each subsequent trial. Depending on the subject, five to eight torque levels were attained in this way.

To determine the total torque increment, the above trials were repeated, while the subjects were asked voluntarily to reproduce the forces attained during the electrical stimulation by matching the torque level which was preset on an oscilloscope. During all trials the subjects were asked to maintain the background torque without interfering with the imposed stretch. The increments in torque from the stretch, in relation to the background torque were measured from averaged signals at $300 \mathrm{~ms}$ following stretch onset. Non-reflex torque was subtracted from the total torque at matched background torques to obtain the torque attributable to the stretch reflex (Sinkjaer et al., 1988). 


\subsubsection{Transcranial magnetic stimulation (TMS)}

In Study IV the aim was to determine if a transcortical pathway is able to contribute to the LLR of the knee extensors. For this purpose the technique of transcranial magnetic stimulation was implemented.

A Magstim 200 (Magstim Company Ltd, UK) with a focal figure of eight double
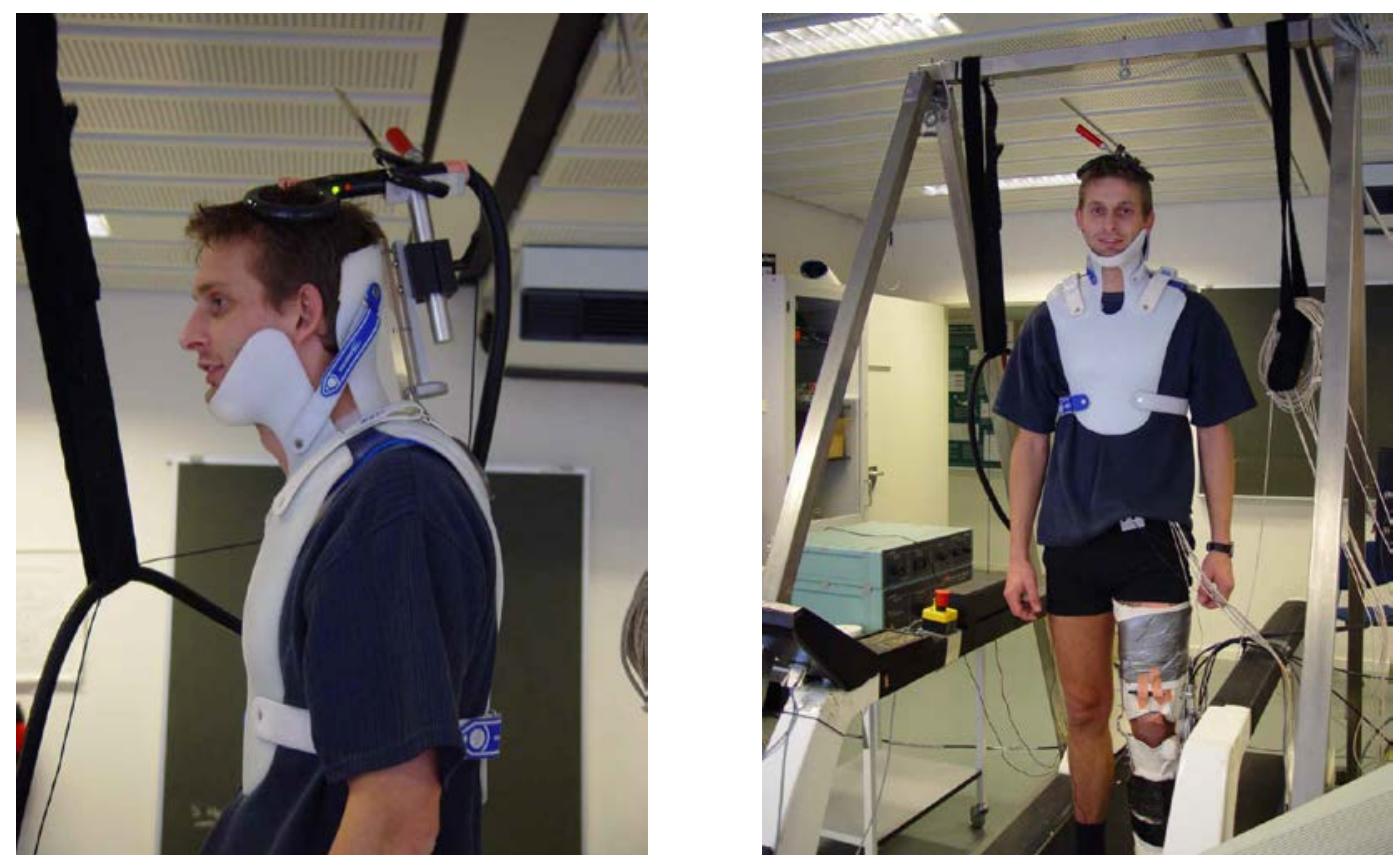

Figure 5: Fixation of figure of eight coned coil used for applying TMS. With the coil fixed relative to the head, the intensity of the magnetic stimulus was decreased to a level that produced a MEP in the RF with a similar size to that of the stretch reflex. Thirty stimuli were applied every three to five seconds to produce an ensemble averaged record with which to measure the MEP. The onset of the MEP was determined by visual inspection and defined as the first major deflection from baseline. The amplitude of the MEP was measured under the area of the full waved rectified curve in a $20 \mathrm{~ms}$ window commencing $25 \mathrm{~ms}$ after the stimulus onset.

coned coil was used to apply single pulses to elicit a motor evoked potential (MEP) in the muscle of primary interest which was the RF muscle. Initially the stimulation intensity was set at approximately $50 \%$ of stimulator output to find the optimal site for evoking a MEP in the RF. The coil position was maintained by 
fixing it to the head with a custom made brace that immobilized the head in relation to the trunk (Fig. 5). This ensured that the stimulation was always applied over the same area of the motor cortex. In all subjects, a stimulation applied to this area also evoked a response in the VL, VM, and BF.

Subsequently, a set of trials was collected in which the arrival of the MEP was timed to coincide with different components of the stretch reflex. The magnetic stimulus, knee perturbation, or combination of magnetic stimulus and perturbation were presented randomly. When applied in combination, the delay between the onset of the stretch reflex and the MEP was varied from 0 - 150 ms in steps of 4 5 ms. For each condition or combination, 10 to 20 trials were collected.

\subsubsection{Somatosensory evoked potentials (SEPs)}

To determine the efferent conduction time following an imposed knee flexion, the resulting somatosensory potentials were recorded. These cortical potentials evoked by the imposed stretch of the quadriceps were recorded with surface electrodes placed on the scalp, over the quadriceps area of the motor cortex. Somatosensory evoked potentials were recorded with a single vertex electrode (band pass, $0.05-500 \mathrm{~Hz}$; sampling rate, $2 \mathrm{kHz}$, bilateral ears referenced). A minimum of 200 traces was recorded and ensemble averaged online. The onset of the evoked potential was defined as the first major deflection in the ensemble averaged record, as determined by visual inspection. 


\subsection{Methodological considerations}

\subsubsection{Portable stretch device}

During the experiments conducted with the portable stretch device, the weight of the portable stretching apparatus added an extra load of approximately $2 \mathrm{~kg}$ to the left leg. To determine if this had an influence on the normal walking pattern, gait variables were compared while subjects walked with and without the device. All subjects were asked to walk on a treadmill (Powerjog, EG30) at their preferred speed $(3.5-4 \mathrm{~km} / \mathrm{h})$. Following a warm-up period, EMG and kinematic data were collected for 30 consecutive steps. Immediately following this, the mechanical stretch device was attached to the left leg of the subject. The subjects were allowed to walk at the same preferred speed until they felt comfortable, at which time data collection began for another 30 consecutive steps. No stretches were applied during this walking protocol. Total stride time was calculated from a foot switch attached under the heel of the left foot. Onset and offset times for all muscles were determined by calculating $2 \times$ RMS of a quiet period of the rectified EMG of the respective muscle. Onset was defined as that time when the EMG signal surpassed this value for a minimum of $50 \mathrm{~ms}$ and offset when the signal was below this value for a minimum of 50 ms. Integrated EMG (IEMG) for the entire stride cycle was determined for each muscle by calculating the area under the rectified EMG signal. This was used as an indication of the power produced by the respective muscle. Lastly, the peak activity and time to peak activity was extracted from the EMG data of all muscles investigated. Variations of stride cycle time were tested in the two conditions using paired Student's t-test and found to not be statistically different ( $\mathrm{p}>0.05$ ). Paired Student's t-tests revealed no 
statistically significant difference between the two conditions in all parameters extracted from the EMG of all muscles ( $\mathrm{p}>0.05)$.

\subsubsection{Stationary stretch device}

The stationary hydraulic actuator system was used to apply the unexpected knee flexion perturbations for all parts of Studies I, II and III and hence a brief discussion on methodological concerns is warranted. As described in the experimental set-up (section 3.2.1.), the knee joint axis of rotation has to be carefully aligned with the fulcrum of the actuator. This ensures that the rotational displacement produced by the actuator is transferred directly to the knee joint. Since the subjects were asked to pre-contract their knee extensors to various levels of MVC it is likely that small shifts occurred in the original alignment. This would also be the case for when the quadriceps are activated by electrical stimulation as was done in Study I. While this cannot be ruled out, the position of the knee joint axis of rotation in relation to the fulcrum of the actuator was frequently checked to ensure that any such potential shifts were minimized.

\subsubsection{Electrical stimulation of muscle}

In the Study I of this thesis, electrical stimulation was used to obtain the intrinsic torque contribution to the total joint torque. It is well known that the recruitment pattern of motor units differs when this is performed electrically vs. voluntarily (Nichols \& Houk, 1976). Muscle activation is changed not only by recruitment of more motor units but also by increased firing rate. Here stimulation frequency was maintained constant and only the amplitude of the stimulation was varied. In the cat soleus muscle it has been shown that the force resulting from stretch does not vary if stimulation frequency is altered, or if the crossed extensor reflex is used to 
recruit motor units (Nichols \& Houk, 1976). Carter et al. (1990) found no significant differences in torque produced with either amplitude or frequency of stimulation. It may be argued, however, that since the knee joint is comprised of a number of extensor muscles it may be difficult to accurately match the conditions during voluntary contractions vs. electrical stimulation. In Study I, torque records produced by either method prior to possible effects of the reflex are closely matched (Fig. 6). This lends support to the notion that the non-reflex torque contribution to the total torque was accurately predicted.

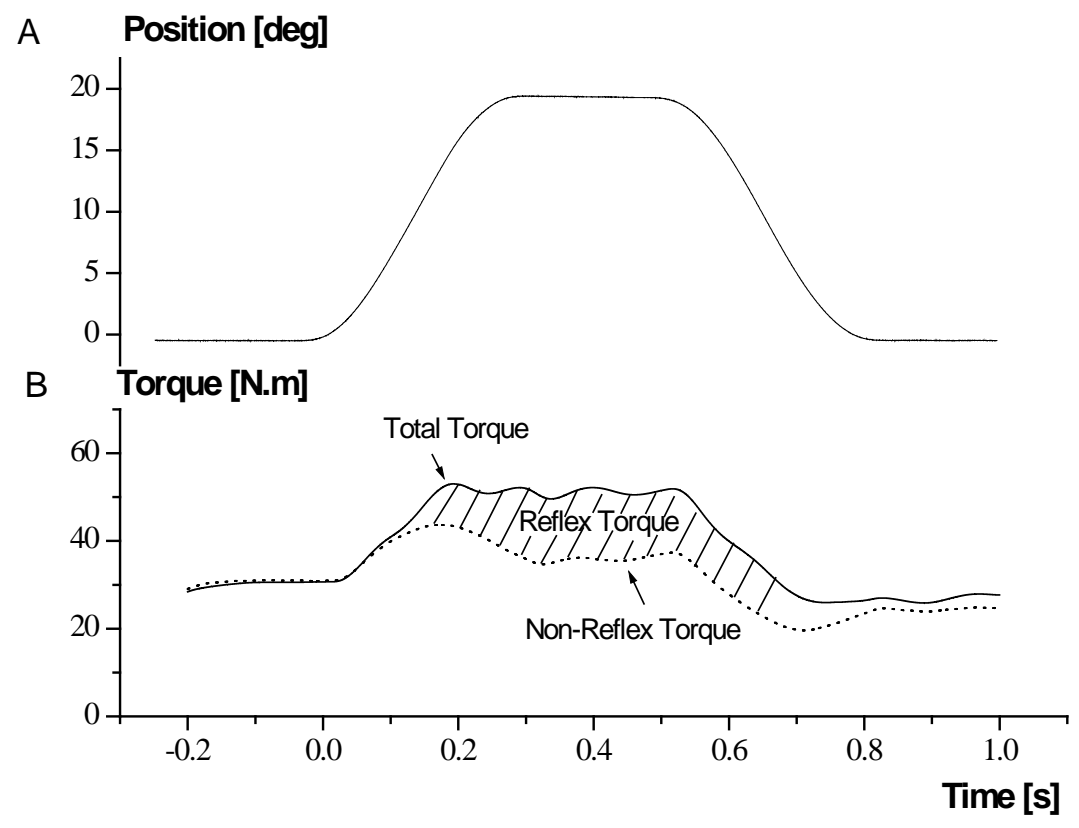

Figure 6: A) Knee flexion angle. B) Time course of total and non-reflex torque of knee extensors in response to a $20^{\circ}$ stretch. 


\section{$4 \quad$ Results}

A comprehensive analysis of the results is contained within the separate publications arising from each study conducted during this $\mathrm{PhD}$ (refer to Appendix). This section will therefore concentrate on those results that directly relate to the formulated aims in this thesis. Where necessary, figures have been replicated from the articles to enhance the readability of this section.

\subsection{Knee extensor reflex contribution to total torque around the knee joint}

\subsubsection{Electromyographic Results}

In Study I, a reflex response as measured by electromyography (EMG) was observed in all knee extensors at onset latencies ranging between $26-36 \mathrm{~ms}$. The duration of a typical response is approximately 100 to $120 \mathrm{~ms}$ and consists of a number of peaks. Thereafter a tonic response was observed which continued until the cessation of the stretch. Both phasic and tonic EMG stretch responses increased with increasing background torques (Fig. 7). Lines of best fit produced correlation coefficients of $0.59-0.78$. 


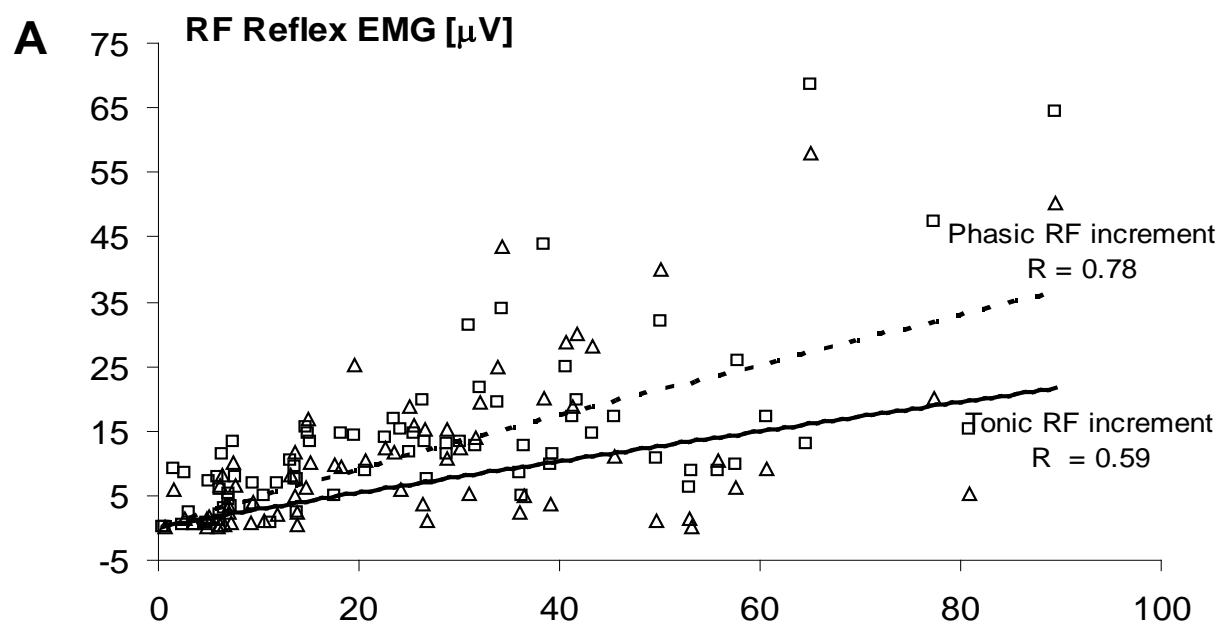

Background Torque [\% MVC]
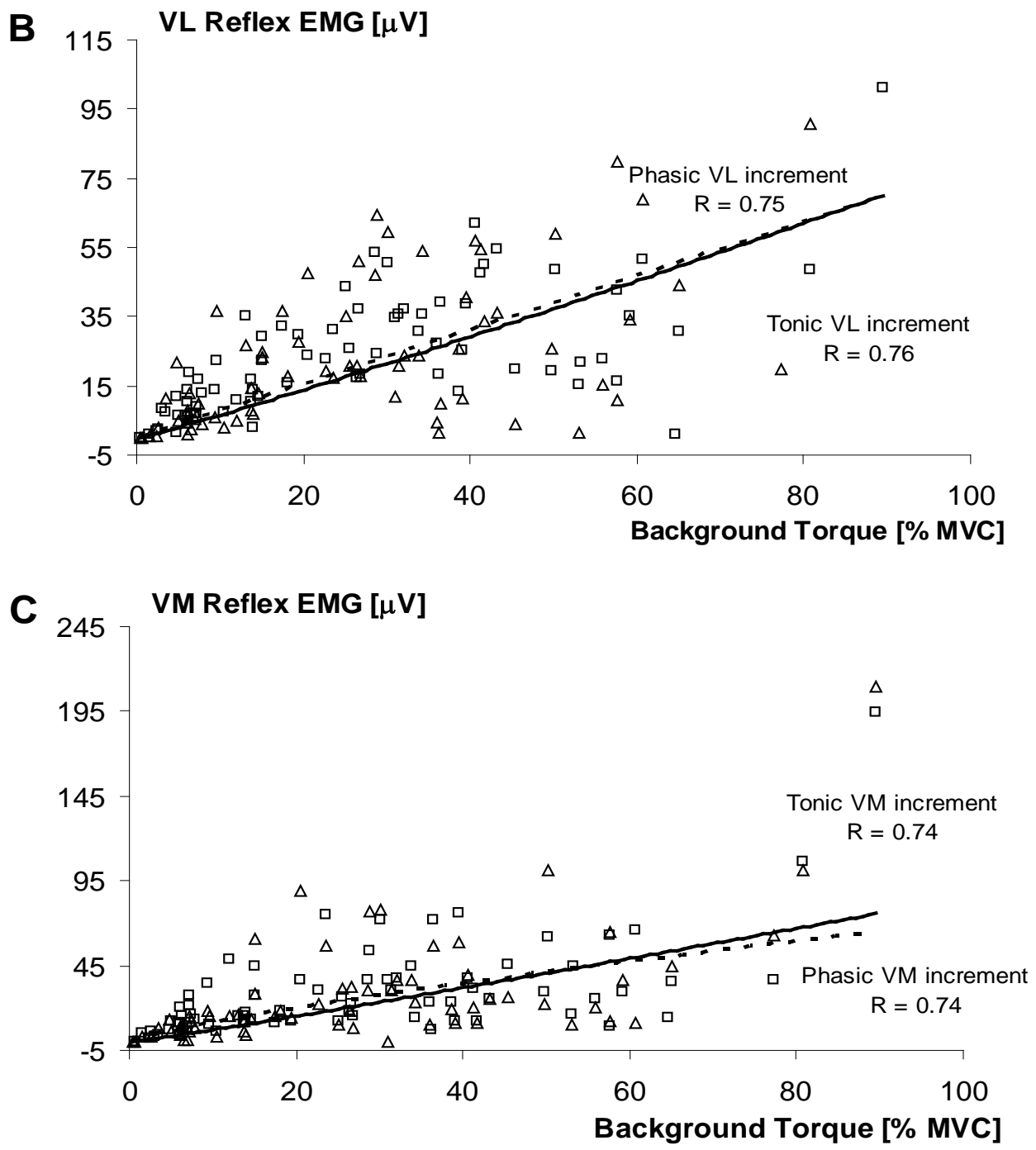

Figure 7: Average rectified phasic and tonic EMG measurements for all subjects as a function of background torque ( $\Delta=$ Tonic; $\square=$ Phasic). Linear lines of best fit with associated $\mathrm{R}$ values are also shown. In all graphs the solid line indicates tonic EMG increment, and the dotted line indicates phasic EMG increment. A - C represent RF, VL and VM, respectively. 


\subsubsection{Mechanical Results}

For the first $60-80$ ms following the onset of the applied external knee flexion perturbation, the non-reflex torque as recorded during electrical stimulation and the total torque increment recorded during voluntary contraction exhibit the same pattern (Fig. 6). This similarity is in part due to the inertia of the moved plate, leg and foot segment (Allum \& Mauritz, 1984). Following this initial period the nonreflex torque increased further but to a lesser degree than the total torque, until it reached its maximum value approximately $150 \mathrm{~ms}$ following perturbation onset, at which it stabilized. It returned towards the level of background torque either at the cessation of the imposed knee flexion or slightly earlier. The total torque reached its maximum at approximately 200 - $300 \mathrm{~ms}$ after stretch onset. It remained constant until cessation of the stretch when it decreased to the level of the background torque. The difference between the non-reflex and total torque in Figure 6 is attributed to the stretch reflex.

Non-reflex torque increased linearly with background torque. The line of best fit for the data from all subjects has a correlation coefficient of 0.90 . The total torque increased without peaking even at high levels of background torque. A second order polynomial with a correlation coefficient of 0.90 could be fitted to the data. The reflex torque was calculated by subtracting the non-reflex torque from the total torque increment at $300 \mathrm{~ms}$ following stretch onset. Individual subjects vary in the magnitude of reflex torque contribution to the total joint torque. Total torque, non-reflex torque and reflex torque across various background torques for one subject are shown in the upper trace of Figure 8A. Note that at lower background torques the total torque and non-reflex torque are almost identical. With increasing background torque, the contribution from reflexes rapidly 
increases up to a background torque of 30 to $40 \%$ MVC. Data were also pooled for all subjects and averaged in 10 blocks of $10 \%$ increments of background
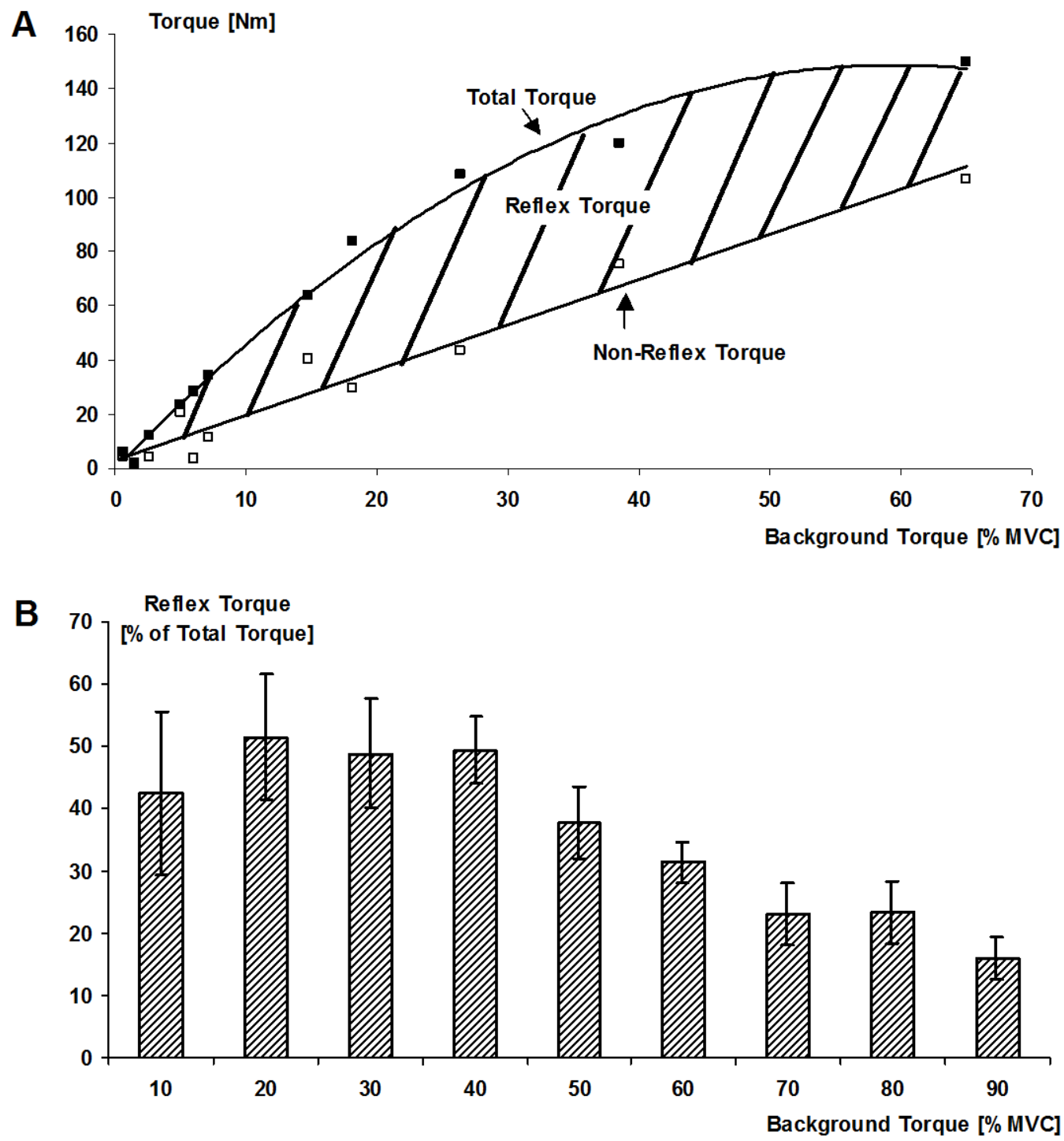

Figure 8: A) The total and non-reflex torque plotted against the background torque at $300 \mathrm{~ms}$ following the applied knee flexion perturbation for one subject. Data points indicate means over ten stretches. B) Reflex torque increments as a percentage of total torque with changing background torques measured $300 \mathrm{~ms}$ following the onset of the perturbation. Data were averaged for $10 \%$ background torque windows. Standard deviations are also shown.

torque respectively (Fig. 8B). The abscissa expresses the reflex torque as a percentage of the total torque. Across all subjects, the contribution of the reflex mediated torque was initially low and peaked at background torques of $20-40 \%$ 
MVC. In terms of the total torque, the reflex contributed $16-52 \%$ across all levels of background torque.

\subsection{Knee extensor stretch reflex response to perturbations of low amplitude}

In Study I the response to the applied perturbation observed in the EMG of all knee extensors investigated was unlike what had been reported in the past for the muscles of the ankle joint in that it did not contain clearly definable peaks. This is likely to be contributed to by both the high amplitude and very slow rise time of the applied stretch in that study. Therefore, we chose to continue investigating the stretch reflex of the knee extensors by using applied perturbations of lower amplitude. The observed response still consists of multiple peaks, however these are more clearly defined. In the following subsections a brief general overview of the onset time as well as the general pattern of the responses observed in RF, VL and VM is given highlighting the similarity of these for Studies II - IV.

\subsubsection{Onset latencies}

The onset latency of the first observed response in the target muscle following an imposed perturbation was similar in all paradigms. The average latencies ranged from $22-27 \mathrm{~ms}$ for RF, $23-28 \mathrm{~ms}$ for VL and $22-29 \mathrm{~ms}$ for VM. This was unaffected by either the velocity or amplitude of the imposed perturbation (Study I), nor by the specific task in which the subject was engaged at the time (Study I, II, III and IV). 


\subsubsection{Three response peaks}

Except when very slow perturbations were applied (Study I), the response to an imposed unexpected knee flexion generally consisted of three discernible peaks (Fig. 3). These were labelled short latency response (SLR), medium latency response (MLR) and long latency response (LLR). Throughout all studies of this thesis, no attempt was made to determine the onset times of the MLR or LLR as this coincides with the cessation of the respective previous response. In Study III however, the peak latencies of all three bursts were determined. The SLR maximums occurred as follows: RF: $38 \pm 3 \mathrm{~ms}$, VL: $39 \pm 4 \mathrm{~ms}$, and VM: $42 \pm 3 \mathrm{~ms}$; and the MLR maximum for RF was at $52 \pm 6 \mathrm{~ms}$, for VL at $48 \pm 4 \mathrm{~ms}$ and for VM at $51 \pm 5 \mathrm{~ms}$. An obvious LLR burst was only evident in seven subjects out of the 11 subjects tested, with a peak with a latency of $83 \pm 7 \mathrm{~ms}, 77 \pm 10 \mathrm{~ms}, 83 \pm 8 \mathrm{~ms}$ for the RF, VL and VM muscles, respectively. The remaining four subjects showed only an increase in the EMG levels above background values. The duration of the total reflex response across studies II - IV was as follows: RF: 79 - $110 \mathrm{~ms}, \mathrm{VL}: 54 \pm 110 \mathrm{~ms}$, and VM: $57 \pm 110 \mathrm{~ms}$.

\subsection{Peripheral pathways generating the different quadriceps stretch reflex components}

\subsubsection{Characteristics of the response to perturbation modifications}

\subsubsection{Velocity sensitivity}

The effect of altering the velocity of the knee flexion perturbation while the amplitude was unchanged at four degrees was investigated using five different 
stretch velocities: 70, 130, 150, 180 and $220 \%$ s. Figure 9A - C represent the averaged $(n=10)$ rectified EMG data of RF, VL and VM for one subject and three different stretch velocities (130, 180 and $\left.220^{\circ} / \mathrm{s}\right)$. The solid line represents the EMG response at a stretch velocity of $130^{\circ} / \mathrm{s}$, while the dotted line represents the EMG response at a velocity of $180^{\circ} / \mathrm{s}$ and the dashed line the response at a velocity of $220^{\circ} / \mathrm{s}$. In all trials, the subject was asked to pre-contract the quadriceps muscles to approximately 10\% MVC. Across all subjects, the average SLR amplitude increased with increasing stretch velocity while both the MLR and LLR either decreased or remained unchanged. Figure 9D - F displays the average SLR, MLR and LLR magnitude and standard deviations for all knee extensors and for all subjects $(n=13)$ at all velocities investigated as a percentage of background EMG. A repeated measure ANOVA revealed a significant increase of the magnitude of the SLR with increasing velocity of the applied knee flexion perturbation ( $\mathrm{p}<0.001$ for $\mathrm{RF}, \mathrm{VL}$ and $\mathrm{VM}$ ). The magnitude of the MLR remained unchanged $(p=0.08$ for $R F, p=0.64$ for $V L$ and $p=0.49$ for $V M$ ), while the LLR magnitude remained unchanged for the RF $(p=0.52)$ and decreased significantly with increases in stretch velocity for VL and VM $(p<0.001)$. At stretch velocities above $150 \%$ s an inhibition was observed at the time of the LLR in both VL (Fig. 9E) and VM (Fig. 9F) as seen by a drop in the EMG values below 100\%. 

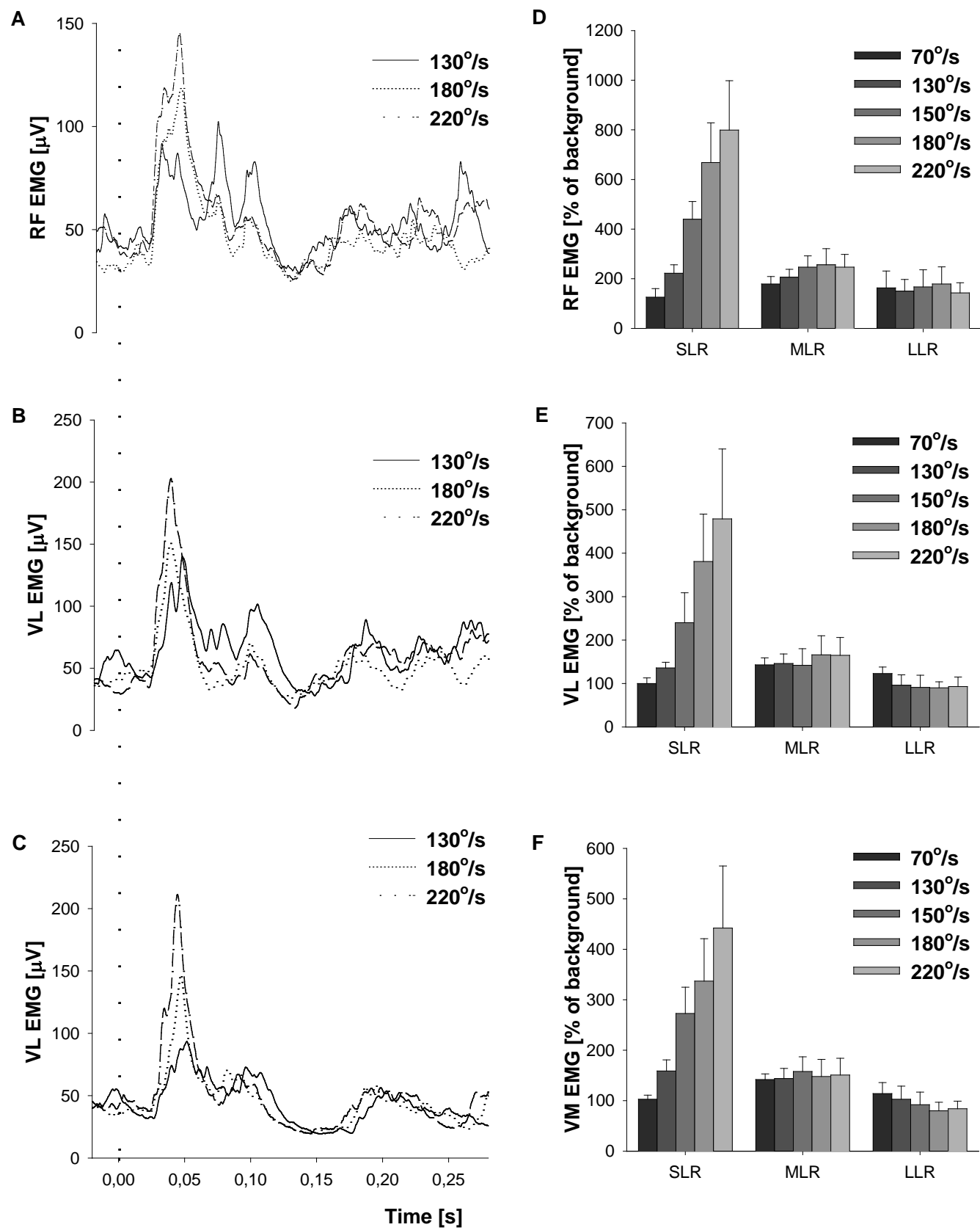

Figure 9: Effect of altered velocity of the imposed knee flexion on the RF, VL and VM responses A) Average RF EMG following an imposed knee flexion $\left(4^{\circ}, 130^{\circ} / \mathrm{s}\right.$ - solid line, $4^{\circ}, 180^{\circ} / \mathrm{s}$ - dotted line, $4^{\circ}, 220^{\circ} / \mathrm{s}-$ dashed line). Data are the averages of 10 trials for one subject. B) As for A but in VL. C) As for A but in VM. D) Average RF SLR, MLR and LLR size across all subjects $(n=13)$ for imposed knee flexion perturbations of $4^{\circ}$ amplitude and 70, 130, 150, 180 and $220^{\circ} / \mathrm{s}$ velocity. E) As for D but in VL. F) As for D but in VM. 


\subsubsection{Amplitude sensitivity}

As a second condition, the amplitude of the applied knee flexion was set to either $4^{\circ}, 6^{\circ}$ or $8^{\circ}$ while the velocity of the perturbation was maintained at $150^{\circ} / \mathrm{s}$. The subjects were again asked to pre-contract their quadriceps muscle to approximately $10 \%$ of MVC. Figure $10 \mathrm{~A}-\mathrm{C}$ shows the rectified EMG data for the RF, VL and VM, respectively. Each trace is the average of 10 trials; the solid line represents the stretch amplitude of $4^{\circ}$, the dotted line one of $8^{\circ}$. For this subject, while the magnitude of the MLR increased with perturbation amplitude, the SLR remained either invariant (VL - Fig. 10B) or decreased slightly (RF Fig. 10A). Figure 10D - F shows the average RF, VL and VM SLR, MLR and LLR magnitudes as well as standard deviations for all subjects. Across all subjects, no significant changes were found for the SLR response size $(p=0.5$, 0.11 and 0.09 for RF, VL and VM, respectively) in any of the three conditions. The MLR magnitude increased significantly with increases in perturbation amplitude ( $\mathrm{p}=0.01,0.007$ and 0.001 for RF, VL and VM, respectively), as did the LLR magnitude $(\mathrm{p}<0.001)$. 
A
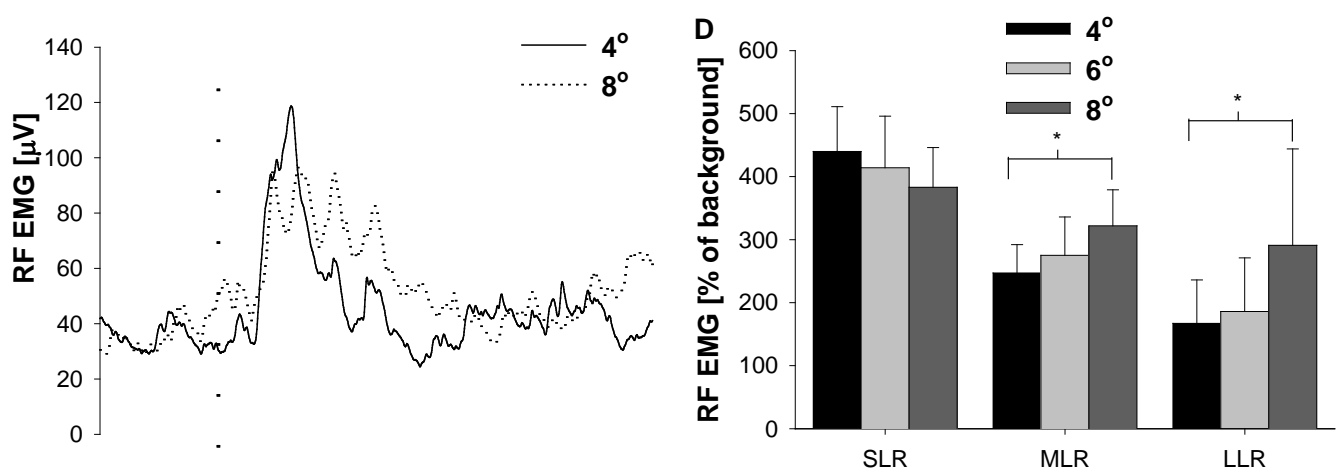

B
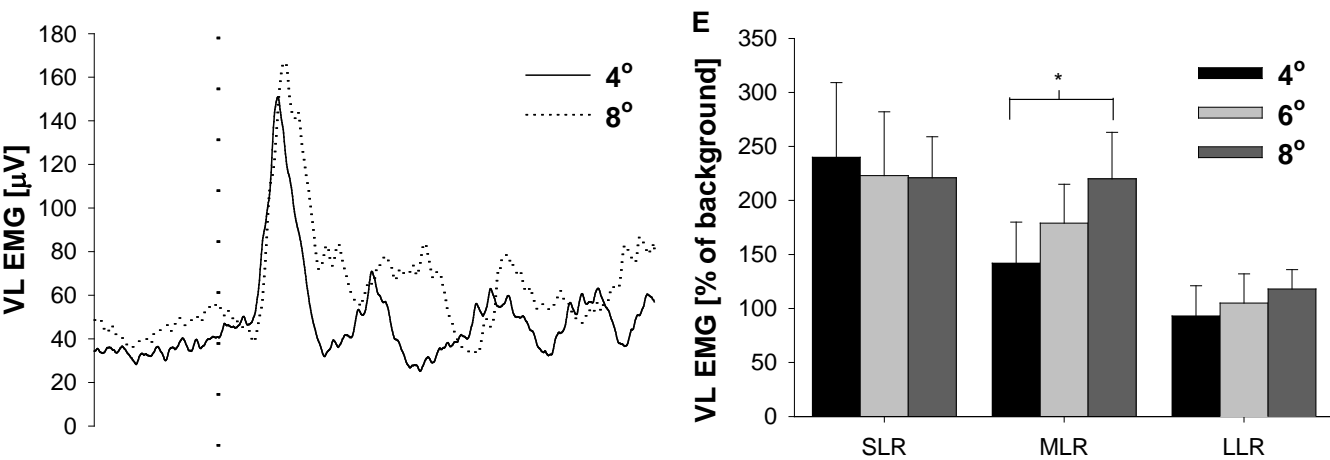

C
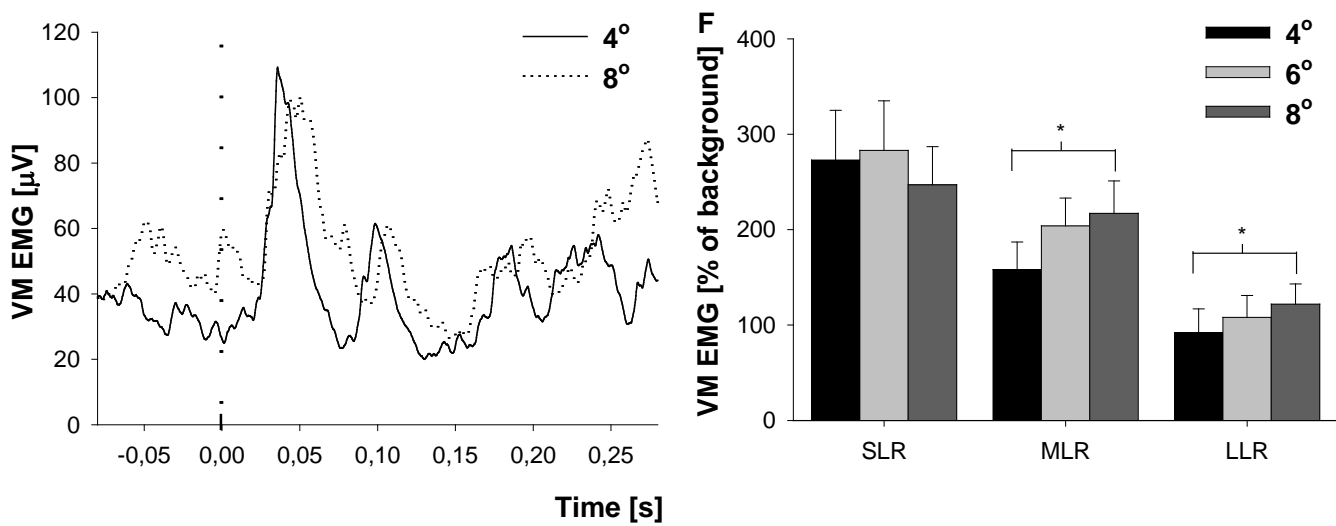

Figure 10: Effect of altering the amplitude of the imposed knee flexion on the RF, $\mathrm{VL}$ and $\mathrm{VM}$ responses A) Average RF EMG following an imposed knee flexion $\left(4^{\circ}, 150^{\circ} / \mathrm{s}\right.$ - solid line, $8^{\circ}, 150^{\circ} / \mathrm{s}$ - dotted line). Data are the averages of 10 trials in one subject. B) As for A but in VL. C) As for A but in VM. D) Average RF SLR, MLR and LLR size across all subjects $(\mathrm{n}=13)$ for imposed knee flexion perturbations of $4^{\circ}, 6^{\circ}$ and $8^{\circ}$ amplitude at a constant velocity of $150^{\circ} / \mathrm{s}$. E) As for D but in VL F) As for D but in VM. 


\subsubsection{Characteristics of the response to background contraction modifications}

\subsubsection{Response size at increasing levels of isolated knee extensor contraction}

Increasing the pre-activation of the knee extensors resulted in a significant increase in the SLR, MLR and LLR response magnitude $(\mathrm{p}<0.05)$ for RF, VL and VM.

\subsubsection{Co-contraction versus isolated knee extension}

An effect on the magnitude of the SLR for the RF, VL and VM when the knee flexion perturbation was applied either during an isolated knee extension or a cocontraction task is shown in Figure 11A. Data are the averages over all subjects. The applied knee flexion perturbation was $8^{\circ}$ in amplitude and had a velocity of $150^{\circ} /$ s. Also included are the matching background activation levels for each condition and muscle (Fig. 11B). The background activation was not significantly different between conditions $(\mathrm{p}=0.31,0.47$ and 0.33 for RF, VL and VM, respectively) and approximately 20\% MVC. The magnitude of the SLR however, was significantly reduced during co-contraction compared to isolated knee extension for all knee extensors (Fig. 11A; $\mathrm{p}=0.038,0.02$ and 0.03 for the RF, VL and VM, respectively).

No significant differences were found for the MLR and the LLR (Fig. 11C and D) $(\mathrm{p}=0.37-0.96$ for MLR and $\mathrm{p}=0.47-0.79$ for LLR). 
A

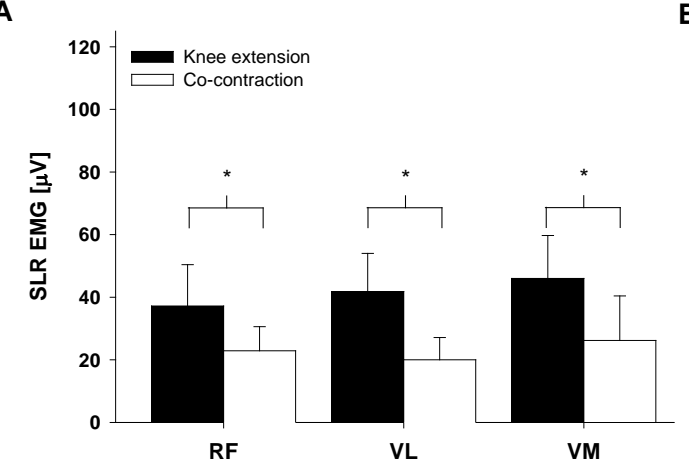

C

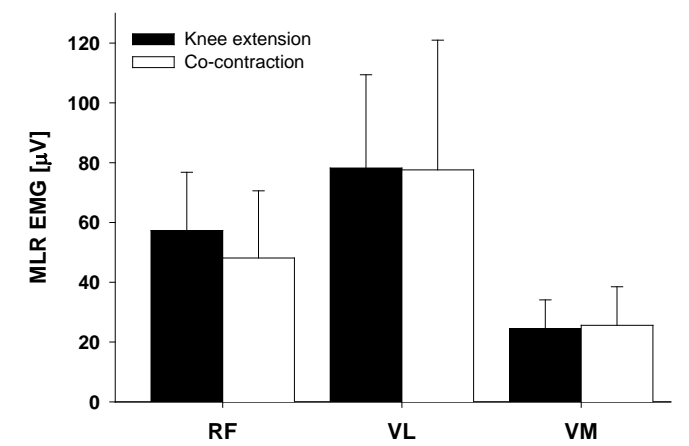

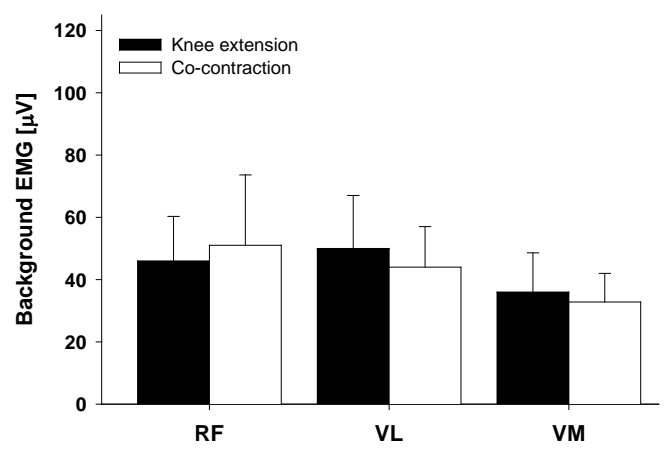

D

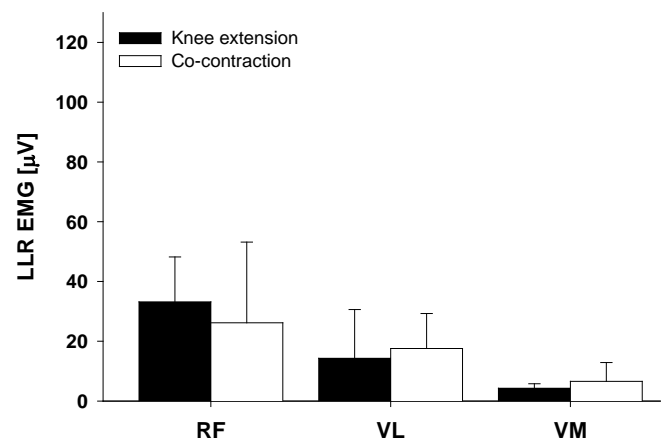

Figure 11: Effect of co-contraction versus isolated knee extension on RF, VL and VM responses. A) Average SLR size for RF, VL and VM during cocontraction versus isolated knee extension across all subjects $(n=13)$. The imposed knee flexion had an amplitude of $8^{\circ}$ and a velocity of $150 \%$ s. B) Average background EMG of RF, VL and VM across all subjects for the same conditions as in A. C) Average MLR size for RF, $\mathrm{VL}$ and VM across all subjects for the same conditions as in A. D) Average LLR size for RF, VL and VM across all subjects for the same conditions as in A. Also shown are standard deviations. Significance is indicated by an asterisk.

Responses were also characterized for two different levels of co-contraction for eight subjects (at 20\% and $70 \%$ of MVC). The average SLR magnitude is shown in Figure 12A. Figure 12B displays the background activation for all knee extensors during the two conditions. Although the background activation was significantly different $(\mathrm{p}=0.003,0.003$ and 0,008 for $\mathrm{RF}$, VL and VM, respectively), the SLR magnitude did not change ( $p=0.15,0.2$ and 0.75 for $R F$, VL and VM, respectively). 
The MLR increased significantly with increasing levels of co-contraction ( $<<0.001$ for RF, VL and VM) (Fig. 12C).

A

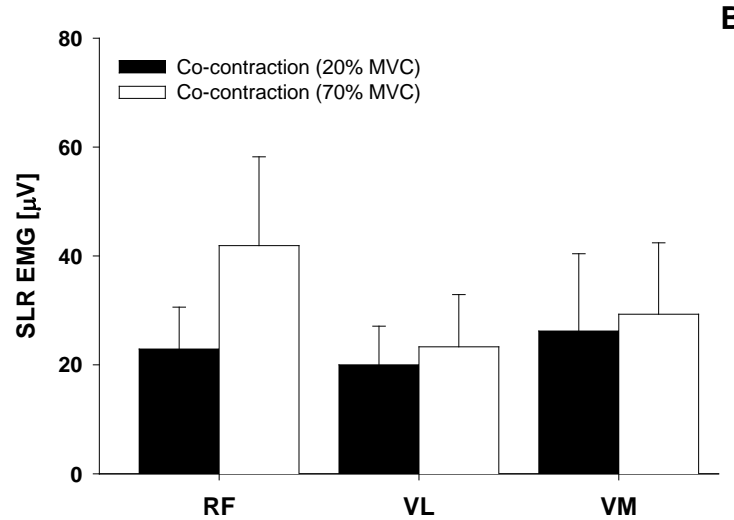

C

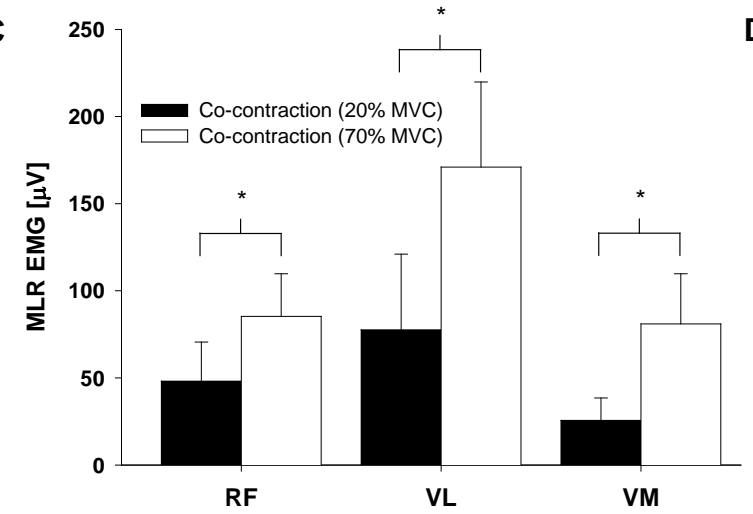

B

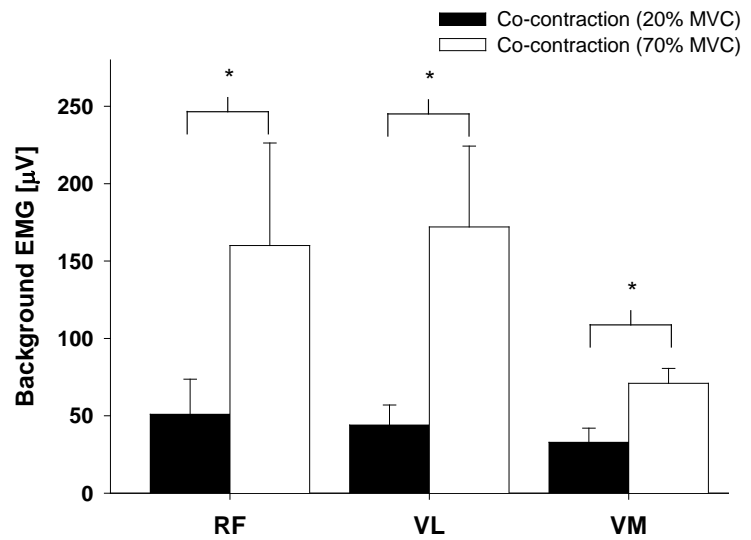

D

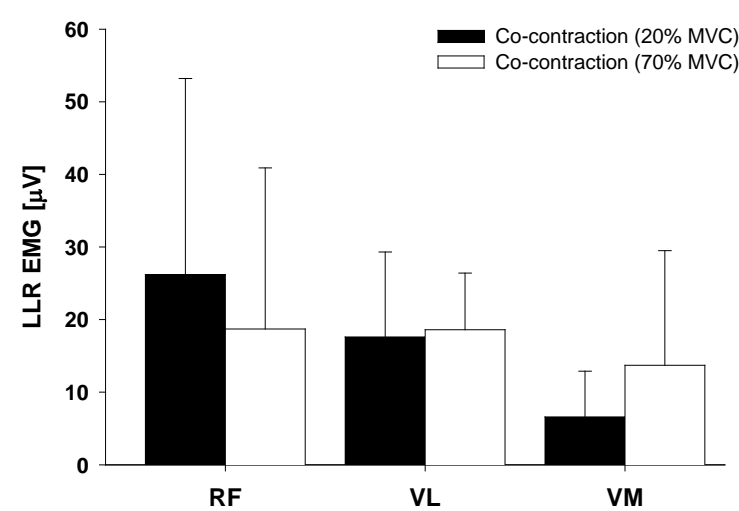

Figure 12: Effect of increasing levels of co-contraction on RF, VL and VM SLR responses A) Average SLR size for RF, VL and VM during 20\% MVC versus $70 \%$ MVC co-contraction across all subjects $(n=13)$. The imposed knee flexion had an amplitude of $8^{\circ}$ and a velocity of $150^{\circ} / \mathrm{s}$. B) Average background EMG of RF, VL and VM across all subjects for the same conditions as in A. C) Average SLR size for RF, VL and VM across all subjects for relaxed, 10\%, 30\% and 50\% MVC knee extensor pre-contraction during the same stretch as applied in A. D) Average SLR size for RF, VL and VM for eight subjects during either relaxed or antagonist pre-activation (20\% MVC) during the same stretch as applied in A. Also shown are standard deviations. Significance is indicated by an asterisk.

In comparison to the SLR and the MLR, the response size of the LLR was considerably smaller in all knee extensors investigated. The LLR magnitude was not affected by increasing levels of co-contraction (Fig. 12D). 
To complete the data set, the response magnitude of the SLR was compared during relaxed trials and trials when only the antagonists (knee flexors) were active. Only eight out of 13 subjects displayed an obvious SLR during the relaxed trials. While the SLR magnitude was reduced in the relaxed condition compared to quadriceps pre-activation, during antagonist pre-activation the SLR was almost completely abolished. The difference of the SLR size between relaxed and antagonist activation conditions was significant for all knee extensors investigated ( $p=0.03,0.04$ and 0.04 for $R F, V L$ and $V M$ ) as was the reduction in MLR magnitude ( $p=0.04,0.03$ and 0.04 for RF, VL and VM). The LLR magnitude was not affected by antagonist pre-activation $(\mathrm{p}=0.37,0.8$ and 0.96 for RF, VL and VM).

\subsection{Cortical contribution to the quadriceps stretch reflex}

The aim of Study III was to examine the possibility of a supraspinal contribution to the long latency stretch reflex of the human quadriceps muscle complex, during a sitting task. We quantified the reflex response to an imposed knee flexion delivered in combination with a transcranial magnetic stimulus in four muscles: RF, VL, VM and BF. Three different conditions were examined: responses during an unexpected stretch of the knee extensors $\left(S_{1}\right)$ alone, when transcranial magnetic stimulation (TMS) was applied alone $\left(\mathrm{S}_{2}\right)$, and when the two stimuli were applied in combination $\left(\mathrm{S}_{12}\right)$. This method has been used previously to examine the role of supraspinal centres in the shaping of the stretch response of the tibialis anterior muscle (Petersen et al., 1998). 


\subsubsection{Motor and Somatosensory Evoked Potentials}

To determine the fastest possible conduction time of the efferent pathway, a motor evoked potential in the RF muscle was elicited by stimulating the motor cortex with transcranial magnetic stimulation. Figure $13 \mathrm{~F}$ shows the motor evoked potential (MEP) in an ensemble averaged data record for the same subject as in Figure $13 \mathrm{~A}-\mathrm{E}$. The onset of the MEP at 22 ms reflects the efferent conduction velocity for this subject.

Recordings were also made of the somatosensory evoked potentials (SEP) induced by the imposed knee perturbation (Fig. 13G) to estimate the conduction velocity in the corticospinal tract and, therefore, the earliest time that would allow a transcortical pathway to contribute to the RF stretch reflex. The data presented in Figure 13G is an ensemble averaged SEP $(n=200)$ for the same subject as in Figure 13A - F. In this case the SEP onset latency was 23 ms. Therefore, the earliest time at which a transcortical pathway can contribute to the RF stretch reflex response in this subject is $55 \mathrm{~ms}$ (efferent conduction time (22 ms) plus afferent conduction time (23 ms) plus the estimated central processing delay (10 ms - Nielsen et al., 1997; Kurusu \& Kitamura, 1999).

The mean MEP and SEP onset latencies across all subjects were $20 \pm 4$ ms and 24 $\pm 2 \mathrm{~ms}$, respectively. Therefore, a transcortical pathway has the potential to contribute to the RF stretch reflex no earlier than $54 \pm 6 \mathrm{~ms}(\mathrm{MEP}+\mathrm{SEP}+$ central processing delay). 
A

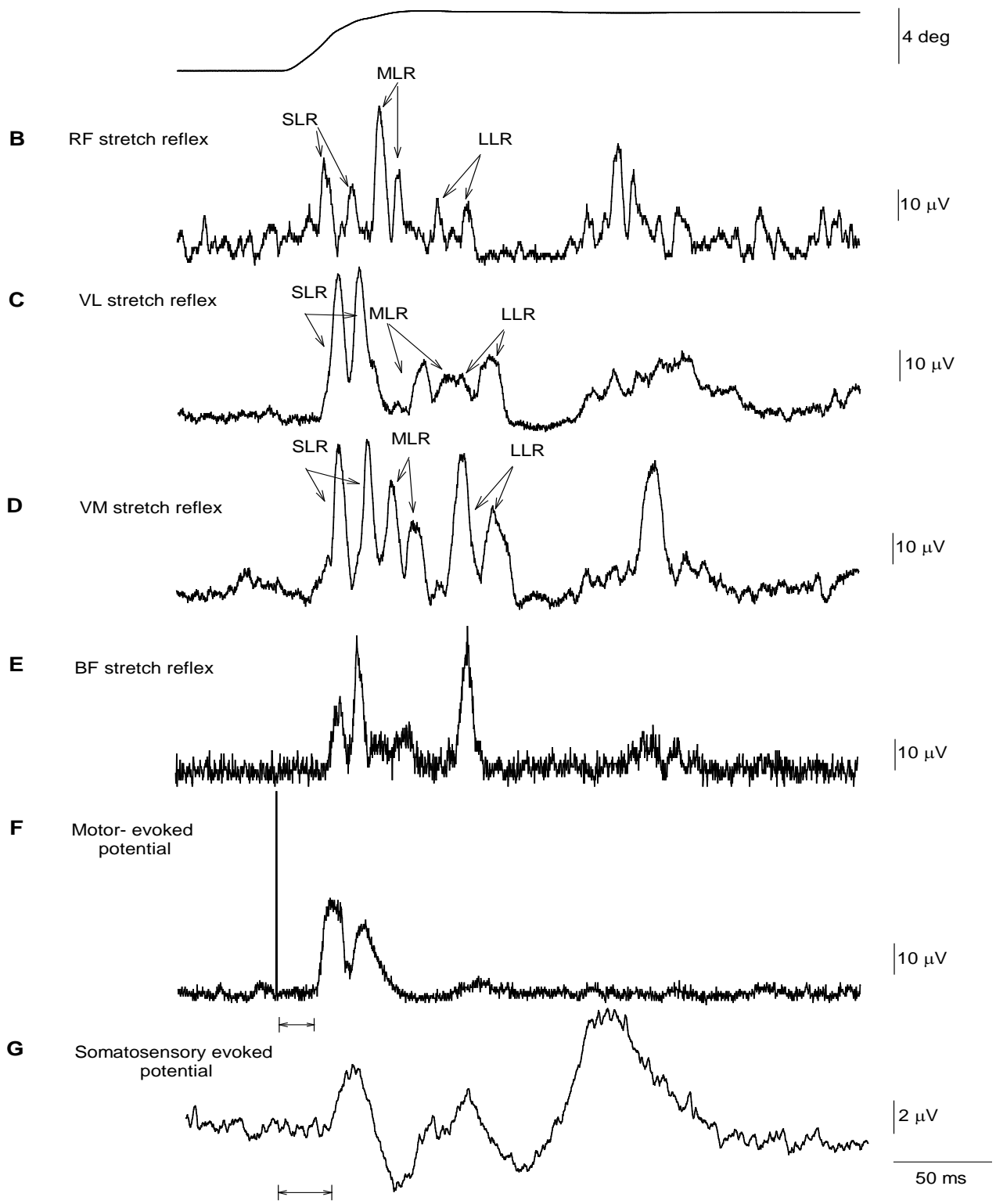

Figure 13: Muscular response patterns to stretch and calculation of the minimum conduction time necessary for a transcortical stretch reflex in the RF A) Knee joint angular position during an imposed knee flexion perturbation $\left(4^{\circ}\right.$, $150^{\circ} / \mathrm{s}$ ) for one subject. Each data record is an ensemble average of 20 trials. B) Electromyogram of the rectus femoris (RF) muscle showing stretch reflex response evoked by the perturbation. The knee was held in a tonic knee extension at $10 \%$ of maximal voluntary effort prior to the perturbation. Three distinct bursts are seen in the rectified EMG trace and indicated by arrows. The approximate peak latencies are $40 \mathrm{~ms}$ (labelled SLR), $58 \mathrm{~ms}$ (labelled MLR) and $80 \mathrm{~ms}$ (labelled LLR). C - E) Electromyograms for vastus lateralis (VL), vastus medialis (VM) and biceps femoris (BF) muscles showing stretch reflex responses. F) Motor evoked potential in the $\mathrm{RF}$ evoked by magnetic stimulation of the motor cortex. The onset latency is $22 \mathrm{~ms} . \mathrm{G})$ Somatosensory evoked potential evoked after stretching the knee extensors as in A. The onset latency is $23 \mathrm{~ms}$. 


\subsubsection{MEP facilitation as a response to stretch}

To determine if the RF stretch reflex or any of its components are contributed to by cortical pathways, transcranial magnetic stimuli were applied such that the arrival of the MEP coincided with different components of the RF stretch reflex. In any one experimental run, the stretch was either applied alone, the TMS was applied alone or the two stimuli were combined with varying inter-stimulus intervals. For each condition, ten to twenty trials were collected. If the MEP arrival was timed to coincide with the RF SLR peak, the magnitude of the resulting response was approximately equal to the algebraic sum of the response magnitudes when the stretch and MEP are elicited alone. However, if the MEP was superimposed on the RF LLR peak, the response was more than four times greater than their algebraic sum when elicited separately. The MEP and stretch reflex magnitude averages across all subjects are summarized in Figure 14. Figure 14A represents the facilitation of the response when the MEP arrival coincided with either, the SLR, MLR and LLR peaks. Figure 14B shows the average facilitation including standard deviations across all subjects as recorded for various inter-stimulus intervals between the MEP arrival and the stretch reflex. Time zero indicates the onset of the imposed knee joint rotation.

If this extra facilitation can be considered to represent a cortical involvement in the shaping of the LLR then an extra facilitation should be observed prior to the peak of the LLR, i.e. at the onset of the LLR. Figure 14B displays the time course of the facilitation across all subjects. The onset of the extra facilitation precedes the LLR peak commencing on average $78 \mathrm{~ms}$ after the imposed knee joint rotation. This is considerably earlier than the peak latency of the LLR. A repeated measures ANOVA revealed a significant interaction between the timing of the 
MEP in relation to the RF stretch reflex and the size of the recorded responses across all subjects $\left(\mathrm{F}_{40,360}=5.25, \mathrm{p}<0.001\right)$. Planned contrasts between the size of the responses at the time of the peak SLR and peak LLR and between the peak MLR and peak LLR revealed significant differences $(t=3.493, \mathrm{p}<0.001)$.

A

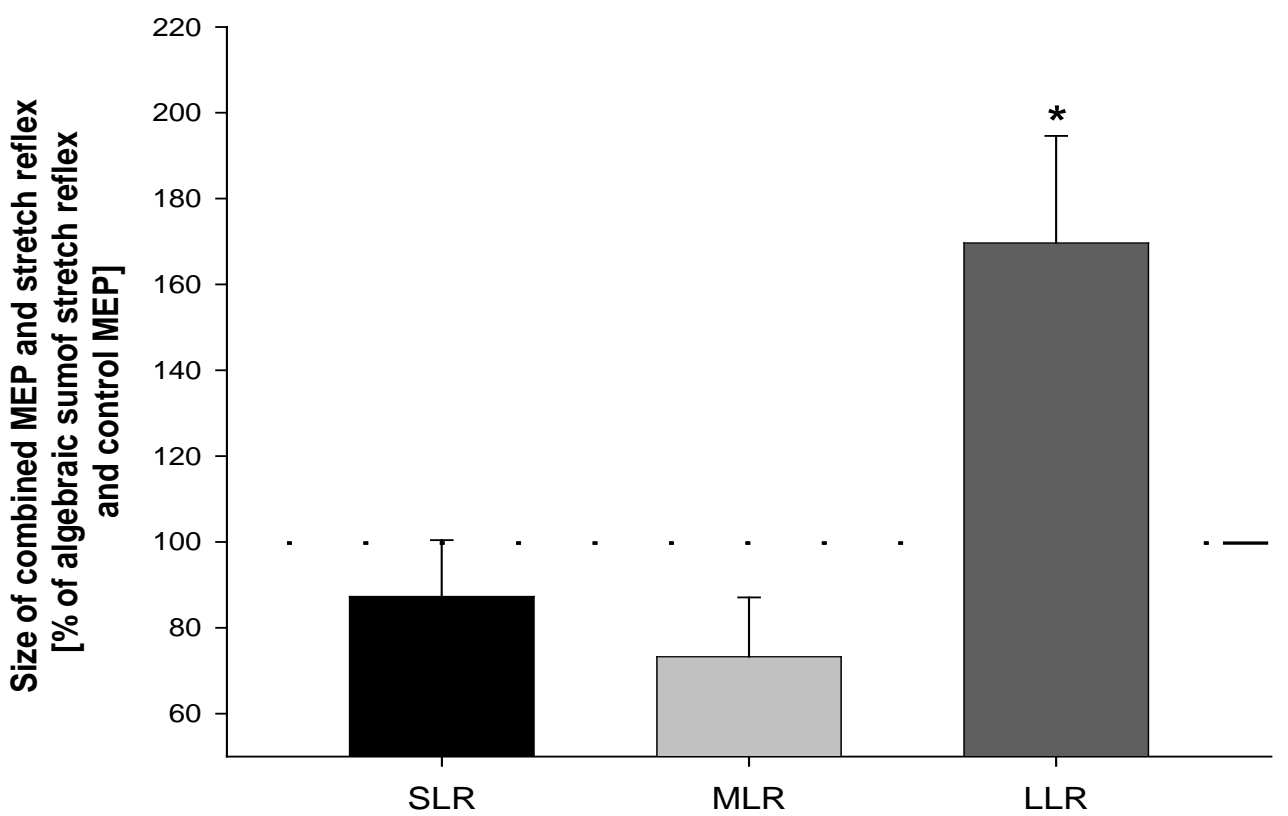

B

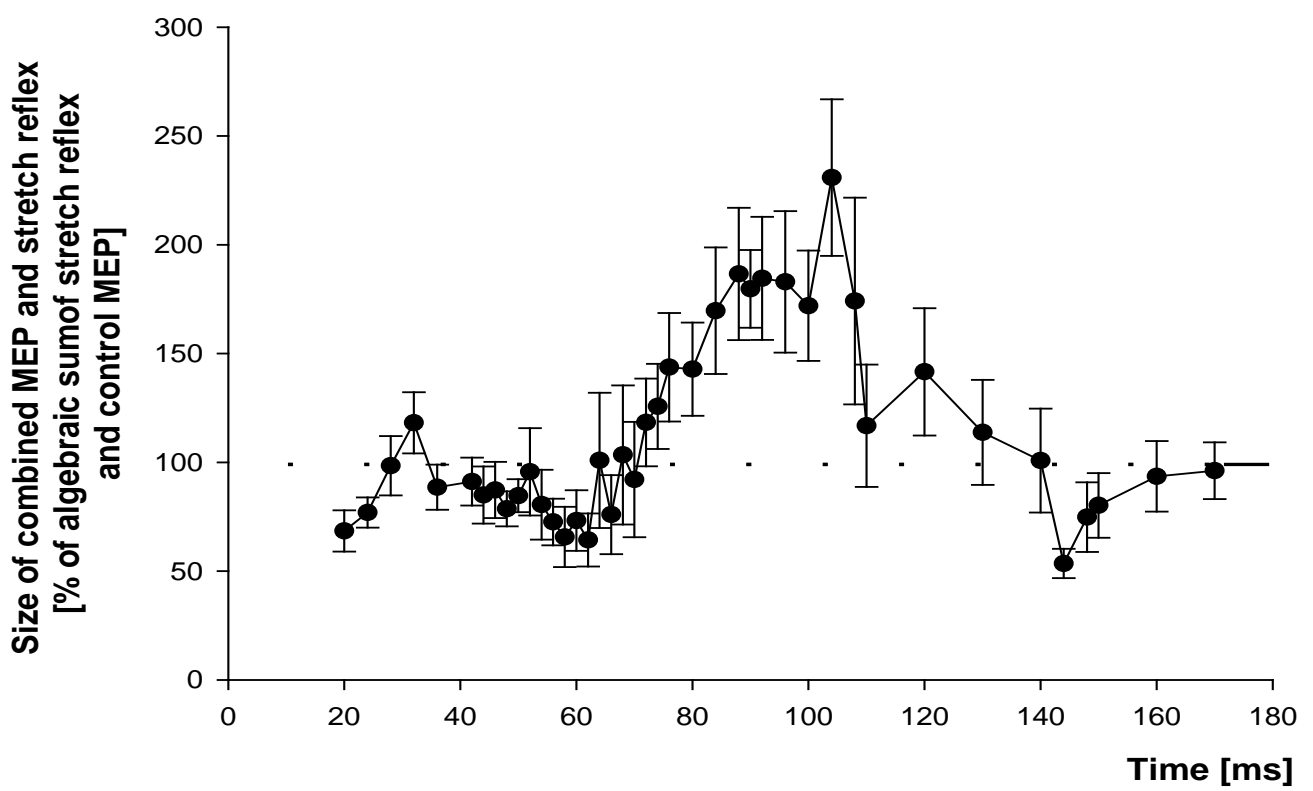

Figure 14: Facilitation of the RF MEP across all subjects A) Facilitation of the RF MEP when the response was timed to arrive either with the SLR, MLR or LLR bursts. The mean response across all 11 subjects is shown. The error bars represent standard deviations. Significant effects $(p<0.05)$ are indicated with an asterisk. B) Time course of the RF MEP facilitation (expressed as a percentage of the algebraic sum of the stretch reflex and MEP when elicited separately) when the MEP was applied at various intervals to the stretch. Mean values are shown together with standard deviations. 
The VL and VM muscles share a similar area of cortical representation to the RF and they are stretched at the same time as the RF muscle when the knee is perturbed. It was not surprising that the cortical stimulus also elicited a MEP in these muscles. Therefore, we investigated if a similar facilitation as seen in the RF was present in its synergists. A repeated measures ANOVA across all subjects revealed no significant facilitation of the MEP as recorded from both the VL and VM ( $p=0.26$ and 0.31 , respectively). The cortical area representing the RF, VL and $\mathrm{VM}$ is also shared with the representation of the antagonistic BF (Bonnard et al., 2002). The cortical stimulus as applied in Study III also elicited a MEP in the $\mathrm{BF}$ and thus it was possible to investigate the effects of the conditioning stimulus on the activity of the BF. However, a repeated measures ANOVA revealed no significant effect on the BF muscle $(p=0.25)$.

\subsection{Knee extensor stretch reflex response modulation during a dynamic task}

Figure 15 contains an example of the responses observed in all investigated muscles when an unexpected knee flexion perturbation was applied in either the late swing or the early stance phase of human walking. The data are the average of 30 trials from one subject who was walking at a self selected pace. 

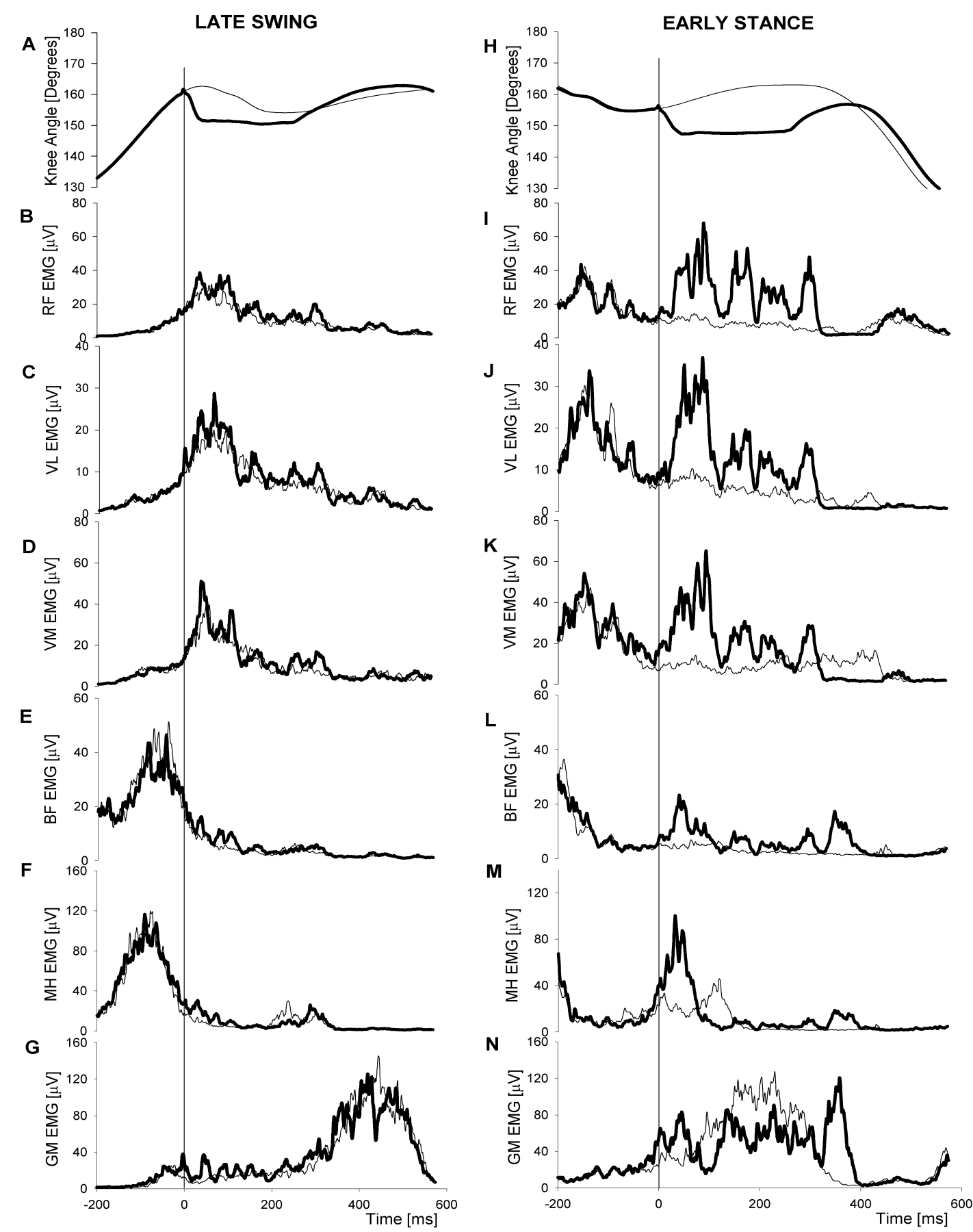

Figure 15: Phase dependent reflex response. The knee angular displacement, RF, VL, VM, BF, MH and GM EMG pattern during a perturbed step (thick lines) and a normal step (thin lines). A) - G) A stretch was applied during the late swing phase of the gait cycle. H) - N) A stretch was applied during the early stance phase of the gait cycle. Data are for one subject; 30 trials were averaged.

The average magnitudes within the three reflex response windows SLR, MLR and LLR were analyzed. To allow for comparisons of modulation patterns across subjects, the SLR, MLR and LLR responses were scaled with respect to their 
maximum amplitudes and averaged across all subjects (Fig. 16A - C). There was a significant modulation of the MLR and LLR responses for all knee extensors $(p=0.001$ and $p=0.008)$, which was absent in the SLR $(p=0.20)$. Post hoc analysis showed that these differences were significant for the late swing and early stance phases. Between muscles no significant differences in the pattern of modulation were found (SLR: $\mathrm{p}=0.72$, MLR: $\mathrm{p}=0.89$ and LLR: $\mathrm{p}=0.99$ ).

Figure 16D shows RF, VL and VM stretch reflex response amplitudes as a fraction of the background activity for the SLR window. Significant differences $(p<0.05)$ were found between the biarticular RF and the two vastii, but not between the VL and VM. During the late swing phase, the SLR of all knee extensors was approximately twice the size of the ongoing background activity. As the stance phase progressed both VL and VM SLR responses remained at this level while the RF SLR response progressively increased. At 25 - 33\% of the gait cycle the SLR reflex size of the RF attained values of six to eight times the size of the ongoing background activity.

The magnitude of the MLR increased progressively during the stance phase for all knee extensors (Fig. 16E). At approximately 20\% of the gait cycle the amplitude, now four to six times larger than the background activity, remained elevated for the duration of the stance phase. No significant differences in MLR amplitude were found between the RF, VL and VM.

The amplitudes in the LLR window were significantly greater than those in either the SLR or MLR time windows. Interestingly, although the LLR was of similar magnitude in all knee extensors during the late swing phase, at $8 \%$ of the gait cycle both VL and VM LLRs increased significantly compared to the RF LLR. At $12 \%$ of the gait cycle, the LLR amplitude of the VM increased proportionally 
more compared to the VL. All extensors attained their maximum LLR amplitude at approximately $20 \%$ of the gait cycle and maintained this level for the remainder of the stance phase. The maximum LLR values for RF, VL and VM were 8, 11 and 15 times higher than the ongoing background activity, respectively.
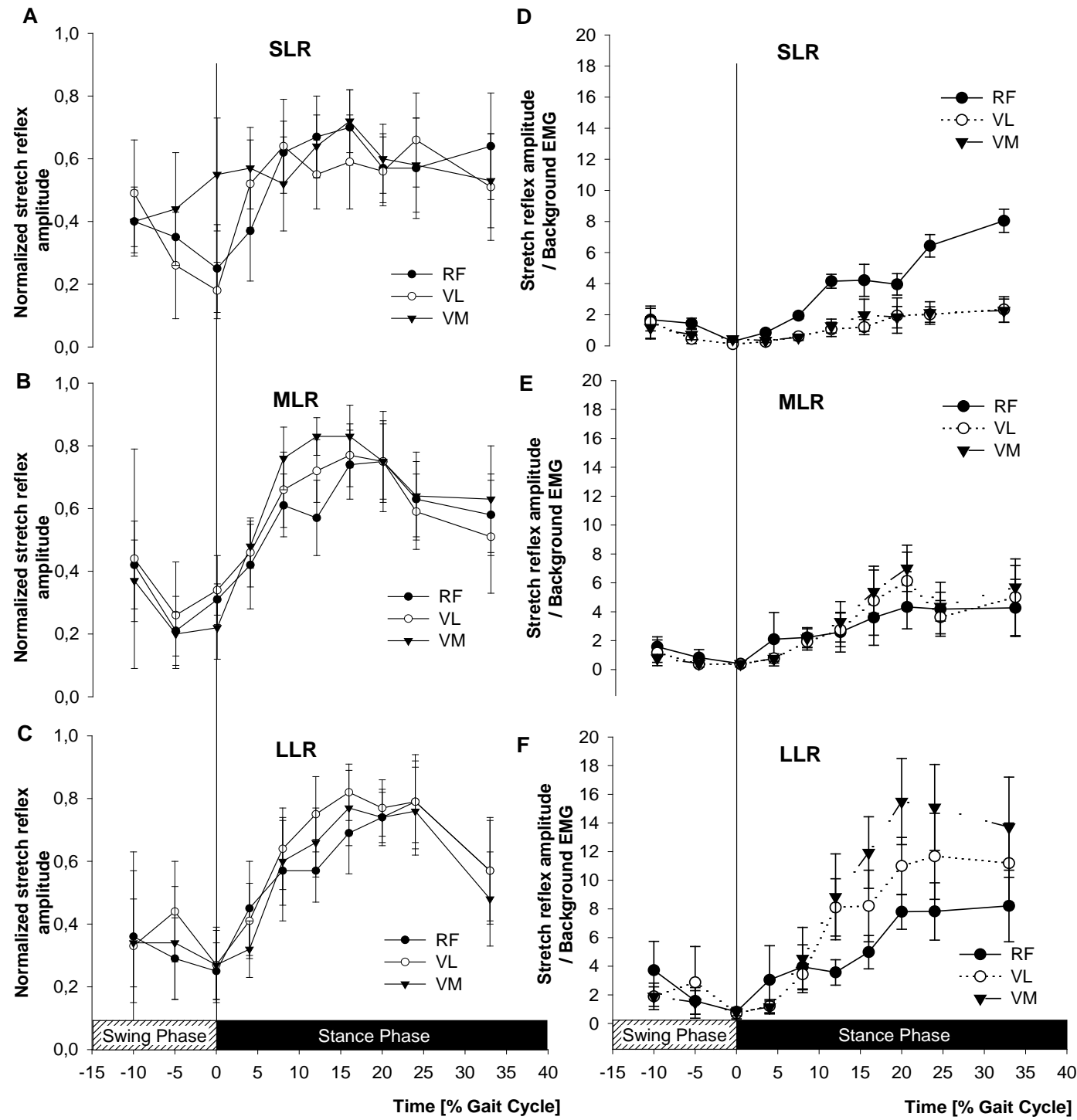

Figure 16: Extensor SLR, MLR and LLR modulation. A-C) RF (filled circles), VL (open circles) and VM (upside-down filled triangles) amplitudes as a function of gait cycle phase for SLR (A), for MLR (B) and for LLR (C). Data are the averages and standard deviations for all subjects and have been normalized to the maximum stretch reflex amplitude for the gait cycle for each subject and muscle. D-F) RF (filled circles), VL (open circles) and VM (upside-down filled triangles) amplitudes normalized to the ongoing background activity for SLR (A), for MLR (B) and for LLR (C). Data are the averages and standard deviations for all subjects. 


\subsubsection{Non-reflex torque modulation during walking}

The torque response to the imposed knee flexion for one subject is shown in

Figure 17C. During the initial part of the stretch the torque is dominated by the

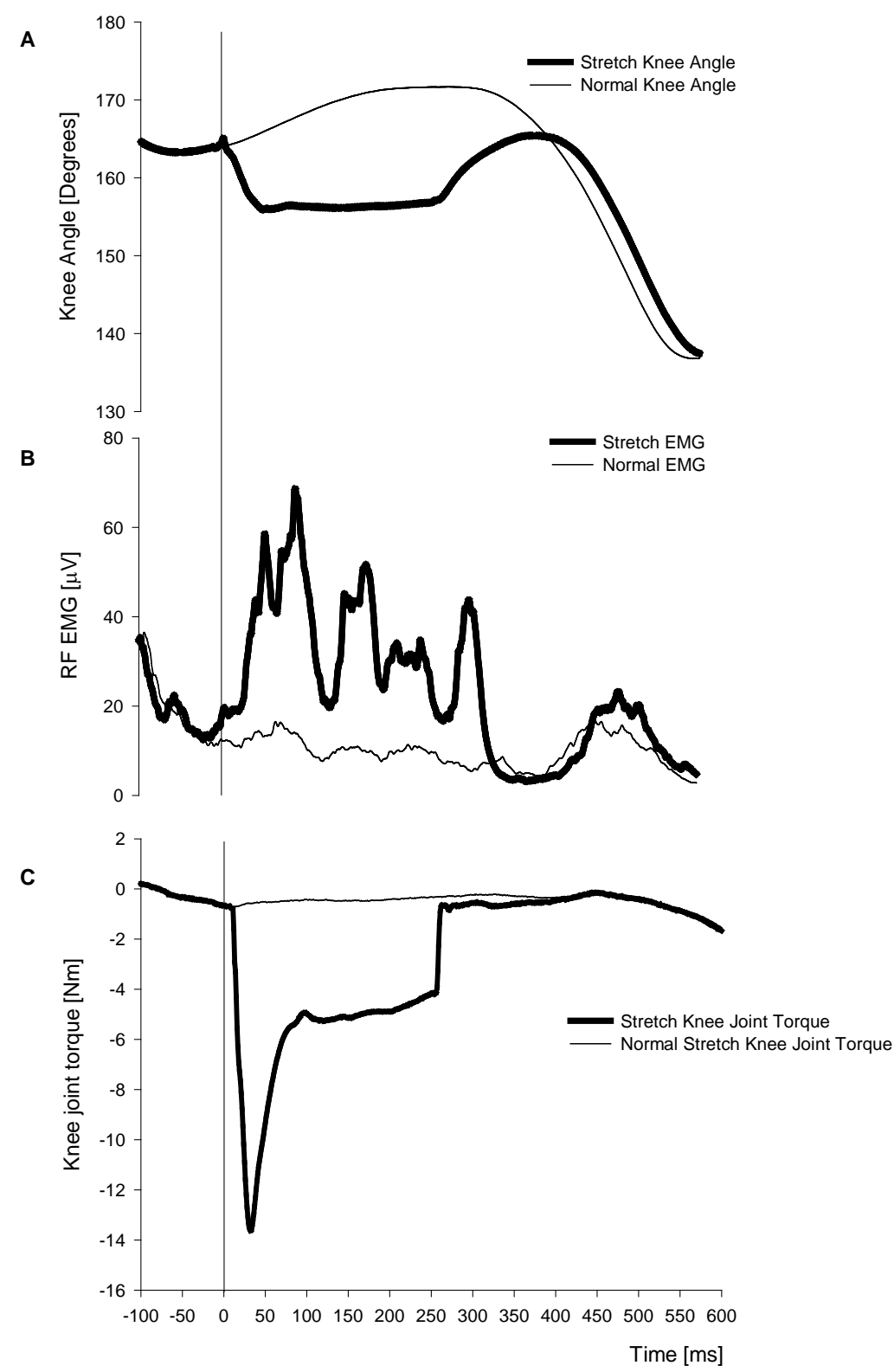

Figure 17: A) Knee angular position. B) Muscular response. C) Knee Torque

high inertia of the lower leg segment as well as by the intrinsic properties of the contracting muscles (Sinkjaer et al., 1988). The slight decrease observed has a 
time course that follows the decrease in velocity as the new position is attained (Fig. 17A).

The torque response following this initial part will also have a reflex component. It was not possible to separate the reflex and non-reflex torque components. However it was possible to quantify the non-reflex torque for the initial period prior to reflexes being able to contribute. This non-reflex torque was quantified during both the swing and the stance phase of human walking. Figure 18 exhibits the averaged non-reflex torque across all subjects.

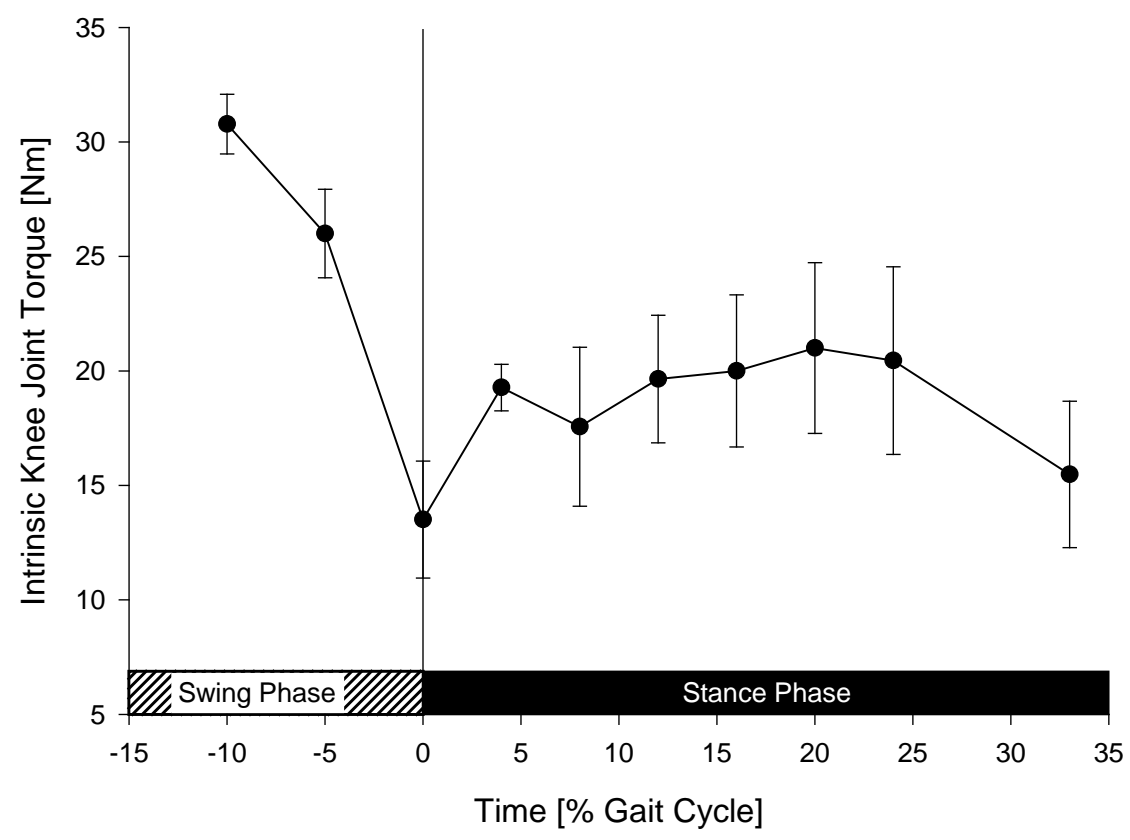

Figure 18: Non reflex torque as a function of gait cycle. Each data point represents the average of al subjects. Standard deviations are also shown.

\subsection{Knee extensor reflex modulation between tasks}

To determine if the SLR, MLR and LLR responses depended on the task performed, the stretches as applied during walking were repeated in seven subjects during standing. The subjects were asked to pre-contract their knee 
extensors to background muscle activity levels that were closely matched to those recorded during the stance phase of walking. An example for one subject and one muscle is illustrated in Figure 19A - C. The SLR, MLR and LLR amplitudes are plotted against the average ongoing background activity. A linear regression line
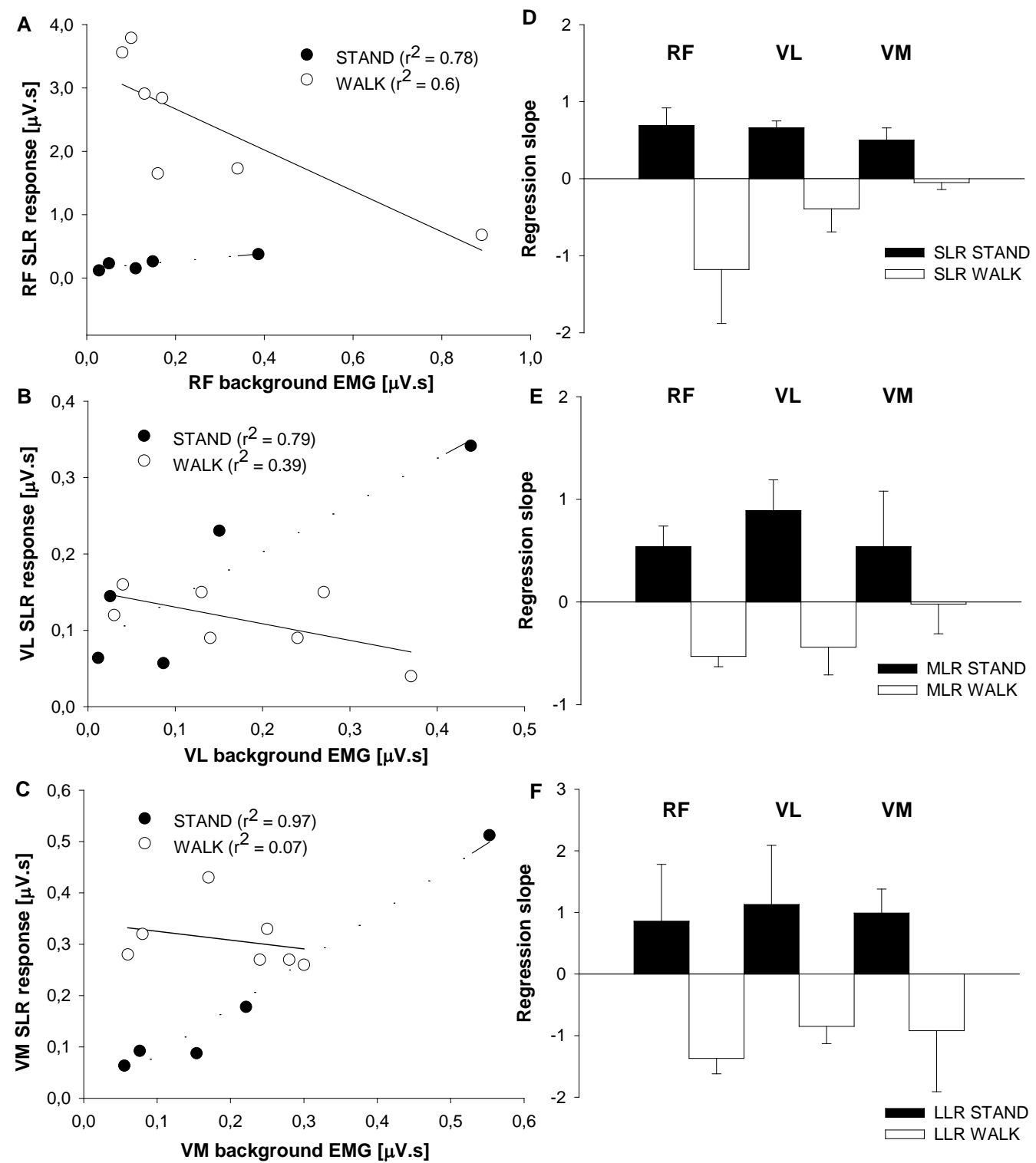

Figure 19. Task dependent reflex. A-C) SLR amplitudes for RF (A), VL (B) and VM (C) in relation to background EMG during standing $(\bullet$, dashed line) and walking ( $\circ$, plain line) and calculated regression lines. Date are for one subject. D-F) The average regression slope calculated across all subjects for the relationship between stretch reflex amplitude and background activity during standing (filled column) and during walking (open column) for SLR (D), MLR (E) and LLR (F). Standard deviations are also shown. 
was fitted to the data for both the standing and walking trials. The amplitude of the SLR, MLR and LLR increased with increasing levels of background activity during standing $\left(r^{2}=0.78-0.97\right)$. In contrast, during walking no relationship to the ongoing background activity was found $\left(r^{2}=0.07-0.6\right)$. Across all subjects, the slopes of the regression lines were pooled for each response window and task. Figure 19D - F shows the averages and standard deviations of the regression slopes for RF, VL and VM respectively. For all response windows and for all muscles, the slopes were significantly different between standing and walking $(\mathrm{p}<0.05)$.

\subsection{Knee flexor responses when knee extensors are stretched}

A response was observed in the investigated knee flexors BF and $\mathrm{MH}$ (also including GM for Study IV) when the knee extensors were perturbed. The onset of the first observable response ranged from $21-31 \mathrm{~ms}$ for BF, $21-27 \mathrm{~ms}$ for MH and 51 - 63 ms for GM. These responses also consisted of bursts of activity; however, they were not as clearly separated as in the knee extensors. For Study IV we chose to quantify only the GRR and to compare the modulation of this to the GRR of the extensors. No significant modulation was found for BF and $\mathrm{MH}$ ( $p>0.05$ ), however, the GM was significantly modulated being strongly inhibited during the stance phase of the gait cycle $(\mathrm{p}<0.05)$.

In Study II, to allow the same SLR, MLR and LLR windows in time to be compared between agonists and antagonists the $\mathrm{BF}$ and $\mathrm{MH}$ activity pattern was analyzed in the same manner as that of the knee extensors. Tables three and four presented below are a summary of the results for the knee flexors. 
Table 3: Results for BF.

\begin{tabular}{|l|c|c|c|}
\hline \multirow{2}{*}{ Parameter investigated } & \multicolumn{3}{|c|}{ BF significance values } \\
\cline { 2 - 4 } & SLR & MLR & LLR \\
\hline Perturbation velocity & + & $\mathrm{X}$ & $\mathrm{X}$ \\
\hline Perturbation amplitude & $\mathrm{X}$ & + & + \\
\hline Extensors pre-contraction & + & + & + \\
\hline $\begin{array}{l}\text { Co-contraction vs. isolated knee } \\
\text { extension }\end{array}$ & $\mathrm{X}$ & $\mathrm{X}$ & $\mathrm{X}$ \\
\hline $\begin{array}{l}\text { Low vs. High level of co- } \\
\text { contraction }\end{array}$ & $\mathrm{X}$ & $\mathrm{X}$ & $\mathrm{X}$ \\
\hline Flexor pre-contraction & $\mathrm{X}$ & $\mathrm{X}$ & $\mathrm{X}$ \\
\hline
\end{tabular}

X: No effect; + significant positive effect

Table 4: Results for MH.

\begin{tabular}{|l|c|c|c|}
\hline \multirow{2}{*}{ Parameter investigated } & \multicolumn{3}{|c|}{ MH significance values } \\
\cline { 2 - 4 } & SLR & MLR & LLR \\
\hline Perturbation velocity & + & $\mathrm{X}$ & $\mathrm{X}$ \\
\hline Perturbation amplitude & $\mathrm{X}$ & + & + \\
\hline Extensors pre-contraction & + & $\mathrm{X}$ & $\mathrm{X}$ \\
\hline $\begin{array}{l}\text { Co-contraction vs. isolated knee } \\
\text { extension }\end{array}$ & $\mathrm{X}$ & $\mathrm{X}$ & $\mathrm{X}$ \\
\hline $\begin{array}{l}\text { Low vs. High level of co- } \\
\text { contraction }\end{array}$ & $\mathrm{X}$ & $\mathrm{X}$ & $\mathrm{X}$ \\
\hline Flexor pre-contraction & $\mathrm{X}$ & $\mathrm{X}$ & $\mathrm{X}$ \\
\hline
\end{tabular}

X: No effect; + significant positive effect 


\section{Discussion}

The regulation of joint stiffness in the human lower limb has only been investigated in the ankle joint. Several important differences between the ankle and the knee joint were brought forward in the introduction. Firstly, during at least a running task, the knee joint provides the main contribution to overall leg stiffness as defined by Winter (1980). This may be attributed to the greater number of muscles that control the knee joint - there are at least 15 muscles spanning the knee joint compared to 10 surrounding the ankle joint. In addition, the greater bulk of the knee extensor and flexor muscles may account for the greater joint stiffness through an increase in the intrinsic stiffness component. Aside from these structural discrepancies between the ankle and the knee joint, there are also differences in the activation pattern of agonists and antagonists at the knee joint compared to the ankle joint. The knee extensors and flexors are engaged in co-contraction during tasks such as walking while the ankle extensors and flexors are reciprocally activated. Co-contraction greatly increases joint stiffness (Llewellyn et al., 1990; Carter et al., 1993). While it is easy to envision that the intrinsic component of muscular stiffness contributes to enhancing overall knee joint stiffness, it was of interest to examine if reflex contributions were comparable between the ankle and the knee joint or if indeed a greater intrinsic component would negate the necessity of a reflex mediated stiffness around the knee joint. This was investigated by imposing a sudden lengthening perturbation to the pre-activated quadriceps muscle complex and quantifying the resulting mechanical response.

Results from Study I demonstrated that muscle afferent feedback information from the quadriceps muscle complex can contribute significantly (up to 52\%) to 
the total torque produced around the knee joint in a sitting task. This functionality of the knee extensor reflex is comparable to what has been reported for the ankle extensor soleus (Sinkjaer et al., 1988; Toft et al., 1989).

Subsequent studies were conducted to determine which afferent pathways are likely to contribute to the observed neural response. The results from Studies II and III indicate that not surprisingly the SLR is of spinal origin. This is partly attributed to the short onset and peak latencies, as a supraspinal pathway would not have the ability to contribute to this early response. The behaviour of the SLR when stretch parameters were modified (Study II) indicates that the SLR is mediated by the velocity sensitive group Ia afferents. The origin of the MLR appears to be more complex. Results presented in this thesis indicate that it is significantly affected by the amplitude but not by the velocity of the imposed perturbation. The peak latency ranged between $44-58$ ms thus it is unlikely that supraspinal mechanisms contribute to the MLR. Study III demonstrated that the earliest time a transcortical pathway may influence the activity of the knee extensor muscles is $55 \mathrm{~ms}$ following the onset of the perturbation. Arguments will be presented later in the discussion, which favour a contribution from Group II afferents to the MLR. The LLR is possibly influenced by supraspinal pathways as it is not affected by reciprocal inhibition or co-contraction (Study II). Results from Study III indicate that at least for the RF, supra-spinal pathways can contribute to the LLR.

The modulation pattern of both the entire quadriceps reflex response (GRR) as well as the different components (SLR, MLR and LLR) during the transition from the swing to the stance phase of human walking suggests that the central nervous system integrates the afferent information in a task dependent manner. Further 
substantiation was provided by the standing experiments conducted as part of Study IV.

In the following sections the data from the quadriceps will be compared to what has been observed for muscles around the ankle joint. Possible reasons for discrepancies will be discussed.

\subsection{Mechanical Response}

\subsubsection{Non-reflex torque}

There are two important points of interest when comparing the non-reflex torque values obtained in this thesis with that from other studies. Firstly, previous studies in both animals (Nichols \& Houk, 1976) and humans (Allum et al., 1982b; Carter et al., 1990) have demonstrated a significant early yield in torque in the absence of reflexes, as soon as the short range stiffness of the muscle was exceeded. This effect was not observed in the present results. It is likely that this may be attributable to the high amplitude and slow velocity of the stretch or that the yield is simply not detectable because of the high inertia of the moving limb. Carter et al. (1990) suggested that muscle yield has both an amplitude and a velocity threshold. In this thesis the stretch was high in amplitude $\left(20^{\circ}\right)$ and low in velocity $\left(67^{\circ} / \mathrm{s}\right)$. The high amplitude of the imposed stretch would likely produce significant yield at high stretch velocities. However the velocity was quite low and even though Carter et al. (1990) reported significant yield at velocities of $50^{\circ} / \mathrm{s}$, this was for the first dorsal interosseous (FDI) - a hand muscle. It is likely that the slow stretch velocity allowed any broken or disconnected cross bridges resulting from the large stretch amplitude to reform at the new length without any discernible decreases in torque. An alternative explanation for the lack of yield in 
the data of this thesis and for that of the ankle joint may be that extension as well as flexion is controlled by more than one muscle. It is conceivable that yield did occur in all muscles yet at different points in time. If this is the case then the yield may not have been reflected in the total torque measure (Carter et al., 1990).

The second interesting observation in the data presented here is that although there is no early yield of the non-reflex torque, it does attain a maximum value at approximately $200 \mathrm{~ms}$ at which point it decreases again slightly and stabilizes at the new torque level. This decrease of the non-reflex torque (or rather muscular force as described in the following studies) was also reported by Hoffer and Andreassen (1981) (refer to Fig. 2C and 3B in their paper) and by Allum and Mauritz (1984) (refer to Fig. 2 in their paper). However, neither of these studies provides an explanation for this gradual decrease in muscular force. The latter authors separated the non-reflex force from the reflex force of the soleus by comparing the stretch response during ischemia and no ischemia. Interestingly in their study, the non-reflex force continued to decrease significantly until approximately $160 \mathrm{~ms}$ following stretch onset (refer to Fig. 2 in their paper) at which point it increased again. This is also the time at which volitional responses can be seen and as the instructions to their subjects were to increase plantarflexion force as rapidly as possible once the rotation had commenced this may reasonably explain the sudden increase in non-reflex force. In this thesis, subjects were instructed to not intervene with the imposed knee flexion rotation and as Figures 3B and 4B of Paper I (Appendix) show, the non-reflex torque does not increase at the time when voluntary contraction can impact upon it. One possibility is, that as the decline commences at a time when the new position has already been attained, that the inertial properties of the combined foot and leg 
segment are no longer contributing and as such the yield normally observed earlier (i.e. in Hoffer and Andreassen, 1981 for the total force when reflexes cannot compensate as yet) can now show its effect.

When reflexes are absent, the joint torque is dependent on the mechanical properties of both passive tissue and active muscle fibres. In this thesis the passive and intrinsic components were not accounted for separately. However, the nonreflex torque measured at zero background torque is assumed to reflect the passive torque contribution (Sinkjaer et al., 1993). The intercept of the non-reflex torque when plotted against background torques (Fig. 5, Paper I, Appendix) have values approaching zero Nm implying only small contributions from passive tissues. In addition, the relationship between non-reflex torque and background torque at 300 ms following stretch was highly linear $(r=0.9)$, suggesting that the number of attached cross bridges increases linearly with increasing background torque. It may thus be assumed that at least at $300 \mathrm{~ms}$ after stretch onset the intrinsic torque was dominant at all levels of background torque.

\subsubsection{Reflex torque}

Only a few studies have examined the torque generated from reflexes at background torques beyond 60\% MVC (Sinkjaer et al., 1988). The inability of subjects to maintain high pre-contraction levels and the necessity of a powerful actuator to apply the stretches are major limiting factors. In this thesis background torques of up to $90 \%$ MVC were investigated. However, only a few subjects were able to maintain background torques higher than $70 \%$ of a MVC contraction. A slight tremor in the force trace was observed when subjects had difficulties. Small oscillations superimposed on the perturbation result in a significant decrease of the reflex torque (Stein \& Kearney, 1995). This is synonymous to the vibration 
reflex. Great care was taken to eliminate such trials. Mirbagheri et al. (2000) also observed variability of the reflex torque between subjects, and argued that reflexes in subjects expressing low stiffness may not be of importance.

The highest contribution of the reflex to the total joint torque was measured for background torques of $20 \%$ to $40 \%$ MVC. This confirms reports from cat and human ankle extensors (Crago et al., 1976; Hoffer \& Andreassen, 1981; Toft et al., 1991; Mirbagheri et al., 2000). Across all background torques, the average values for reflex torque attained in this thesis ranged from $16 \%$ to $52 \%$ of total torque. Past studies have reported similar values for reflex contribution from human ankle flexors (Sinkjaer et al., 1988) and extensors (Toft et al., 1991; Kearney et al., 1997).

It is interesting to note that in confirmation with others (Crago et al., 1976; Hoffer \& Andreassen, 1981; Toft et al., 1991), the reflex EMG recordings (both phasic and tonic) correlated well with reflex torques at low levels of pre-contraction but less at the higher levels. Both tonic and phasic EMG reflex responses increase approximately linearly with increases in background torque. However, at background torques higher than 50\% MVC the additional muscle activity is unable to enhance reflex torque further. Similar results were reported in cat ankle extensors (Hoffer \& Andreassen, 1981). Although most motor units will be recruited at the higher force levels, further increases in EMG magnitude can be obtained by enhancing their firing frequency. Since at high background torques no additional torque is generated it stands to reason that all motor units are already firing close to their fusion frequency. Thus there was saturation at the muscular level. Toft et al. (1991) applied a simple model, which successfully verified this observation. At low pre-contraction levels the effect of the relationship between 
background torque and muscle activity was able to accurately predict the torque increment. At higher levels the magnitude behaviour of a single twitch elicited by supramaximal nerve stimulation had to be included in the model to accurately predict the total torque.

\subsubsection{Functional implications}

The total torque is comprised of passive, intrinsic and reflex components. During lengthening the intrinsic contribution is limited by the elasticity of the contractile machinery. If this is exceeded, intrinsic torque is unable to compensate for changes in total torque. Reflexes, however, can compensate for this discrepancy. During dynamic tasks such as walking the knee extensor stretch reflex is highly modulated during the progression from the late swing to the early stance phase (refer to Paper IV in Appendix). The highest values are present while the knee extensors are contracting to raise the centre of gravity upwards in readiness for the following take off phase. While it has been found that a substantial part of the ongoing activity in ankle extensors during this phase is attributable to afferent feedback and thus reflex activity (Yang et al., 1988; Sinkjaer et al., 2000; Nielsen \& Sinkjaer, 2002) this has not been demonstrated for the extensors of the knee. Even so, reflexes during a static task as presented here can contribute significantly to the total torque produced around the knee joint. It stands to reason that with a high reflex gain during the stance phase of walking that the knee extensors have the potential to contribute to the joint torque during a more dynamic task, at least in a situation when unexpected perturbations are encountered. 


\subsection{Neural Response}

The neural activity arising from the imposed stretch of the knee extensors that results in the functionally strong mechanical effect consists of a number of distinct reflex bursts (Fig. 3 and 4).

Reflex pathways form a rich network within the spinal cord which makes it difficult to determine the afferents responsible for the responses observed. Data have been available for the interconnectivity of such networks within the cat nervous system for some time (Baldissera et al., 1981) though the extrapolation to the human nervous system is sometimes not possible. An example are the effects of Group I fibres from ankle muscles to quadriceps motoneurons which are very potent in man though absent or negligible in the cat (Pierrot-Deseilligny et al., 1981). Human experiments most often require non-invasive tools and while these have been available for some time, the limitations of these must be considered in the interpretation of the data collected. Data are now available detailing the pattern of Group I and II fibre projections between various muscles of the lower limb (Meunier et al., 1993; Marque et al., 1996; Marque et al., 2005). The effect of the perturbation as applied here was confined to the knee joint as far as possible. In this way it was possible to exclude the effect of pathways (whether excitatory or inhibitory) from muscles crossing other joints. However, during Study IV this was made more difficult as the knee extensors acted within an intact moving system in which both the ankle and the hip joints are displaced.

With these limitations in mind, and based on the data collected throughout the experimental paradigms implemented for this thesis, arguments will be brought forward in the following sections as to the possible pathways involved in shaping 
the responses to unexpected perturbations applied at the knee joint, designed to stretch the knee extensors while unloading the knee flexors.

\subsubsection{SLR}

The onset latency for the first observable response in the knee extensors was between 18 to $23 \mathrm{~ms}$. Taking into account the distance of the recording site from the spinal cord, only the fastest conducting afferents, the velocity sensitive Group Ia afferents are possible candidates for its initiation. Latency data obtained from experiments when either an H-reflex (Dietz et al., 1990b) or a tendon tap (Dietz et al., 1990a) was used to perturb the quadriceps are in agreement with data presented in this thesis. Increasing the velocity of the knee flexion perturbation produced a concomitant increase in the size of the SLR component of the stretch reflex while maintaining the same perturbation velocity and increasing only the knee flexion amplitude resulted in no change. This is in agreement with the velocity sensitivity of the Group Ia afferents. If the conduction velocities of the afferent fibres as well as the distance between the thigh muscles and the spinal cord are considered, it is unlikely that either disynaptic, polysynaptic or supraspinal pathways contribute to it. It is thus concluded that this initial response is contributed to by the velocity sensitive Group Ia spindle afferents (Matthews, 1986; Yang et al., 1991).

Since the early work of Sherrington (1905) it has been assumed that the monosynaptic stretch reflex is completely abolished when the antagonists are activated. This was confirmed by data collected in Study II (Fig. 7, Paper II, Appendix). However, since the knee extensors are frequently activated concomitantly with their antagonists it is likely that this inhibition is diminished during such task involving co-contraction such as human walking. To date only 
one study has investigated the effect of co-contraction compared to isolated agonist contraction on the size of the SLR. Nielsen et al. (1994) found the size of the soleus SLR (M1 in their terminology) to decrease at weak levels of cocontraction compared to isolated plantar-flexion which is similar to what was shown for the knee extensors (Fig. 5, Paper II, Appendix). Since the background activation prior to the perturbation was matched for the two conditions, the most likely explanation for a decrease in the SLR was an increase in pre-synaptic inhibition of homonymous Ia fibres during co-contraction (Nielsen \& Kagamihara, 1993).

The quadriceps SLR was the same size at all levels of co-contraction investigated in this Study II (20 and 70\% MVC). This contradicts reports by Nielsen et al. (1994) who demonstrated that the soleus SLR increased with increasing levels of co-contraction. In that study, the possibility was raised that the mechanical stretch induced a repetitive discharge of Ia afferents and that this decreased the sensitivity of the synapses to pre-synaptic inhibition. Data presented in this thesis do not support their hypothesis since the SLR magnitude remained invariant with increases in co-contraction levels. This raises the possibility that pre-synaptic inhibition is not only increased during co-contraction but that it increases with increasing levels of co-contraction for the knee extensors. In an earlier publication Nielsen et al. (1993) argued that increasing the level of pre-synaptic inhibition would protect the agonistic and antagonistic muscles from going into uncontrollable oscillations since the excitability state of both motoneuronal pools is already set quite high.

An alternative explanation for the results observed during different levels of cocontraction may be that at high levels of co-contraction the effect of Group Ia 
inhibition from the antagonists increases in potency. Thus the reciprocal inhibition from the knee flexors may be able to exert a stronger effect. A third possibility is that high levels of co-contraction may reduce the stretch applied from the motor to the knee extensors as the stiffness of the knee joint is presumably higher than during an isolated knee extension.

From a functional point of view, the stiffness of the knee joint will already be increased during co-contraction due to the simultaneous activity of the agonist and antagonist. Intrinsic muscle activity may thus add importantly to the total joint stiffness. This suggests that the SLR of the quadriceps does not make an important contribution to any compensatory actions evoked by unexpected knee flexion perturbations as proposed by Chaix et al. (1999) as well as Simonetta-Moreau et al. (1999) during co-contraction. However, the results from Study I do not support this hypothesis as the reflex contribution to the total knee joint stiffness attained values of up to $52 \%$.

\subsubsection{MLR}

To this date, this is the first systematic investigation of changes to the quadriceps MLR amplitude with changes in both stretch parameters and contraction task. Hagbarth et al. (1980) argued that any activity above baseline following the initial SLR is due to segmentation of the Ia afferent firing. However, results presented here demonstrate that the MLR is not sensitive to changes in the velocity of the applied knee flexion perturbation (Fig. 9). If the later responses occurred due to segmentation, then the MLR would be expected to increase in magnitude as the velocity of the stretch increased. The size of the MLR was however significantly affected by changes in the amplitude of the applied stretch (Fig. 10). This would suggest that Group Ia afferents do not contribute to the MLR. Indeed, with the 
application of tendon vibration during an imposed flexion perturbation, only the initial reflex burst (SLR as defined in this thesis) is present in at least the RF (Matthews, 1986). Tendon vibration is known to preferentially excite Group Ia afferents.

Matthews (1986) proposed that the only viable candidate for the later occurring stretch responses in the RF (amongst other muscles) are the slower conducting Group II spindle afferents. Recent evidence from other leg muscles, in particular the soleus, support this hypothesis (Schieppati \& Nardone, 1997; Grey et al., 2001; Nardone \& Schieppati, 2004). However, others have provided evidence that Group Ib afferents arising from GTOs contribute to the MLR response (Dietz, 1998; Dietz \& Duysens, 2000). It is likely that both types of afferents may contribute to the MLR to different degrees depending on the task (Grey et al., 2001). The conditions under which the data were collected in this thesis, do not allow a comprehensive conclusion as to which of the two types of proprioceptors may contribute to the shaping of the MLR.

However, some mention must also be made regarding the heteronymous connections between the various components of the quadriceps and various lower limb muscles and how these may affect the size of the quadriceps MLR. Such connections may be either excitatory or inhibitory. In recent experiments in man, strong monosynaptic excitatory Ia connections (Pierrot-Deseilligny et al., 1981) and excitatory Group II heteronymous connections (Simonetta-Moreau et al., 1999) were reported to exist from the ankle muscles to the quadriceps motoneurons. However, Ib inhibitory connections have also been reported from the GM to the quadriceps (Pierrot-Deseilligny et al., 1981). To exclude the possibility of such connections contributing to the quadriceps stretch reflex during 
the experiments conducted in the first part of this thesis it was ensured that the perturbation imposed acted on the functionally isolated knee joint while both the ankle and hip joints were fixated. However, the biarticular GM spans both the knee and the ankle joint and it was therefore not possible to exclude its influence on the quadriceps responses.

During the experiments where the antagonists were relaxed, possible effects of any heteronymous connections from knee flexors are unlikely. However, it was surprising that the MLR like the SLR was completely abolished during antagonist only pre-activation. The disynaptic reciprocal pathway, mediated by the Group Ia afferents is responsible for the depression of the SLR, however the Group Ia afferents were shown not to contribute to the MLR. This indicates that reciprocal inhibition through a pathway other than the well known disynaptic reciprocal pathway may depress the MLR of the quadriceps. As the antagonists are being unloaded by the perturbation it is unlikely that either a Group Ia or II mediated feedback contributed to this decrease in the MLR. One possibility may be an effect through monosynaptic Group Ib induced inhibition which is known to exist from the GM as well as BF GTOs onto quadriceps motoneurons (PierrotDeseilligny et al., 1981). Such feedback may cause a postsynaptic depression of the motoneurons and thus mask a facilitatory effect from Group II homonymous afferent pathways.

Further support favouring a contribution from muscle secondary spindle afferents to the MLR is suggested by the behaviour of the MLR during co-contraction. Figure 5 (Paper II, Appendix) demonstrates that the size of the MLR is similar during an isometric knee extension contraction and co-contraction. As stated previously, pre-synaptic inhibition is increased during co-contraction (Nielsen \& 
Kagamihara, 1993) and Group II spindle afferents are not subjected to presynaptic inhibition from Group Ia afferents (Baldissera et al., 1981) at least in the cat. During strong co-contraction the size of the MLR is greatly increased. The question arises: What causes this significant increase in the size of the MLR during strong co-contraction? Here it is important to realize that during the imposed perturbation, the knee flexors are unloaded. If the effect of knee flexors onto extensors is mainly inhibitory (as no lengthening of the antagonists takes place and thus heteronymous Group Ia and II excitatory connections can be ruled out), then an unloading of them alone could simply decrease their inhibitory effect. Such an unloading of antagonists has been found to contribute to an increase in the size of the short latency soleus stretch reflex in the decerebrate cat (Sinkjaer \& Hoffer, 1990). There it was postulated that the effect was produced by a decrease in Ia afferent discharge from the unloaded antagonist and hence a reduction in reciprocal inhibition. It is not known if the unloading of the knee flexors also affects the heteronymous Ib inhibitory pathways to quadriceps motoneurons though it is easy to envision that their effect is enhanced during strong co-contraction as opposed to weak co-contraction. If this is indeed the case, then it is conceivable that if transmission in these is reduced due to the unloading and that if indeed they contribute to the MLR, that the MLR would be enhanced during strong co-contraction as opposed to weak co-contraction. Sinkjaer et al. (1995) reported an average increase of $29 \pm 13 \%$ of the soleus MLR when the common peroneal nerve was reversibly blocked indicating that the afferent fibres of the common peroneal nerve contribute importantly to the size of the soleus stretch reflex. 


\subsubsection{LLR}

Aside from the aforementioned bursts, there is a third burst of activity which is not present in all subjects at rest. Matthews (1986) proposed the LLR much like the MLR to arise from peripheral Group II afferent feedback. However, supraspinal centres have been implicated to contribute to the LLR of the dorsiflexors at the ankle joint (Petersen et al., 1998; van Doornik et al., 2004), while there is evidence that the LLR of the triceps surae muscle is not of supraspinal origin (Berardelli et al., 1983; Zuur et al., 2004). In Study II the LLR of all knee extensors increased with increases in perturbation amplitude but not velocity which would support the view by Matthews (1986) that it like the MLR is shaped by Group II spindle afferents. However, the LLR was not affected in a similar manner to the MLR by reciprocal inhibition (Fig. 7B and C, Paper III, Appendix) or increasing levels of co-contraction (Fig. 15C and D), indicating that they may not originate from the same receptors or pass through the same pathways. Evidence against the notion that the LLR of some upper limb muscles is due to Group II afferents was provided by Marsden et al. (1976). They argued that since the onset of the LLR was the same for both the infraspinatus and FPL, Group II afferents could not initiate this response since if they did, the LLR would have had to be delayed more in the FPL than in the infraspinatus. Matthews (1987) later conducted studies where he measured F-wave and LLR latencies following cooling of the arm. Both increased in latency by the same amount which suggests that the LLR may arise from fast conducting Ia afferents which are included in a transcortical loop pathway (Matthews, 1987). Care must be taken, however, when comparing the muscular responses to a mechanical perturbation in the upper and lower limb. As for example the LLR observed in lower limb muscles is not necessarily analogous to the LLR seen in upper limb 
muscles (Marsden et al., 1983). With this in mind, Rothwell et al. (1990) suggested that the contribution of transcortical pathways to the LLR differs between muscles and species and may also be specific to the task. Results presented here strongly suggest that the quadriceps LLR is not mediated by the same afferents as the MLR and that at least the RF LLR is contributed to by supraspinal pathways.

Previous studies applying similar paradigms as in this thesis, have demonstrated a significant facilitation of the tibialis anterior MEP at the time of the LLR but not the SLR or MLR components of the stretch reflex (Petersen et al., 1998). The argument that this reflects a cortical contribution to the LLR was strengthened as transcranial electrical stimulation (TES) did not produce the same effect as TMS when responses from single motor units were investigated.

The effects of TMS versus TES were not compared in this thesis. Therefore, results provide only indirect support for the notion that a transcortical pathway traversing the sensory motor cortex is involved in shaping the LLR. However, if the stretch of the RF muscle produces an afferent input to the spinal cord that shapes the observed response, it is likely that both the MEP in the VL and VM muscles would display a similar facilitation to that of the RF muscle because both of these muscles have similar response patterns and magnitudes to the RF. Indeed, when Figure $4 \mathrm{~B}$ is compared to Figure $5 \mathrm{~B}-\mathrm{D}$ in Paper III (Appendix) the modulation of the MEP size in all muscles investigated has a similar shape until $78 \mathrm{~ms}$ following stretch onset. In all muscles there is an initial non-significant facilitation, followed by an inhibition that is also not significant and may be the result of an occlusion effect which does not allow for a full summation of the MEP and stretch reflex responses. However, care was taken to ensure that the 
intensity of the magnetic stimulus was low enough to induce a MEP below 50\% of the maximum MEP. In addition the imposed stretch had a small amplitude and velocity that could not have recruited the entire motoneuron pool, thus it is unlikely that an occlusion phenomenon could have caused the decrease in the size of the combined MEP and stretch reflex response observed. Further, this does not explain the extra facilitation seen only in the RF but not in the VL and VM when the arrival of the MEP was timed to coincide with the LLR. It would appear then, that during the investigated task the RF LLR is under some cortical or at the least supraspinal control whereas the LLRs of the VL and VM are not.

The question remains why the LLR of the RF should in part be shaped by supraspinal centres while neither the VL nor the VM receive such input. The answer may be related to the functional role of these muscles. Recently, convincing evidence was provided by Nene et al. (2004) that the biarticular RF acts exclusively as a hip flexor during human walking whereas the primary role of the VL and VM is that of knee extension. To date, results from studies where the origin of the LLR in muscles of the lower limb were investigated have only demonstrated a cortical contribution to the LLR of the ankle flexor muscles (Petersen et al., 1998; Christensen et al., 2001; van Doornik et al., 2004). Thilmann et al. (1991) reported that the late response in the triceps surae muscle group, ankle extensors, is still present in patients with Huntington's disease, a condition in which the supraspinal pathways are thought to be dysfunctional. An alternative explanation may be the existence of strong bi-directional inhibitory connections between the RF and the vastii in man as found in the decerebrate cat (Wilmink \& Nichols, 2003). It is possible that the effect of these connections is 
masked during human walking due to other mechanisms, yet as potent as in the decerebrate cat during a sitting task.

\subsection{Task specificity of the quadriceps stretch reflex}

The SLR amplitude in RF, VL and VM as quantified in this thesis was not modulated significantly during the gait cycle. It is generally accepted that the SLR is mediated by the velocity sensitive group Ia afferents (Matthews, 1986; Yang et al., 1991). The H-reflex is the electrical equivalent to the stretch reflex, bypassing the fusimotor system. Both the RF and VL H-reflexes are significantly modulated during human locomotion. The maximum H-reflex amplitudes occur at $10 \%$ of the gait cycle following which they decrease towards the minimum value at $20 \%$ of the gait cycle (Dietz et al., 1990b; Larsen, 2005). This modulation has been attributed to changes in pre-synaptic inhibition of the quadriceps Ia terminals. In the soleus muscle, Sinkjaer et al. (1996) reported differences in the modulation of the H-reflex and the stretch reflex during human walking. In the RF and VL, Dietz et al., (1990b) found the modulation of the SLR to be the same as that of the RF and VL H-reflex. One important difference between data collected here and those of Dietz et al. (1990a) is the technique implemented to stretch the investigated muscle. Dietz et al. (1990a) used a tendon tap and, as has been stated previously, this is likely to produce a synchronized volley in the Ia afferents, similar to the $\mathrm{H}$ reflex. The perturbations as applied here were whole joint rotations, which presumably is a more natural disruption to the ongoing movement. Morita et al. (1998) demonstrated that the SLR is less sensitive to presynaptic inhibition as compared to the H-reflex. This may explain the lack of SLR modulation observed in data presented here. 
Although the normalized SLR amplitude is similar and not significantly modulated in any of the knee extensors investigated, the relative size of the SLR amplitude in relation to the background activity is three to four times greater for the RF as compared to the VL and VM. The anatomical insertion point of the vastii and the RF is at the patellar tendon, though their origins differ. It is possible that the stretch as applied in this thesis caused a greater change in muscle length in the RF as opposed to the VL or VM, or that the vasti and RF stretch reflexes have different sensitivities to a stretch (Wilmink \& Nichols, 2003). Both mechanisms could explain the difference in SLR reflex size.

The modulation of the MLR response, unlike the SLR has previously not been investigated in the knee extensors during human walking. The MLR was significantly increased in the stance phase as compared to the swing phase. Recently, Grey et al. (2001) reported the ankle extensor soleus MLR to be strongly modulated during the stance phase of human walking. The neurological control of this response is uncertain and has been proposed to be partly mediated by Group II spindle afferents (Grey et al., 2001) or alternatively load sensitive Group Ib afferents (Dietz, 1998; Dietz \& Duysens, 2000).

Similar to the MLR, the LLR reflex response is modulated profoundly from the progression of swing into stance. Compared to the SLR and MLR, the LLR attains the highest amplitude relative to the ongoing background activity. Studies on the origin of the LLR in the ankle dorsiflexor TA have shown that at least part of this response is mediated by a transcortical pathway (Petersen et al., 1998). While it is not known if these pathways also contribute to the quadriceps LLR during human walking, the relatively greater size of the stretch reflex size with respect to the 
ongoing background activity compared to the SLR or MLR, suggests it may be mediated by different pathways than the SLR or MLR.

It is not known why the LLR amplitude is significantly different between the biarticular RF and the monoarticular VL and VM during the later part of the stance phase. Study III demonstrated that supraspinal pathways contribute to the LLR of only the RF and as such this disparity in reflex magnitude could reflect a difference in the cortical control of the muscles. However, in Study III the subjects were engaged in a sitting task which is not as functionally demanding as walking - i.e. the whole body weight does not have to be supported by the two lower limbs. Nevertheless it is possible that the presence of a LLR does not immediately indicate a transcortical contribution. Alternatively it could also simply reflect differences related to the level of excitability at the motoneuron level. It is striking that the amplitude of the LLR of RF is smaller than the LLR of the vastii, whereas the SLR of the RF is larger than the SLR of the vastii.

The comparison of the amplitude of the SLR, MLR and LLR reflex response at matched stretches and background activity levels during standing and the stance phase of walking revealed significant differences. During standing, the amplitude of all components of the reflex increased with background activity, whereas during the stance phase of walking it was inversely proportional to background activity. The reflex responses are thus not simply related to the excitability of the motoneuron pool. This is in contrast to what has been reported for the ankle extensors (Sinkjaer et al., 1996). 


\subsubsection{Functional implications}

The reflex responses as measured in Study IV (Appendix) were quantified by the size of the recorded EMG signal. As a consequence there is no direct mechanical measure of the effect these responses may have at the knee joint. Kearney et al. (1999) compared the mechanical and EMG responses of the soleus stretch reflex during both active and simulated walking. Although these authors reported dissociation between the size of the reflex, and the size of the reflex torque, the greatest reflex torques were recorded during the stance phase, while during both the late stance and swing phase the mechanical effect of the reflex was negligible. The intrinsic torque around the knee joint was quantified for the first $30 \mathrm{~ms}$ following the imposed stretch. At this time the reflex could not have manifest itself in a mechanical response (Fig. 17) and the torque is dominated by the large inertia of the foot and leg segment as well as the activation of the muscles. The non-reflex torque was considerably higher during the late swing phase compared to the early stance phase. In comparison, the quadriceps reflex size was relatively low while the co-contraction between the knee flexors and extensors was considerably high. This implies that during the late swing phase, the necessity for a reflex contribution to knee joint stability is negated by the strong co-contraction present between the agonists and antagonists. The results presented here demonstrate that the highest reflex responses occur during the stance phase of the gait cycle when the stability of the knee is of major importance to maintain balance. It was further shown that the quadriceps reflex responses obtained during a standing task at matched background activities were lower as compared to the relevant phase of the gait cycle. This demonstrates that the quadriceps stretch reflex is modulated in a task dependent manner. In addition, as the strongest reflex responses were observed during a time when the centre of gravity was passing 
over the supporting foot this indicates that the central nervous system makes functional use of the quadriceps stretch reflex. The way that the central nervous system integrates afferent information from the perturbed muscles in formulating the reflex response is strongly dependent on the phase of the task and cannot simply be deduced from the reflex pathways.

\subsection{Knee flexor responses when knee extensors are stretched}

It is not a new finding that a short and long latency response is observed in the antagonist when it is being unloaded while the agonist is perturbed (Miscio et al., 2001). Miscio et al. (2001) suggested that the early responses likely arise from crosstalk while the later responses are true responses. In the present thesis both the SLR and the MLR of the knee flexors behave in a similar manner with changes in stretch parameters as well as with increases in the tonic pre-activation of the knee extensors. This would support the notion that crosstalk may produce these, especially so for the SLR when considering it is of such high magnitude during the sitting task investigated here. However, unlike the knee extensor SLR and MLR which are almost completely abolished when only the antagonists are activated, the knee flexor magnitude of the SLR and MLR remains unchanged compared to the condition when both flexors and extensors are relaxed. Similarly, during a co-contraction task the BF and MH SLR is of the same magnitude as during an isolated knee extension task, while the RF, VL and VM SLR are significantly decreased. It has to be considered that the SLR and MLR (as well as the LLR) responses observed in the knee flexors are true responses. The question then arises as to what pathways mediate them. One possible explanation is that Ia 
heteronymous projections as found in human infants (Leonard et al., 1995) are also present but not as potent in adult humans (Mao et al., 1984).

No data has previously been reported on the activity of the knee flexors to an imposed stretch of the knee extensors during human walking. The knee flexors are being shortened during the unexpected perturbation, but despite this unloading, short latency facilitation was observed in both $\mathrm{BF}$ and $\mathrm{MH}$. The responses observed were modulated in a similar pattern to those of the knee extensors. This may indicate the presence of excitatory connections between the knee extensors and flexors as first proposed by Eccles et al. (1958). Previous studies of the ankle flexors and extensors have revealed a distinct reciprocal activation pattern in both background and reflex activity (Nielsen, 1998). The soleus stretch reflex is completely suppressed when the TA is activated and vice versa. During cocontraction, the disynaptic reciprocal inhibition is greatly reduced (Nielsen \& Kagamihara, 1993; Nielsen \& Kagamihara, 1994) and the strength of this reciprocal inhibition is dependent on the motor task and independent of the level of motor activity of the ankle flexors (Lavoie et al., 1997). Lavoie et al. (1997) postulated that reciprocal inhibition is centrally determined. To date there has been no study investigating reciprocal inhibition between knee extensors and flexors during human walking. However, evidence suggests that there is cofacilitation of motor evoked potentials (MEPs) recorded from RF and BF (Bonnnard et al., 2002). If reciprocal inhibition is controlled by central mechanisms then the results from Bonnard et al. (2002) indirectly suggest that reciprocal inhibition between knee extensors and knee flexors is diminished during human walking. However, even if this is the case, this fails to explain the reflex response in the knee flexors as they are being unloaded. A tendon tap 
applied to the patellar tendon induces reflex irradiation in the antagonists in human infants (Leonard et al., 1995). These Ia heteronymous projections are also present in the adult human (Mao et al., 1984). However, in the adult their ability to elicit excitatory post synaptic potentials (EPSPs) is decreased. Nevertheless, during a task such as human walking the effectiveness of these projections may be increased to provide stability to an unexpected knee perturbation.

Schillings et al. (1999) observed distinct long latency reflex responses in both knee extensors and flexors in subjects stumbling over obstacles. During the gait cycle, the co-activation of the knee extensors and flexors contributes to the stability of the knee joint at foot strike in preparation for the subsequent weight transfer to the supporting leg. Furthermore, the centre of gravity of the body is prevented from its downward acceleration by the powerful action of the knee extensors.

In contrast to the $\mathrm{BF}$ and $\mathrm{MH}$, the activity of the $\mathrm{GM}$, which is also a knee flexor, is briefly facilitated and then its activity rapidly and significantly decreases following the unexpected stretch. The decreased activity can be explained by an unloading of the muscle spindle receptors in GM as the knee joint is being flexed (Sinkjaer et al., 2000). Being a biarticular muscle the GM also acts as a plantar flexor at the ankle joint. A strong excitatory response from this muscle would not only serve to flex the knee joint, but also to produce a plantar flexion of the ankle joint. If this occurred during the early stance phase at a time when the centre of gravity has not passed over the supporting foot, this action would push the subject backward which is an undesirable response. In contrast, if this happened at a time when the centre of gravity had passed over the supporting leg, a plantar flexion would push the subject forward before the subject is ready for take-off. Although 
this later response seems favourable, if the centre of gravity is already propelled forward by the strong response observed in the knee extensors, an additional strong plantar flexion may cause the centre of gravity to be too far in front of the foot thus unbalancing the subject. 


\section{Conclusion}

The results from the four studies included in this $\mathrm{PhD}$ thesis have contributed the

following novel findings with regards to the quadriceps stretch reflex:

1. The quadriceps stretch reflex, elicited when the knee joint in unexpectedly rotated in the direction of knee flexion, can contribute up to $50 \%$ to the total torque produced around the knee joint.

2. The muscular response consists of a number of bursts of activity similar to what has been found for the ankle extensor soleus. These were labelled SLR, MLR and LLR. Unlike the soleus SLR, the quadriceps SLR is not modulated during human walking. However, the later responses (MLR and LLR) are significantly modulated attaining their greatest magnitude in the stance phase. Of the later responses, the LLR is the strongest reflex response.

3. The SLR is significantly affected by changes in the velocity of the applied perturbation while the MLR and LLR are significantly affected only by changes in the amplitude of the applied perturbation. This is similar to what has been found for the soleus and suggests that the SLR is mediated by the velocity sensitive Group Ia afferents, while Group II afferents contribute to the MLR.

4. The magnitude of the SLR is significantly decreased when the knee extensors are activated concomitantly with their antagonists for low levels of precontraction. This is similar to what has been found for the soleus. Both the MLR and LLR are unaffected. 
5. At increasing levels of co-contraction both the magnitudes of the SLR and LLR are unaffected. However the size of the MLR increases significantly as co-contraction increases as opposed to the soleus.

6. Only the SLR and MLR are diminished when the antagonists are preactivated while the LLR size is unaffected. This suggests that the LLR is mediated by different pathways to the MLR and LLR.

7. A supra-spinal pathway is likely to contribute to the shaping of the RF LLR but not to that of the VL and VM LLR during a sitting task.

8. The knee flexors consistently respond when the knee extensors are stretched. This suggests that even during a task where there is no co-contraction, the knee flexors are not inhibited by the knee extensors. However, at least the SLR and MLR are inhibited by the activity of the knee flexors.

Most of the existing studies in the human have focused on the contribution of stretch reflexes around the ankle joint. Studies on the muscles surrounding the knee joint are scarce. The results presented in this thesis have shown that the quadriceps reflex can make an important mechanical contribution to the knee joint torque similar to that of the soleus at the ankle joint. However, while the mechanical response is similar for ankle and knee extensors, this is not always the case for the neural responses observed. For example, while the SLR of the soleus is strongly enhanced during co-contraction compared to isolated plantarflexor activity, the SLR of the quadriceps is decreased during co-contraction. Such discrepancies in the behaviour of the SLR, MLR and LLR of knee extensors versus ankle extensors may be reflective of the monosynaptic and polysynaptic heteronymous projections to quadriceps motoneurons. These have been extensively investigated in the human by a group within the laboratory of Pierrot- 
Desseiligny (e.g. Pierrot-Deseilligny et al., 1981; Forget et al., 1989; Meunier et al., 1994). The quadriceps motoneurons receive substantial excitatory and inhibitory inputs from both their antagonists as well as the muscles spanning the ankle joint. Such connections have been postulated to reflect a functional coupling between muscles acting as synergists. While care was taken to impose a perturbation only to the knee joint, the unloading response of the knee flexors may have had a strong effect on the stretch reflex of the quadriceps. It is unlikely that excitation from spindle afferents could have exerted an influence though feedback from GTOs cannot be ruled out. Thus for example, it is known that strong heteronymous Ib connections exist between the GM and the quadriceps.

\section{$7 \quad$ Future directions}

Reflex behaviour when applying an external perturbation to the target muscle provides only the ability of the stretch reflex to compensate for external perturbations. Such studies cannot be directly extrapolated to infer that afferent mediated feedback also makes an important contribution during unperturbed tasks. Further studies are required aimed at investigating the role of the quadriceps afferent feedback during unperturbed activities as well as their interaction with muscles spanning both the ankle and hip joints. 


\section{$8 \quad$ Reference list}

Akazawa K, Milner TE, Stein RB (1983). Modulation of reflex EMG and stiffness in response to stretch of human finger muscle. J Neurophysiol 49: 16-27.

Allum JH, Mauritz KH (1984). Compensation for intrinsic muscle stiffness by short-latency reflexes in human triceps surae muscles. J Neurophysiol 52: 797-818.

Allum JH, Mauritz KH, Vogele H (1982a). Stiffness regulation provided by shortlatency reflexes in human triceps surae muscles. Brain Res 234: 159-164.

Allum JH, Mauritz KH, Vogele H (1982b). The mechanical effectiveness of short latency reflexes in human triceps surae muscles revealed by ischaemia and vibration. Exp Brain Res 48: 153-156.

Andersen JB, Sinkjaer $\mathrm{T}$ (1995). An actuator system for investigating electrophysiological and biomechanical features around the human ankle joint during gait. IEEE Trans Rehabil Eng 3: 299-306.

Andersen JB, Sinkjaer T (1999). The stretch reflex and H-reflex of the human soleus muscle during walking. Motor Control 3: 151-157.

Andersen JB, Sinkjaer T (2003). Mobile ankle and knee perturbator. IEEE Trans Biomed Eng 50: 1208-1211.

Baldissera F, Hultborn H, Illert M (1981). Integration in spinal neuronal systems. In Am. Physiol. Soc. (Ed), Handbook of Physiology. The Nervous System. Motor Control Sect 1, (2), 1, chapt. 12, p. 509-595. Bethesda: MD.

Bayoumi A, Ashby P (1989). Projections of group Ia afferents to motoneurons of thigh muscles in man. Exp Brain Res 76: 223-228. 
Berardelli A, Sabra AF, Hallett M, Berenberg W, Simon SR (1983). Stretch reflexes of triceps surae in patients with upper motor neuron syndromes. $J$ Neurol Neurosurg Psychiatry 46: 54-60.

Bergui M, Dimanico U, Paglia G, Quattrocolo G, Troni W, Bergamini L (1992). Stretch reflex of quadriceps femoris in normal man: methodological considerations and normative data. Electromyogr Clin Neurophysiol 32: 597-601.

Bergui M, Paglia G, Lopiano L, Quattrocolo G, Bergamini L, Bergamasco B (1993). Early modification of stretch reflex in Parkinson's disease.[comment]. Acta Neurol Scand 88: 16-20.

Bonnard M, Camus M, Coyle T, Pailhous J (2002). Task-induced modulation of motor evoked potentials in upper-leg muscles during human gait: a TMS study. Eur J Neurosci 16: 2225-2230.

Capaday C, Forget R, Fraser R, Lamarre Y (1991). Evidence for a contribution of the motor cortex to the long-latency stretch reflex of the human thumb. $J$ Physiol 440: 243-255.

Capaday C (2002). The special nature of human walking and its neural control. Trends Neurosci 25: 370-376.

Carter RR, Crago PE, Gorman PH (1993). Nonlinear stretch reflex interaction during co contraction. J Neurophysiol 69: 943-952.

Carter RR, Crago PE, Keith MW (1990). Stiffness regulation by reflex action in the normal human hand. J Neurophysiol 64:105-118. 
Chaix Y, Marque P, Meunier S, Pierrot-Deseilligny E, Simonetta-Moreau M (1997). Further evidence for non-monosynaptic group I excitation of motoneurones in the human lower limb. Exp Brain Res 115: 35-46.

Christensen LO, Andersen JB, Sinkjaer T, Nielsen JB (2001). Transcranial magnetic stimulation and stretch reflexes in the tibialis anterior muscle during human walking. J Physiol 531: 545-557.

Crago PE, Houk JC, Hasan Z (1976). Regulatory actions of human stretch reflex. J Neurophysiol 39: 925-935.

Dietz V. (1998). Evidence for a load-receptor contribution to the control of posture and locomotion. Neurosci Biobehav Rev 22: 495-499.

Dietz V, Discher M, Faist M, Trippel M (1990a). Amplitude modulation of the human quadriceps tendon jerk reflex during gait. Exp Brain Res 82: 211213.

Dietz V, Duysens J (2000). Significance of load receptor input during locomotion: a review. Gait Posture 11: 102-110.

Dietz V, Faist M, Pierrot-Deseilligny E (1990b). Amplitude modulation of the quadriceps H-reflex in the human during the early stance phase of gait. Exp Brain Res 79: 221-224.

Eccles RM, Lundberg A (1958). Integrative pattern of Ia synaptic actions on motoneurons of hip and knee muscles. J Physiol 144: 271-298.

Feldman AG (1980). Superposition of motor programs. I. Rythmic forearm movements in man. Neuroscience 5: 81-90. 
Forget R, Pantieri R, Pierrot-Deseilligny E, Shindo M, Tanaka R (1989). Facilitation of quadriceps motoneurones by group I afferents from pretibial flexors in man. 1. Possible interneuronal pathway. Exp Brain Res 78: $10-20$.

Garland SJ, Gerilovsky L, Enoka RM (1994). Association between muscle architecture and quadriceps femoris H-reflex. Muscle Nerve 17: 581-592.

Grey MJ, Ladouceur M, Andersen JB, Nielsen JB, Sinkjaer T (2001). Group II muscle afferents probably contribute to the medium latency soleus stretch reflex during walking in humans. J Physiol 534: 925-933.

Grey MJ, Larsen B, Sinkjaer T (2002). A task dependent change in the medium latency component of the soleus stretch reflex. Exp Brain Res 145: 316322.

Hagbarth KE, Young RR, Hägglund JV, Wallin EU (1980). Segmentation of human spindle and EMG responses to sudden muscle stretch. Neurosci Lett 19: 213-217.

Hansen NL, Hansen S, Christensen LO, Petersen NT, Nielsen JB (2001). Synchronization of lower limb motor unit activity during walking in human subjects. J Neurophysiol 86: 1266-1276.

Hof AL (2000). On the interpretation of the support moment. Gait Posture 12: 196-199.

Hoffer JA, Andreassen S (1981). Regulation of soleus muscle stiffness in premammillary cats: intrinsic and reflex components. J Neurophysiol 45: 267-285. 
Kearney RE, Lortie M, Stein RB (1999). Modulation of stretch reflexes during imposed walking movements of the human ankle. J Neurophysiol 81: 2893-2902.

Kearney RE, Stein RB, Parameswaran L (1997). Identification of intrinsic and reflex contributions to human ankle stiffness dynamics. IEEE Trans Biomed Eng 44: 493-504.

Kurusu K, Kitamura J (1999). Long-latency reflexes in contracted hand and foot muscles and their relations to somatosensory evoked potentials and transcranial magnetic stimulation of the motor cortex. Clin Neurophysiol 110: 2014-2019.

Lamontagne A, Voigt M, Larsen K, Sinkjaer T (2000). Early and late components of the quadriceps stretch reflex in human. 57.1. Proceedings of the Society for Neuroscience, $26^{\text {th }}$ Annual Meeting. New Orleans, USA.

Larsen B (2005). Stretch Reflex Properties during pedalling exercises. Aalborg, Denmark: Aalborg University.

Lavoie BA, Devanne H, Capaday C (1997). Differential control of reciprocal inhibition during walking versus postural and voluntary motor tasks in humans. J Neurophysiol 78: 429-438.

Lee RG, Tatton WG (1975). Motor responses to sudden limb displacements in primates with specific CNS lesions and in human patients with motor system disorders. Can J Neurol Sci 2: 285-293.

Leonard CT, Matsumoto T, Diedrich P (1995). Human myotatic reflex development of the lower extremities. Early Hum Dev 43: 75-93. 
Llewellyn M, Yang JF, Prochazka A (1990). Human H-reflexes are smaller in difficult beam walking than in normal treadmill walking. Exp Brain Res 83: 22-28.

Mao CC, Ashby P, Wang M, McCrea D (1984). Synaptic connections from large muscle afferents to the motoneurons of various leg muscles in man. Exp Brain Res 56: 341-350.

Marque, P., Nicolas, G., Marchand-Pauvert, V., Gautier, J., Simonetta-Moreau, M., \& Pierrot-Deseilligny, E. (2001). Group I projections from intrinsic foot muscles to motoneurones of leg and thigh muscles in humans. $J$ Physiol 536: 313-327.

Marque P, Nicolas G, Simonetta-Moreau M, Pierrot-Deseilligny E, MarchandPauvert V (2005). Group II excitations from plantar foot muscles to human leg and thigh motoneurones. Exp Brain Res 161: 486-501.

Marque P, Pierrot-Deseilligny E, Simonetta-Moreau M (1996). Evidence for excitation of the human lower limb motoneurones by group II muscle afferents. Exp Brain Res 109: 357-360.

Marsden CD, Merton PA, Morton HB (1973). Is the human stretch reflex cortical rather than spinal? Lancet 1: 759-761.

Marsden CD, Merton PA, Morton HB (1976). Stretch reflex and servo-action in a variety of human muscles. J Physiol 259: 531-560.

Marsden CD, Merton PA, Morton HB, Adam J (1977). The effect of lesions of the sensorimotor cortex and the capsular pathways on servo responses from the human long thumb flexor. Brain 100: 503-526. 
Marsden CD, Rothwell JC, Day BL (1983). Long-latency automatic responses to muscle stretch: Origin and function. In JE Desmedt (Ed), Motor Control Mechanisms in Health and Disease pp. 509-539. Raven Press: New York.

Matthews PBC (1984). Evidence from the use of vibration that the human longlatency stretch reflex depends upon spindle secondary afferents. J Physiol 348: 383-415.

Matthews PBC (1987). Effect of arm cooling on long-latency reflex responses from the human first dorsal interosseous muscle - evidence for a group I contribution. J Physiol 394: 102P.

Matthews PBC (1986). What are the afferents of origin of the human stretch reflex, and is it a purely spinal reaction? Prog Brain Res 64: 55-66.

McMahon TA, Valiant G, Frederick EC (1987). Groucho Running. J App Physiol 62: 2326-2337.

Meunier S, Pierrot-Deseilligny E, Simonetta-Moreau M (1994). Pattern of heteronymous recurrent inhibition in the human lower limb. Exp Brain Res 102: 149-159.

Meunier S, Pierrot-Deseilligny E, Simonetta M (1993). Pattern of monosynaptic heteronymous Ia connections in the human lower limb. Exp Brain Res 96: 534-544.

Mirbagheri MM, Barbeau H, Kearney RE (2000). Intrinsic and reflex contributions to human ankle stiffness: variation with activation level and position. Exp Brain Res 135: 423-436. 
Mirbagheri MM, Barbeau H, Ladouceur M, Kearney RE (2001). Intrinsic and reflex stiffness in normal and spastic, spinal cord injured subjects. Exp Brain Res 141: 446-459.

Miscio G, Pisano F, Del Conte C, Pianca D, Colombo R, Schieppati M (2001). The shortening reaction of forearm muscles: the influence of central set. Clin Neurophysiol 112: 884-894.

Morita H, Petersen N, Christensen LO, Sinkjaer T, Nielsen J (1998). Sensitivity of H-reflexes and stretch reflexes to presynaptic inhibition in humans. $J$ Neurophysiol 80: 610-620.

Nardone A, Schieppati M (1998). Medium-latency response to muscle stretch in human lower limb: estimation of conduction velocity of group II fibres and central delay. Neurosci Lett 249: 29-32.

Nardone A, Schieppati M (2004). Group II spindle fibres and afferent control of stance. Clues from diabetic neuropathy. Clin Neurophysiol 115: 779-789.

Nene A, Mayagoitia R, Veltink P (1999). Assessment of rectus femoris function during initial swing phase. Gait \& Posture 9: 1-9.

Nichols TR, Houk JC (1976). Improvement in linearity and regulation of stiffness that results from actions of stretch reflex. J Neurophysiol 39: 119-142.

Nielsen J, Kagamihara Y (1993). The regulation of presynaptic inhibition during co-contraction of antagonistic muscles in man. J Physiol 464: 575-593.

Nielsen J, Kagamihara Y (1994). Synchronization of human leg motor units during co-contraction in man. Exp Brain Res 102: 94. 
Nielsen J, Petersen N, Fedirchuck B (1997). Evidence suggesting a transcortical pathway from cutaneous foot afferents to tibialis anterior motoneurones in man. J Physiol 501: 473-484.

Nielsen J, Sinkjaer T, Toft E, Kagamihara Y. (1994). Segmental reflexes and ankle joint stiffness during co-contraction of antagonistic ankle muscles in man. Exp Brain Res 102: 350-358.

Nielsen JB (1998). Co-contraction of antagonistic muscles in man. Dan Med Bull 45: 423-435.

Nielsen JB, Sinkjaer T (2002). Afferent feedback in the control of human gait. $J$ Electromyogr Kinesiol 12: 213-217.

Palmer E, Ashby P (1992). Evidence that a long latency stretch reflex in humans is transcortical. $J$ Physiol 449: 429-440.

Petersen N, Christensen LO, Morita H, Sinkjaer T, Nielsen J (1998). Evidence that a transcortical pathway contributes to stretch reflexes in the tibialis anterior muscle in man. $J$ Physiol 512: 267-276.

Pierrot-Deseilligny E, Morin C, Bergego C, Tankov N (1981). Pattern of group I fibre projections from ankle flexor and extensor muscles in man. Exp Brain Res 42: 337-350.

Rothwell JC (1990). Long latency reflexes of human arm muscles in health and disease. Electroencephalogr Clin Neurophysiol Suppl 41: 251-263.

Schieppati M, Nardone A (1997). Medium-latency stretch reflexes of foot and leg muscles analysed by cooling the lower limb in standing humans. $J$ Physiol 503: 691-698. 
Schieppati M, Nardone A (1999). Group II spindle afferent fibers in humans: their possible role in the reflex control of stance. Prog Brain Res 123: 461-472.

Schieppati M, Nardone A, Siliotto R, Grasso M (1995). Early and late stretch responses of human foot muscles induced by perturbation of stance. Exp Brain Res 105: 411-422.

Schillings AM, van Wezel BMH, Mulder TH, Duysens J (1999). Widespread short-latency stretch reflexes and their modulation during stumbling over obstacles. Brain Res 816: 480-486.

Sherrington CS (1905). On Reciprocal Innervation of Antagonistic Muscles.-Eighth Note. Proceedings of the Royal Society of London.Series B, Containing Papers of a Biological Character 76, 269-297.

Sherrington CS (1906). The Integrative Action of the Nervous System. London: Constable.

Simonetta-Moreau M, Marque P, Marchand-Pauvert V, Pierrot-Deseilligny E (1999). The pattern of excitation of human lower limb motoneurones by probable group II muscle afferents. J Physiol 517: 287-300.

Sinkjaer T (1997). Muscle, reflex and central components in the control of the ankle joint in healthy and spastic man. Acta Neurol Scand Suppl 170: 128.

Sinkjaer T, Andersen JB, Ladouceur M, Christensen LO, Nielsen JB (2000). Major role for sensory feedback in soleus EMG activity in the stance phase of walking in man. J Physiol 523: 817-827.

Sinkjaer T, Andersen JB, Larsen B (1996). Soleus stretch reflex modulation during gait in humans. J Neurophysiol 76: 1112-1120. 
Sinkjaer T, Andersen JB, Nielsen JB, Hansen HJ (1999). Soleus long-latency stretch reflexes during walking in healthy and spastic humans. Clin Neurophysiol 110: 951-959.

Sinkjaer T, Hayashi R (1989). Regulation of wrist stiffness by the stretch reflex. $J$ Biomech 22: 1133-1140.

Sinkjaer T, Hoffer JA (1990). Factors determining segmental reflex action in normal and decerebrate cats. J Neurophysiol 64: 1625-1635.

Sinkjaer T, Nielsen J, Toft E (1995). Mechanical and electromyographic analysis of reciprocal inhibition at the human ankle joint. $J$ Neurophysiol 74: 849855.

Sinkjaer T, Toft E, Andreassen S, Hornemann BC (1988). Muscle stiffness in human ankle dorsiflexors: intrinsic and reflex components. $J$ Neurophysiol 60: 1110-1121.

Sinkjaer T, Toft E, Larsen K, Andreassen S (1993). EMG-Torque dynamics at different contraction levels in human ankle muscles. J Electromyogr Kinesiol 3: 67-77.

Stein RB, Capaday C (1988). The modulation of human reflexes during functional motor tasks. Trends Neurosci 11: 328-332.

Stein RB, Kearney RE (1995). Nonlinear behavior of muscle reflexes at the human ankle joint. J Neurophysiol 73: 65-72.

Thilmann AF, Schwarz M, Topper R, Fellows SJ, Noth J (1991). Different mechanisms underlie the long-latency stretch reflex response of active human muscle at different joints. J Physiol 444: 631-643. 
Thomson DB, Chapman AE (1988). The mechanical response of active human muscle during and after stretch. Eur J Appl Physiol 57: 691-697.

Toft E, Sinkjaer T, Andreassen S (1989). Mechanical and electromyographic responses to stretch of the human anterior tibial muscle at different levels of contraction. Exp Brain Res 74: 213-219.

Toft E, Sinkjaer T, Andreassen S, Larsen K (1991). Mechanical and electromyographic responses to stretch of the human ankle extensors. J Neurophysiol 65: 1402-1410.

van Doornik J, Masakado Y, Sinkjaer T, Nielsen JB (2004). The supression of the long-latency stretch reflex in the human tibialis anterior muscle by transcranial magnetic stimulation. Exp Brain Res 157: 403-406.

Voigt M, de Zee M, Sinkjaer T (1999). A fast servo-controlled hydraulic device for the study of muscle mechanical and reflex properties in humans. 578 . Proceedings of the 17th Congress of the International Society of Biomechanics. Calgary, Canada.

Wells R, Evans N (1987). Functions and recruitment patters of one- and two-joint muscles under isometric and walking conditions. Hum Mov Sci 6: 349372.

Wilmink RJH, Nichols TR (2003). Distribution of Heterogenic Reflexes Among the Quadriceps and Triceps Surae Muscles of the Cat Hind Limb. $J$ Neurophysiol 90: 2310-2324.

Winter DA (1980). Overall principle of lower limb support during stance phase of gait. J Biomech 13: 923-927. 
Yang JF, Stein RB, James KB (1988). A method to apply muscle stretch during walking in humans. 42-43. Proceedings of the $5^{\text {th }}$ Meeting of the Canadian Society of Biomechanics, Ottawa, Canada.

Yang JF, Stein RB, James KB (1991). Contribution of peripheral afferents to the activation of the soleus muscle during walking in humans. Exp Brain Res 87: 679-687.

Zhang LQ, Nuber G, Butler J, Bowen M, Rymer WZ (1998). In vivo human knee joint dynamic properties as functions of muscle contraction and joint position. J Biomech 31: 71-76.

Zuur B, Grey MJ, Nielsen JB, Sinkjaer T (2004). Supra-spinal contributions to the long latency stretch reflex during human walking are different for soleus and tibialis anterior. 187.23. Online Abstract Viewer/Itinerary Planner of the Society of Neuroscience, $30^{\text {th }}$ Annual Meeting. Washington DC, USA 
A part of this thesis has been removed from this publication due to copyright. 